\title{
Population Density, Fertility and
}

Demographic Convergence in Developing Countries

D. de la Croix and P. Gobbi

Discussion Paper 2016-3

\section{Institut de Recherches Économiques et Sociales de I'Université catholique de Louvain}




\title{
Population Density, Fertility, and Demographic Convergence in Developing Countries*
}

\author{
David de la Croix ${ }^{\dagger} \quad$ Paula E. Gobbi ${ }^{\ddagger}$
}

January 18, 2016

\begin{abstract}
Whether the population tends towards a long-run stationary value depends on forces of demographic convergence. One such force is the result of fertility rates being negatively affected by population density. We test the existence of such an effect in 44 developing countries, matching georeferenced data from the Demographic and Health Surveys for half a million women with population density grids. When we correct for selection and endogeneity bias and control for the usual determinants of fertility such as education and income, a rise in density from 10 to 1000 inhabitants per square kilometer corresponds with a decrease in fertility of about 0.6 of a child. Duration analysis reveals that both age at marriage and age at first birth increase with density.
\end{abstract}

Keywords: Demographic and Health Survey, Preventive check, Agglomeration externalities, Population Dynamics, Marriage.

JEL classification number: J13, D19, O18, R11

${ }^{*}$ We thank Matteo Cervellati, Bastien Chabé-Ferret, Muriel Dejemeppe, Elena Esposito, Alexia FürnkranzPrskawetz, Oded Galor, Rafael Godefroy, Marc Klemp, Michael Kuhn, Mathias Lerch, Florian Mayneris, William Pariente, Luigi Pascali, and Michèle Tertilt, as well as participants to seminars in Gröningen, Louvain-la-Neuve, Lund, Namur, New Delhi, Rennes and Rostock for precious comments and suggestions. We acknowledge the financial support of the project ARC 15/19-063 of the Belgian French speaking Community.

${ }^{\dagger}$ IRES \& CORE, Université catholique de Louvain

${ }_{\ddagger}^{\ddagger}$ National Fund for Scientific Research (Belgium) and IRES, Université catholique de Louvain 


\section{Introduction}

Long-run population projections are key to assessing the sustainability of our societies. The combination of current age structure and projected fertility levels produces relatively accurate projections with a horizon of 50 years, but longer term predictions rapidly become uncertain (Livi-Bacci 1997). In the projections made by the Population Division of the UN, fertility being estimated in terms of either a high or low scenario (United Nations 2004, Gerland et al. 2014) determines when and the level at which global population will peak. The probabilistic projections of the UN (Gerland et al. 2014) or of IAASA (Lutz and Butz 2014) would benefit from a reduction in the uncertainty surrounding fertility. ${ }^{1}$ In general, the speed at which Africa experiences the demographic transition matters to determining the peak of the world population. Consequently, gaining a better understanding of the determinants of fertility is a priority in terms of improving these long-run forecasts.

We study whether or not fertility behavior reflects some spontaneous convergence forces that lead the population to a stable, long-run level. In the natural sciences, this property is called population homeostasis (Lee 1987). In animal populations, predator - prey models may display such a property, depending on their parameters. In human populations, predators are absent, but human reproduction is subject to limited resources. If convergence forces are at work, one should observe a correlation between fertility and/or mortality and population density. At high levels of density, fertility should be low, and/or mortality high, for a population to stabilize. In this paper, we focus on the first channel, ${ }^{2}$ the one relating fertility to population density, in developing countries.

There are different ways in which population density may affect fertility. For Malthus, areas with higher population density have lower agricultural income, and marriage and fertility are delayed (preventive check) as compared to regions with lower densities. According to a more modern view, while income is higher in more densely populated areas because of agglomeration externalities, fertility decreases with income, leading to the same final negative relationship between density and fertility. More densely populated locales may also yield decreased fertility because they offer more affordable or accessible education and health infrastructure.

Beyond these causal mechanisms, sorting (selection) of individuals can generate an apparent correlation between density and fertility. This is the case when people that are less inclined to have children migrate to more densely populated places to enjoy the greater income opportuni-

\footnotetext{
${ }^{1}$ The difference between these two recent projections essentially relies on different assumptions about Chinese and Nigerian fertility rates.

${ }^{2}$ Mortality can also be affected by population density. For example, André and Platteau (1998) detail the path from population pressure to land conflicts, and, ultimately to violence and genocide in Rwanda.
} 
ties offered by cities (Courgeau 1989) and/or individuals that are more inclined to have children move to regions where the population density is lower and where raising children costs less. In this case, population density may not have a causal relationship to fertility but instead may only affect individual decisions with respect to where to live. The United Nations projects that $66 \%$ of the world's population will live in urban areas by 2050 . In 1950, this figure was only $30 \%$ (United Nations 2014). This movement of people from rural to urban areas may simply be the results of a selection of individuals and not reflect an effect of higher population density on individual decision-makings.

To analyze the relationship between population density and fertility, we use different sources of data. Raster files for population density come from CIESIN et al. (2011). These are based on detailed population data from census administrative units. ${ }^{3}$ Fertility for a population is constructed using data from the Demographic and Health Surveys (DHS) for 44 developing countries. In DHS data, clusters are georeferenced, allowing for mapping population density onto fertility. The caloric suitability index developed by Galor and Özak (2014) is used to control for intrinsic land quality. Satellite light data are used to control for income effects at a very disaggregated level.

We first consider the cluster level (i.e., village or neighborhood), relating the average number of births in a given cluster to the population density of this cluster. Without any control apart from country fixed effects, land quality, and the mean age of women in the cluster, an increase in population density from 10 to 1000 inhabitants decreases fertility by about one child on average. When controlling for additional cluster characteristics such as education, mortality, and income, the size effect is divided by four but remains highly significant. Among all the controls, education seems particularly important, indicating that education is obtained more easily in densely populated areas, where traveling costs are lower, and the fixed costs of schools are more easily covered (Boucekkine, de la Croix, and Peeters 2007).

This relationship could be biased due to an omitted variable problem. Places with greater unobserved amenities might be those to which individuals with certain traits moved in the past and where these traits have persisted. This could lead to a spurious relationship where it is not population density that affects fertility rates but rather the unobserved characteristics of the people living in areas with a specific population density. We therefore exploit geographical differences in remoteness from historical centers and in land productivity gains arising from the Columbian Exchange as instruments of current population density. Controlling for current income, the exclusion restriction is that these instruments have no effect on fertility, other than through population density. We argue that both of these instruments reflect significant

\footnotetext{
${ }^{3}$ See http://sedac.ciesin.columbia.edu/downloads/docs/gpw-v3/balk_etal_geostatpaper_ 2010pdf-1.pdf for methodological details.
} 
technological progress that affected individuals in specific areas very long ago and created incentives for people to move to these specific areas. However, the main reason that these people are in these areas is the persistence of population density. Using these instruments, we estimate an even larger effect of population density on fertility, showing that endogeneity biases have a tendency to attenuate its effect.

In order to further exclude the possibility that population density at the cluster level may proxy local spillovers that affect fertility, we analyze fertility behavior at the individual level distinguishing between individual and cluster effects (e.g., for education). The results are similar to those at the cluster level. The channels through which fertility is reduced are explored using a duration analysis. The latter shows that both age at marriage and age at first birth increase with density.

The individual-level analysis also permits us to study whether or not the relationship between population density and fertility is the result of selection. We first allow for distinct effects of density in urban and rural areas in order to control for selection between these two areas. This does not affect the main results. Directly controlling for migration does not either; estimation results yielded from a subsample of individuals who had not moved during their lifetime are very similar to those yielded from the whole sample.

Other papers have documented a negative relationship between population density and fertility. Among others, Adelman (1963) and Heer (1966) showed such a pattern for country level data. By today standards, however, it would be hard to argue that the correlation they found does not reflect country specific factors (e.g., institutions) that were not accounted for in their analyses. A more robust approach would be to use country panel data, as in Lutz and Qiang (2002) and Lutz, Testa, and Penn (2006), who emphasize the importance of including population density as a determinant of declining fertility rates. Another approach is to compare smaller entities within the same country. For example Firebaugh (1982) show that population density and fertility were negatively related across 22 Indian villages between 1961 and 1972 . However, these approaches limit the analysis to aggregate level data. This increases the likelihood of endogeneity due to the presence of unobserved factors affecting both the fertility of a population and its density. Compared to this literature, this paper is based upon a much broader set of data (490k women in $25 \mathrm{k}$ clusters from 44 developing countries). It also carries out the analysis at the individual level and finds support for a causal effect of density on fertility. Finally, it investigates the channels through which the effect operates (later marriage).

The paper is organized as follows: first, in Section 2 we review the literature examining the effect of density on population growth and highlight the key mechanisms involved. Data are presented in Section 3 and our analysis is provided in Section 4. Interpretation of the results 
for population dynamics is provided in Section 5. The conclusions are presented in Section 6 .

\section{Literature and Mechanisms}

We first describe different mechanisms that may explain a relationship between population density and fertility rates.

\subsection{Malthus and Sadler Models}

The very idea that fertility adjusts to population density is ancient. Montesquieu (1749) describes the view of Greek philosophers on the issue (emphasis added): "In a small and flourishing territory, the number of citizens must soon augment, so as to become a burden. This people of consequence omitted nothing which might prevent an undue increase of children. Their politics were more immediately confined to the regulation of the number of citizens. Plato limits the number of citizens to five thousand and forty, and recommends, according as the case may require: either the prohibition or encouragement of propagation, by motives of honor or ignominy, and by the reasonable admonitions of the elders. He advises also a regulation of the number of marriages. (...) Every parent should be limited to a certain number says Aristotle. And when the children are more numerous than the laws permit, he advises the women to procure abortion before the foetus be endowed with life." ${ }^{4}$ This paragraph echoes the preventive checks put forward by Malthus, but seen from the planner's point of view.

Malthus (1807) description of the effect of too high density on fertility is well known: "The ultimate check to population appears then to be a want of food arising necessarily from the different ratios according to which population and food increase. The preventive checks, as far as it is voluntary, is peculiar to man, and arises from that distinctive superiority in his reasoning faculties, which enables him to calculate distant consequences. (...) Of the preventive checks, the restraint from marriage which is not followed by irregular gratifications may properly be termed moral restraint. Promiscuous intercourse, unnatural passions, violations of the marriage bed, and improper arts to conceal the consequences of irregular connexions, are preventive checks that clearly come under the head of vice." Explained in modern terms, when food is expected to become scarce because of decreasing returns to labor, rational people limit their fertility, by postponing marriage, and by using other (immoral) methods such as prostitution, homosexuality, zoophilia, contraception, and abortion.

\footnotetext{
${ }^{4}$ English translation and citation in Bruckner (1768).
} 
The link between population density and fertility is made totally explicit by Sadler (1830), who writes against Malthus "The Law of Population - in disproof of the superfecundity of human beings, and developing the real principle of their increase". His Law simply claims that

The prolificness of human beings, otherwise similarly circumstanced, varies inversely as their numbers.

This statement is further clarified by Sadler (1830), referring explicitly to population density and specifying the need to control for land quality: "The prolificness of human beings, as thus regulated by the extent of the space they occupy, is furthermore influenced by the quality of that space".

The mechanism by which density influences fertility is the opposite of the Malthusian logic. For Malthus, higher density reduces resources per person, leading to a decline in fertility as a result of preventive (marriage is delayed) and positive checks (mortality increases). For Sadler, on the other hand, affluence increases with population density, as it is purported to do in the modern theories of agglomeration externalities (Fujita and Thisse 2002). ${ }^{5}$ Moreover, Sadler claims that prolificness decreases with affluence, anticipating the Beckerian result by more than a century. The combination of these two assumptions leads to a negative link between population density and fertility.

Sadler discusses many datasets in favor of his theory. For example, Table LXI (page 380 of second volume) has been reproduced in Table 1 to showing that the prolificness of marriage is correlated with population density.

\begin{tabular}{lrr}
\hline Country & Inhabitants on a square mile & children to a marriage \\
\hline Cape of Good Hope & 1 & 5.48 \\
North America & 4 & 5.22 \\
Russia in Europe & 23 & 4.94 \\
Denmark & 73 & 4.89 \\
Prussia & 100 & 4.70 \\
France & 140 & 4.22 \\
England & 160 & 3.66 \\
\hline
\end{tabular}

Table 1: Fertility and Population Density, circa 1800

\footnotetext{
${ }^{5}$ The idea that population density may exert positive externalities on income was already made explicit by Marshall (1890): "Taking account of the fact that an increasing density of population generally brings with it access to new social enjoyments we may give a rather broader scope to this statement and say: An increase of population accompanied by an equal increase in the material sources of enjoyment and aids to production is likely to lead to a more than proportionate increase in the aggregate income of enjoyment of all kinds".
} 
Comparing Sadler and Malthus' theories, both imply that fertility rates should be lower in more densely populated areas, but for different reasons. For Sadler, it is because those areas are richer than others, for Malthus, it is the opposite.

The Malthusian model has been formalized by Ashraf and Galor (2011). The Sadlerian model was never formalized, and never attracted much attention. Appendix A provides a formal, pedagogical version of each model. Both of them can be characterized by the following proposition.

Proposition 1 (Malthus-Sadler Model) If population dynamics follow $P_{t+1}=\Phi\left(P_{t}\right)$, given $P_{0}$, with $\Phi^{\prime}(\cdot)>0$ and $\Phi^{\prime \prime}(\cdot)<0$, then population growth is negatively correlated with population density over time.

Proof: See Appendix A.

The above proposition describes a relationship between population growth and population density over time in a given location. To map it as a relationship across space, one can follow the standard approach provided by growth theory (Galor 1996): consider a world consisting of different locations, each location isolated from the rest, and following the same law of motion $\Phi\left(P_{t}\right)$ described in Proposition 1 (up to a multiplicative constant). If each location starts from a different initial condition $P_{0}$, then population growth is negatively correlated with population density across space.

Figure 1 illustrates this point. The bottom panel represents the distribution of population over locations, $j$, for three points in time, $t=0,1,2 . g_{t}(P)$ is the distribution of the population at time $t$. For the initial period, we represent two locations, 1 and 2, with initial population $P_{0}^{1}$ and $P_{0}^{2}$ (bottom panel). Projecting them on the top panel, which represents the dynamic function $P_{t+1}^{j}=\Phi\left(P_{t}^{j}\right)$, allows us to compute the populations in the next period $P_{1}^{1}$ and $P_{1}^{2}$. After having applied the function $\Phi$ to all locations, one can then compute the new distribution of population $g_{1}(P)$. Given that the function $\Phi$ is concave, we see that the rise in population in location $1, P_{1}^{1}-P_{0}^{1}$, is larger than the one in location $2, P_{1}^{2}-P_{0}^{2}$, which was the initially more densely populated location. As time passes, all populations tend toward a stable steady state $\bar{P}$ and the distribution becomes degenerate.

The assumption that the function $\Phi$ is the same across locations up to a multiplicative constant amounts to assuming that the demographic growth rate is the same in two locations that share the same distance (in \%) from their steady state.

The speed at which population tends toward its steady state depends on the slope of $\Phi .{ }^{6}$

\footnotetext{
${ }^{6}$ See Sato (1966) for an early analysis of adjustment speed in growth models, and Barro and Sala-i Martin (1986) for an empirical application to convergence of income per person across U.S. States.
} 


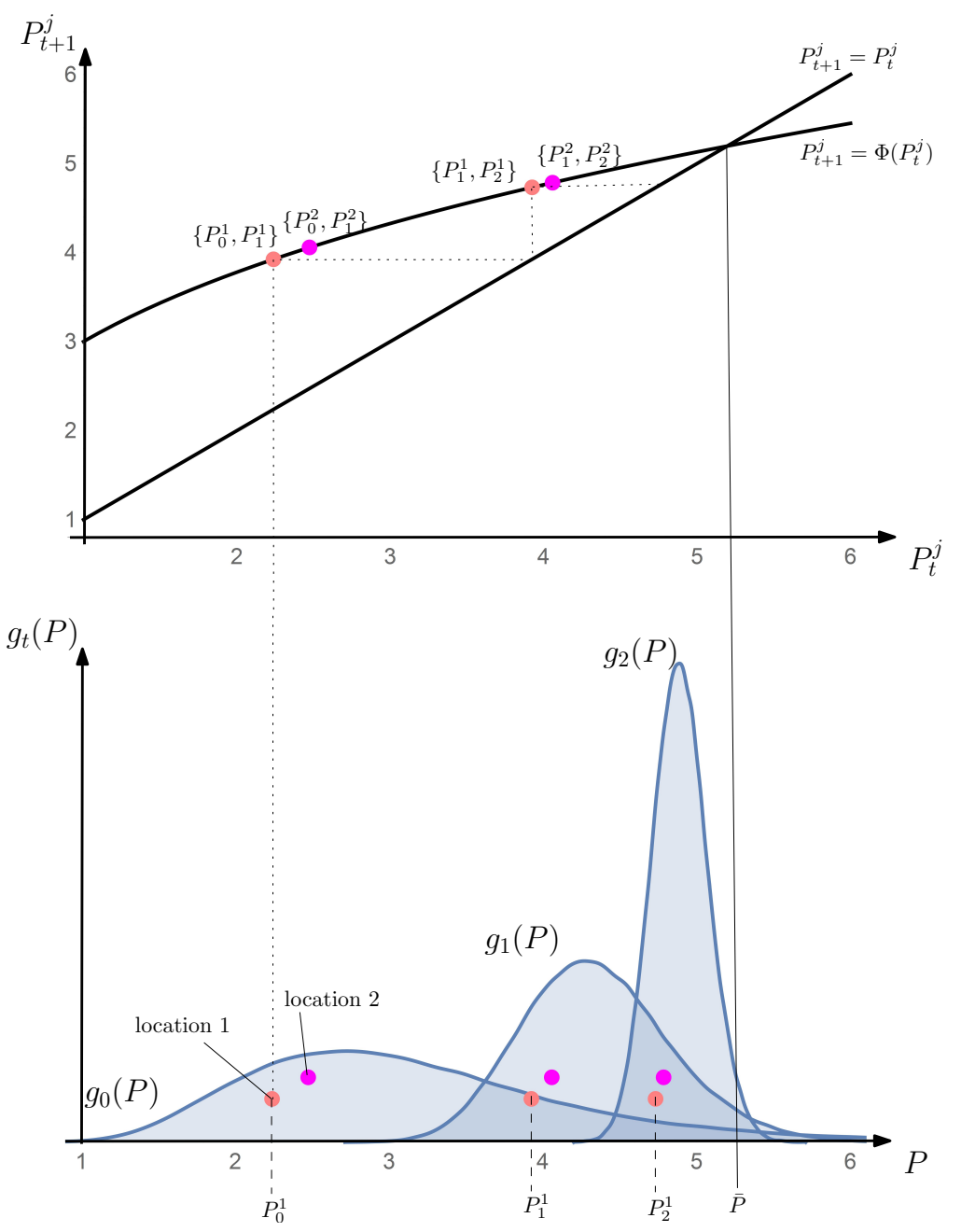

Figure 1: Dynamics and Convergence of Population in the Malthus-Sadler model

The lower the slope, the faster the convergence. In our context, if fertility reacts strongly to population density, the convergence is fast. This results no longer holds if the function $\Phi$ is convex-concave rather than globally concave, as is the case with a logistic function, unless all locations are close enough to their steady state, in which case only the concave portion of $\Phi$ is relevant.

\subsection{Lotka-Volterra Cycles}

Another way to think about population dynamics originates from the work of Lotka and Volterra. $^{7}$ They consider the interaction between a population of prey, which is growing naturally, and a population of predators, that needs preys in order to grow. Humans are probably

\footnotetext{
${ }^{7}$ Lotka used the equations he developed to study chemical reactions to analyze predator-prey interactions (Lotka 1925), while Volterra independently developed the same differential equations (Volterra 1926).
} 
the only living species that do not have natural predators. However, they do need to use renewable natural resource to live, such as water, food, forests, air of good quality etc... The role of prey in the Lotka-Volterra model can be played by a renewable natural resource.

In their model, the growth rate of the population of prey diminishes as the number of predators increases, while the growth of the population of predators increases with an increase in the number of prey. As a consequence, the dynamics of both populations, preys and predators, display oscillations, which can either converge toward a long-run steady state, or last forever. This implies that the relationship between population growth and density is non-monotonic (for both preys and predators). The Lotka-Volterra model was originally set-up in continuous time. A discrete time version could be reduced into a single difference equation of the second order. The following proposition summarizes the result of this approach.

Proposition 2 (Lotka-Volterra Model) Consider population and resource dynamics that follow $P_{t+1}=\Phi\left(P_{t}, Q_{t}\right), Q_{t+1}=\Psi\left(P_{t}, Q_{t}\right)$, given $P_{0}$ and $Q_{0}$, and admit a hyperbolic steady state $\bar{P}, \bar{Q}$ satisfying $\bar{P}=\Phi(\bar{P}, \bar{Q}), \bar{Q}=\Psi(\bar{P}, \bar{Q})$. If the Jacobian matrix of partial derivatives at the steady state has complex eigenvalues, the local dynamics of population density $P_{t}$ oscillate, and the relationship between population growth and population density changes sign periodically.

\section{Proof: See Appendix A.}

Samuelson (1971) generalizes the predator-prey model to more than two species and suggests that predators could be capitalists and preys laborers. Dendrinos and Mullally (1981) apply oscillatory dynamics to explain the evolution of urban populations of Standard Metropolitan Statistical Areas in the United States. Applications of the Lotka-Volterra model to analyze population dynamics in ancient societies is proposed by Brander and Taylor (1998) (with myopic agents) and de la Croix and Dottori (2008) (with a non-cooperative game between clans) for the case of Easter Island. When fewer than 100 people arrived on Easter Island from the Marquesas Islands around CE 400, resources were abundant. Population started to increase, peaking around CE 1400-1600 at over 10,000 inhabitants. The population predated the island forest for firewood, to create land for agriculture, and to make canoes. The process of deforestation was reinforced during the Moai-construction period since trees were cut to facilitate the transportation of the statues. The forest clearance was likely completed by CE 1600 . In CE 1722 when the Island was discovered by Europeans there were basically no trees left and the population was around 2,000. Here, the dynamics led to the extinction of the resource. But, with different parameters, the same model can generate damped oscillations converging toward a stable situation in the long run. 


\subsection{Beckerian Approach}

The type of interactions between resources and fertility advocated by Malthus and LotkaVolterra were eventually discredited by the developments observed since the end of the $19^{\text {th }}$ century. A new generation of models incorporates fertility choices into economic analysis but avoids the pitfalls of Malthusian analysis. These models developed along the lines described by Becker (1993) "Malthus neglects that the time spent on child care becomes more expensive when countries are more productive. The higher value of time raises the cost of children and thereby reduces the demand for large families. It also fails to consider that the greater importance of education and training in industrialized economies encourages parents to invest more in the skills of their children, which also raises the cost of large families. The growing value of time and the increased emphasis on schooling and other human capital explain the decline in fertility as countries develop, and many other features of birth rates in modern economies." Such an approach is proposed in Becker and Barro (1988) and Barro and Becker (1989), for example. Their models have stark implications for the relationship between population growth and population density as explained in the following proposition.

Proposition 3 (Becker Model) If population dynamics follow $\Phi\left(P_{t-i}, \ldots, P_{t-1}, P_{t}, P_{t+1}, \ldots\right.$, $\left.P_{t+j}\right)=0$, given $P_{0}$, with $\Phi(\cdot)$ homogeneous of degree one, then population growth is uncorrelated with population density over time.

Proof: See Appendix A.

Here $\Phi$ represents the set of Euler conditions derived from households' optimization problem. The proposition stresses that, in these models, there is no built-in stabilizing mechanisms that lead population to converge at some level. Taken literally, these models imply that population density converges asymptotically either to 0 or to infinity.

The introduction of an effect of population density on fertility into the Beckerian type of model could be achieved by modeling one of the following three features: the housing market, the provision of public infrastructure (education or pension system), and an endogenous technology. We briefly discuss the literature that accounted for these features below.

In Sato (2007), higher density entails an agglomeration effect and a congestion effect. The agglomeration effect leads to higher productivity and wages and therefore implies both income and substitution effects on fertility: the income effect is due to the assumption that children are normal goods while the substitution effect stems from the fact that in order to raise children, one needs time and this time is more expensive when wages are higher. The congestion effect implies that the price of the land and the cost of living are higher. This diminishes the space 
inside the house to have children and produces a negative effect on fertility. ${ }^{8}$ Murphy, Simon, and Tamura (2008) find that for four of the five US regions that they categorize as having had large baby booms, there is clear evidence of declining population density coinciding with the baby boom. They present a model capable of producing this observed connection in which parents also care about the amount of space their children have growing up. If the price of space falls sufficiently then a baby boom may be produced. Instead of assuming that parents have an affinity for space, de la Croix and Gosseries (2012) introduce space into the production function of children, leading to similar results.

Another mechanism links population density to family choices through the provision of public infrastructure. Here, we need to combine the findings of Boucekkine, de la Croix, and Peeters (2007) with those of Becker, Cinnirella, and Woessmann (2010). When population density increases, it is easier to cover the fixed cost of infrastructure such as schools, and their provision increases (Boucekkine, de la Croix, and Peeters 2007). Increased provision of schools encourages parents to substitute quality for quantity, hence having fewer but better educated children (Becker, Cinnirella, and Woessmann 2010). Hence, higher density leads to more education and lower fertility. Another channel through which public infrastructure could affect fertility is the establishment of a pensions or banking system that allows people to secure their savings. This would decrease the incentive to bear children to ensure support at older ages and would thereby decrease fertility rates.

A further link between density and fertility, along the lines of Galor and Weil (2000), is based on technology. Here, a larger population increases productivity allowing for faster growth (population induced technical progress). Human capital and education are thus required more acutely in the production process in order to deal with fast technical change. The return to education increases, and parents invest more in the quality of their children, at the expense of quantity. In some sense, this mechanism is close to that put forward by Sadler (1830) where population density increases income per person, and reduces fertility.

\subsection{Density - Fertility Correlation through Selection}

An observed relationship between population growth or fertility and population density may not be the result of causal mechanisms such as those described above, but instead may arise from the selection of migrants. Families who move to or remain in places where the density of population is high may have preferences or unobserved resources that lead them to choose to have fewer children. This problem is stressed by Kravdal (2013) in his study of the effect of

\footnotetext{
${ }^{8}$ Using American Census data for the period 1940-2000, Simon and Tamura (2009) show that fertility and the price of living space are negatively correlated.
} 
community education on individual fertility.

Kulu and Boyle (2009) provide a useful example for disentangling selection effects from fundamental effects on fertility choices. They compare fertility in urban, suburban and rural areas in Finland. The selection effect comes from the idea that agents planning to start childbearing may decide to move to suburban locations because of the perceived suitability of the environment for childrearing. Still, suburbs have a fundamental (or "contextual" as it is referred to in the paper) effect on fertility as they are more suitable residential contexts for families than inner city areas, as they tend to have larger houses, gardens, open areas and better schools, as well as less congestion, crime and pollution. Distinguishing migrants from non migrants' fertility allows us to identify a strong selection effect. Still, after controlling for migration, there remains strong variation in fertility rates between urban centers and suburbs which is attributed to the different socio-economic characteristics of women residing there and, particularly, to their housing conditions.

To make this point clear let us show it in a simple model. Assume households have a utility $\ln (c)+\gamma \ln (n)$, where $c$ is consumption, $n$ is number of children and $\gamma$ is the affinity for having children. Households are identical in all respects but their affinity for having children $\gamma$ which is distributed over the population according to some density $g(\gamma)$. The budget constraint is $y=c+\phi n$, where $y$ is income, and $\phi$ is the cost it takes to raise one child. $y$ and $\phi$ depend on where the household is. There are two possible locations, a city and a countryside. In the city, income is higher, $y^{U}>y^{R}$, but the cost of having children is higher too: $\phi^{U}>\phi^{R}(U$ stands for urban and $R$ for rural). Households decide where to be located and how many children to have. For a given location $i$, the optimal choice is:

$$
n^{i}=\frac{\gamma}{\phi^{i}(1+\gamma)} y^{i}, \quad c^{i}=\frac{\gamma}{1+\gamma} y^{i}, \quad i=U, R
$$

Comparing the resulting indirect utilities yields the following proposition.

Proposition 4 (Selection Model) If the city relative cost of children is higher than the city relative income, i.e. if $\phi^{U} / \phi^{R}>y^{U} / y^{R}$, then there exists a threshold

$$
\hat{\gamma}=\frac{\ln \left(y^{U} / y^{Y}\right)}{\ln \left(\phi^{U} / \phi^{R}\right)-\ln \left(y^{U} / y^{Y}\right)}
$$

such that

1. households with $\gamma<\hat{\gamma}$ (resp. $\gamma>\hat{\gamma}$ ) will be located in the city (resp. in the countryside).

2. The urbanization rate is $G(\hat{\gamma})$. 


\section{Fertility is lower in the city.}

Assuming that the city is more densely populated that the countryside, we obtain a negative correlation between density and fertility across locations. This however implies neither a causal relationship between the two, nor a built-in stabilizer for population dynamics. Such a stabilizer would be present as soon as income $y^{i}$ and cost of children $\phi^{i}$ are made endogenous and dependent on population in each location.

\section{Data}

We use a large data set including individual and household surveys carried out in 44 developing countries and estimate the relationship between fertility and other variables, among which population density. This will allow us to weight the relevance of the different theoretical frameworks described in Section 2.

To relate population density to fertility, one needs to combine information from demographic surveys with geographical data on population density and other controls, such as the quality of the land. Individual and household characteristics are derived from the Demographic and Health Surveys (DHS), which in most countries are geo-localized. We have incorporated all countries with "Standard DHS" type datasets available, and selected the waves that are closest to the year 2000. Households are grouped into clusters for which we know the latitude and the longitude from the DHS GPS file. ${ }^{9}$ Raster files for world population density are taken from CIESIN et al. (2011), which provides information on population density in grids with cell sizes of $30 " \times 30 "$ (approximately $1 \mathrm{~km}^{2}$ ). ${ }^{10}$ To avoid a possible reverse causality from fertility to population density, we use density in 1990, which is the earliest year available. Further corrections for endogeneity will be implemented in the next section. Figure 2 shows the position of all the DHS clusters in our sample and their respective population density.

To control for the geographical determinants of land productivity we use one of the caloric suitability indexes developed by Galor and Özak (2014) which have a resolution of 5'×5' (approximately $10 \mathrm{~km}^{2}$ ). Galor and Özak (2015) show that the caloric suitability index dominates the conventionally used agricultural suitability data (Ramankutty et al. 2002) in terms of capturing the effect of land productivity. In this paper, we use the raster file for the maximum potential caloric yield attainable given the set of all crops that are suitable in the post-1500

\footnotetext{
${ }^{9}$ The DHS surveys are built to be representative of a country's population. However, even if they are not representative, it would not affect our study, as we do not consider country level total fertility rates.

${ }^{10} \mathrm{~A}$ map of the population density of the relevant region is provided in Figure B.1, Appendix B.
} 


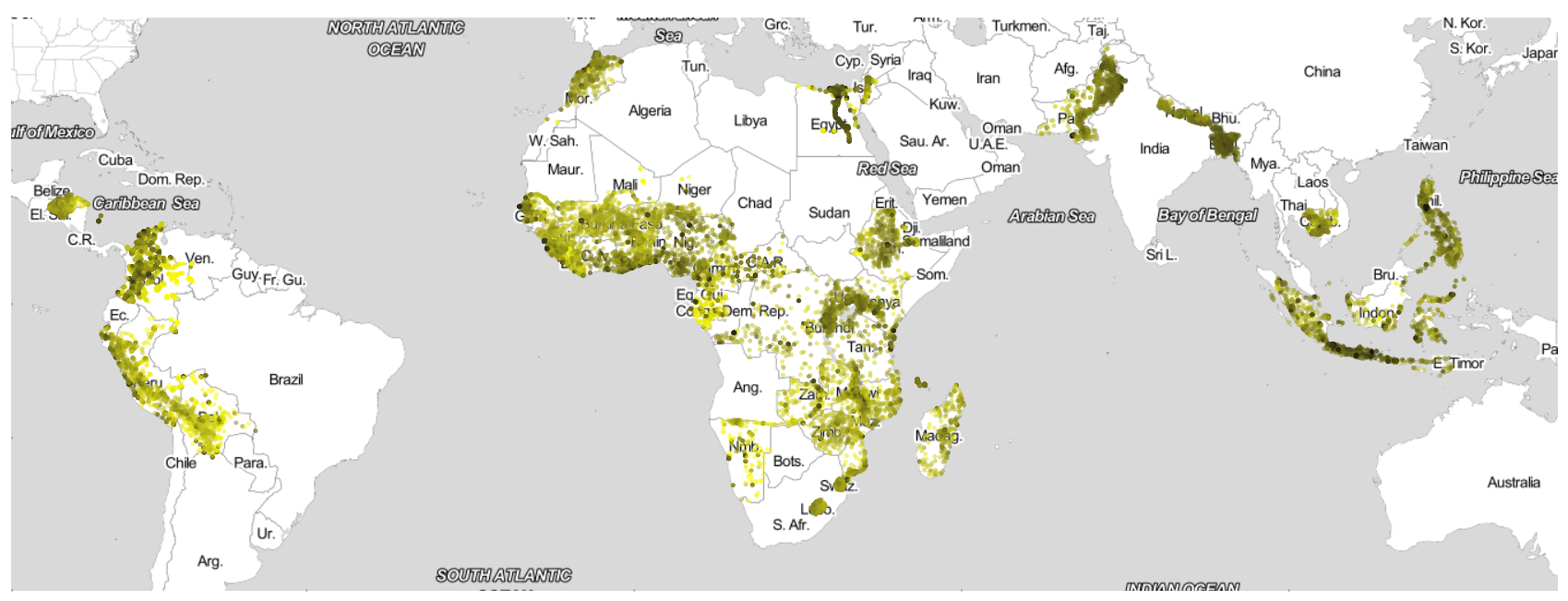

$\begin{array}{llll}1 & 1 & 1 & 1 \\ 2.5 & 5.0 & 7.5 & 10.0\end{array}$

Note: Population density is reported as $\ln (1+$ population density $)$.

Figure 2: Clusters Localization and Population Density (Rescaled)

period. This yield varies across cells depending on their climatic and agronomic characteristics. Figure B.2 depicts this variable.

Finally, as a proxy for income per capita, we use the GDP measures from Ghosh et al. (2010), which are essentially based on nighttime lights satellite data. Henderson, Storeygard, and Weil (2012) show that luminosity is a strong proxy of GDP. Apart from the fact that there is no standardized method for accounting for national income across countries and that informal sectors, often important in developing countries, are difficult to include in national statistics, the major advantage of using this data is that it allows us to capture total economic activity at a disaggregated level. The precision level of the raster is 30 " $\times 30$ "; however, measurement errors at the pixel level are very large. ${ }^{11}$ Ashraf, Galor, and Klemp (2015) argue in favor of measuring GDP on the basis of a continuum of a larger number of nighttime light pixels. We therefore base our measure on an aggregated $20^{\prime} \times 20^{\prime}$ raster. To obtain a per capita variable we divide GDP by our measure of population density taken at the same level of aggregation and discarding pixels with fewer than 0.1 inhabitant per $\mathrm{km}^{2}$. The resulting measure is shown in Figure B.3.

Let us come back to DHS data and provide more detail on the data itself. We use the individual recode, the household recode, and the GPS dataset. The list of the DHS datasets, with the

\footnotetext{
${ }^{11}$ For example, due to over-glow and blooming. We also check whether one should correct for gas flares, but the measure from Ghosh et al. (2010) seems to have filtered them out.
} 
corresponding year and phase, are shown in Table C.1 in Appendix C. The total number of clusters and individuals included in the sample are also provided at the end of the table.

Table 2 provides the list of variables used, and some descriptive statistics. From the individual recode, we built a sample consisting of women between 15 and 49 years of age for whom we know the cluster they are in. ${ }^{12}$ We drop the observations for which the number of years of education is unknown or was higher than 30. All dates are expressed in Century Month Code (CMC). ${ }^{13}$ Mortality rates are computed as the ratio between the total number of living children and the total number of children ever born. Their marital status is coded as either ever married (includes living with a partner, currently married, divorced, or widowed) or single (never married). Data on religion is available in almost all countries except six: Bolivia, Colombia, Egypt, Morocco, Pakistan and Peru. For those for which we do have this information, we divide the sample into Muslims, Christians, Hindus, Buddhists and others. ${ }^{14}$ Figure D.1 in Appendix D shows the histogram of the variables: age, education, infant mortality, and number of births. We observe strong age heaping at ages ending by 0 and 5 , which is evidence of an ignorance of the women themselves of their actual age. Finally, it is worthy of note that the quality of the data on the number of children ever born and their date of birth is subject to misreporting errors, as stressed in the literature on demography (Schoumaker 2014). Appendix K.4 addresses this issue.

From the household recode, we use the information on whether or not the household has electricity or/and a refrigerator. These two variables, and the education level of the partner from the individual recode, are used as additional controls to proxy for income.

From the GPS dataset, we use the urban/rural character ${ }^{15}$ of the cluster and its geographical coordinates. From the geographical coordinates we infer population density, land productivity, and income per capita in each cluster. In order to ensure the anonymity of respondents, urban clusters contain a minimum of 0 and a maximum of 2 kilometers of positional error. Rural clusters contain a minimum of 0 and a maximum of 5 kilometers of error with a further $1 \%$ of the rural clusters displaced a maximum of 10 kilometers. ${ }^{16}$ To account for this error, we set the density in a cluster to the average density in the $2 \mathrm{~km}$ radius' around the center of this cluster

\footnotetext{
${ }^{12}$ In a majority of DHS surveys, eligible individuals include women of reproductive age (15-49). Some countries provided information for older women but we did not keep these observations in the sample.

${ }^{13} \mathrm{CMC}$ is the usual way in which dates are coded in DHS. It counts time in terms of months and starts with the value of 1 for January 1900.

${ }^{14}$ Christians include those who belong to the roman catholic church, the evangelical church, the Anglican church, the protestants, the seventh day adventist, the pentecostal, the methodists, the salvation army, the kimbanguist, the "églises réveillées", the presbyterian, the apostolic sect, the "iglesia ni kristo", the aglipay (Philippine Independent Church) or those coded as "other Christians" by DHS.

${ }^{15}$ DHS Surveys do not precisely define the urban-rural variable. In each country, they adopt a definition that can depend on the size of the population or on the breadth of infrastructures.

${ }^{16}$ See more at: http://dhsprogram.com/What-We-Do/GPS-Data-Collection.cfm
} 


\begin{tabular}{|c|c|c|c|c|c|}
\hline & N. obs. & Mean & St. Dev. & Min & Max \\
\hline \multicolumn{6}{|l|}{ From the Individual Recode } \\
\hline Date of the interview (in $\mathrm{cmc}$ ) & 490669 & 1262.56 & 103.64 & 1110 & 1899 \\
\hline Date of birth of the respondent (in $\mathrm{cmc}$ ) & 490669 & 904.29 & 154.18 & 511 & 1717 \\
\hline Age (in completed years) & 490669 & 29.41 & 9.68 & 15 & 49 \\
\hline Education (in single years) & 490669 & 5.41 & 4.77 & 0 & 27 \\
\hline Partner's Education & 360543 & 6.16 & 5.27 & 0 & 26 \\
\hline Desired number of children & 455194 & 3.90 & 2.42 & 0 & 30 \\
\hline Total number of children ever born & 490669 & 2.71 & 2.69 & 0 & 21 \\
\hline Total number of living children & 490669 & 2.34 & 2.27 & 0 & 16 \\
\hline Children's mortality rate & 490669 & 0.08 & 0.18 & 0 & 1 \\
\hline Births in the last five years & 490669 & 0.67 & 0.83 & 0 & 8 \\
\hline Motherhood rate & 490669 & 0.74 & 0.44 & 0 & 1 \\
\hline Marriage rate & 490669 & 0.77 & 0.42 & 0 & 1 \\
\hline Islamic (\%) & 355361 & 0.34 & 0.47 & 0 & 1 \\
\hline Christian (\%) & 355334 & 0.51 & 0.50 & 0 & 1 \\
\hline Hindu $(\%)$ & 355495 & 0.03 & 0.17 & 0 & 1 \\
\hline Buddhist (\%) & 355487 & 0.04 & 0.20 & 0 & 1 \\
\hline Date of first birth (in cmc) & 360520 & 1108.72 & 151.22 & 669 & 1898 \\
\hline Age at first birth (in years) & 360520 & 19.62 & 4.01 & 7 & 45 \\
\hline Age at first birth (in months) & 360520 & 47.96 & 47.94 & 90 & 543 \\
\hline Date of first marriage (in cmc) & 375104 & 1099.40 & 157.38 & 622 & 1898 \\
\hline Age at first marriage (in years) & 375255 & 18.47 & 4.35 & 5 & 49 \\
\hline Age at first marriage (in months) & 375255 & 226.82 & 52.20 & 60 & 591 \\
\hline Moved from place of residence after $14(\%)$ & 383733 & 0.42 & 0.49 & 0 & 1 \\
\hline \multicolumn{6}{|l|}{ From the Household Recode } \\
\hline Has electricity (percent) & 467150 & 0.51 & 0.50 & 0 & 1 \\
\hline Has a refrigerator (percent) & 441984 & 0.31 & 0.46 & 0 & 1 \\
\hline \multicolumn{6}{|l|}{ From the GPS dataset } \\
\hline Percentage of urban clusters & 24769 & 0.48 & 0.50 & 0 & 1 \\
\hline \multicolumn{6}{|l|}{ From CIESIN et al. (2011) } \\
\hline Population density in 1990 (pop. per km²) & 24769 & 1249 & 3321 & 0.012 & 60987 \\
\hline \multicolumn{6}{|l|}{ From Galor and Özak (2014) } \\
\hline Caloric suitability index post 1500 (/10000) & 24769 & 8.38 & 3.86 & 0 & 17.98 \\
\hline Caloric suitability index pre 1500 (/10000) & 24769 & 6.80 & 3.45 & 0 & 14.84 \\
\hline \multicolumn{6}{|l|}{ From Ghosh et al. (2010) } \\
\hline GDP per capita & 24769 & 0.006 & 0.012 & 0.00001 & 0.333 \\
\hline
\end{tabular}

Table 2: Descriptive Statistics 
if it is an urban cluster. For rural clusters we set the radius at $5 \mathrm{~km} .{ }^{17}$ Finally, as the raster for the Caloric Suitability Index described above has a lower resolution than the population density raster, we impute the land productivity in each cluster from the value of the Index in its given position.

\section{Empirical Analysis}

We proceed in three steps. First, we model the birth rate in a cluster as a function of population density and other variates. In doing so, we discuss possible endogeneity issues. Second, we model the fertility of individuals, as a function of individual and cluster variates. Finally, we model close determinants of individual fertility, such as age at marriage, age at first birth and the gap between marriage and first birth.

\subsection{Analysis at the Cluster Level}

For each cluster, we compute the average value of the number of children ever born, level of education, marriage rate, infant mortality, and the number of Muslims, Christians, Hindus and Buddhists from the individual recode. From the household recode we also compute the average electricity rate and the share of households with a refrigerator in the cluster. We take into account individual or household weights for each woman or household respectively. ${ }^{18}$ Figures E.1 and E.2 in Appendix E shows the histograms of the important variables.

The mean number of women per cluster is 19.8. The average mean age of women is 29.4 years. The average marriage rate within clusters is $77 \%$. The average population density of a cluster in 1990 was 1,249 inhabitants per square kilometer. The mean level of education is six years. $51 \%$ of the households in the clusters have electricity and $31 \%$ have a refrigerator. On average, $51 \%$ of the individuals in the clusters are Christians, $34 \%$ are Muslims, $4 \%$ are Buddhists and $3 \%$ are Hindus.

First, we show the estimates of the relationship between fertility and population density for the

\footnotetext{
${ }^{17}$ Due to the DHS displacement, two clusters in Uganda appear to be inside the water of Lake Victoria. We give each point the minimal radius so as to have positive population density. This is $13 \mathrm{~km}$ for one cluster and $33 \mathrm{~km}$ for the other. A similar issue arose for an urban cluster in Palau Belitung (Indonesia). We allowed the radius to be $6 \mathrm{~km}$ for this cluster. There are also six clusters, all in Egypt, for which the population density at their given location is nil. We gave these clusters the mean density based on a radius of $20 \mathrm{~km}$.

${ }^{18}$ Each observation has a weight that is intended to adjust for the probability of selection and needs to be used in order to make the sample data representative of the entire population. We use these weights to compute the descriptive statistics included in Table 2, but not for regression analysis, as indicated in Rutstein and Rojas (2006).
} 
Ordinary Least Squares estimation and then move to the identification of a causal relationship between population density and fertility using an instrumental variable estimation.

\section{Ordinary Least Squares}

The following equation describes the relationship between fertility and population density at the cluster level, $j$ :

$$
E\left[n_{j}\right]=\beta_{0}+\beta_{1} \ln \left(1+\operatorname{density~}_{j}\right)+\sum_{i=2}^{N} \beta_{i} X_{i j}
$$

where $n_{j} \in \mathbb{R}_{+}$denotes the average number of children born to the women of cluster $j$. The population density in 1990 in cluster $j$, density ${ }_{j}$, enters the equation in logs which allows us to interpret $\beta_{1}$ as a partial elasticity. ${ }^{19} X_{i j}$ are control variates that also affect fertility.

We present the results for all the countries in Table 3. In all regressions, we include country fixed effects in order to account for income differences across countries as well as unobserved characteristics like institutions.

Column (1) of Table 3 shows the effect of population density on fertility, controlling for nothing but the age structure in the cluster, land quality and country fixed effects. Controlling for land productivity accounts for the Malthusian argument according to which more productive land leads to the fathering of more children by means of an income effect. In other words, it allows us to control for the carrying capacity of each location. The point estimates imply that if population density increases from $10 \mathrm{ind} / \mathrm{km}^{2}$ to $1000 \mathrm{ind} / \mathrm{km}^{2}$, then the women in a cluster would have 0.88 fewer children on average. ${ }^{20}$ To clarify this further, Appendix G plots maps of locations with densities ranging from 0.01 to $10000 \mathrm{ind} / \mathrm{km}^{2}$.

The introduction of marriage rates in Column (2) diminishes the direct effect of population density. This may reflect the fact that people marry later in more densely populated areas, which reduces the observed marriage and birth rates in the cluster. Section 4.3 looks in detail at the effect of density on the age at first marriage. In Column (3) we introduce infant mortality rate at the cluster level as a determinant of fertility. Higher mortality is purported to increase fertility as a result of the child replacement effect (Doepke 2005). The impact of density on fertility is reduced by the inclusion of mortality (the reduction is statistically significant, but small in size). Infant mortality captures part of the effect of density: as the provision of health services is higher in more densely populated areas, mortality is lower, decreasing the need to

\footnotetext{
${ }^{19}$ The $\log$ formulation allows us to take care of the strong skewness in the distribution of density. We add 1 to density ${ }_{j}$ in order to avoid attributing too much weight to the few observations in which density is close to zero.

${ }^{20}-0.195 \times(\ln (1001)-\ln (11))$.
} 


\begin{tabular}{|c|c|c|c|c|c|}
\hline & \multicolumn{5}{|c|}{$\begin{array}{c}\text { Dependent variable: } \\
\text { Children ever born, per woman (average in cluster) }\end{array}$} \\
\hline & $(1)$ & $(2)$ & $(3)$ & $(4)$ & $(5)$ \\
\hline $\ln (1+$ density $)$ & $\begin{array}{c}-0.195^{* * *} \\
(0.002)\end{array}$ & $\begin{array}{c}-0.145^{* * *} \\
(0.002)\end{array}$ & $\begin{array}{c}-0.127^{* * *} \\
(0.002)\end{array}$ & $\begin{array}{c}-0.128^{* * *} \\
(0.002)\end{array}$ & $\begin{array}{c}-0.058^{* * *} \\
(0.002)\end{array}$ \\
\hline Caloric Suitability Index & $\begin{array}{c}0.013^{* * *} \\
(0.002)\end{array}$ & $\begin{array}{l}0.004^{* *} \\
(0.002)\end{array}$ & $\begin{array}{c}0.006^{* * *} \\
(0.002)\end{array}$ & $\begin{array}{l}0.006^{* * *} \\
(0.002)\end{array}$ & $\begin{array}{c}0.006^{* * *} \\
(0.002)\end{array}$ \\
\hline age & $\begin{array}{c}0.567^{* * *} \\
(0.017)\end{array}$ & $\begin{array}{c}0.386^{* * *} \\
(0.016)\end{array}$ & $\begin{array}{c}0.331^{* * *} \\
(0.015)\end{array}$ & $\begin{array}{c}0.329^{* * *} \\
(0.015)\end{array}$ & $\begin{array}{c}0.285^{* * *} \\
(0.013)\end{array}$ \\
\hline $\operatorname{age}^{2}$ & $\begin{array}{c}-0.007^{* * *} \\
(0.0003)\end{array}$ & $\begin{array}{c}-0.005^{* * *} \\
(0.0003)\end{array}$ & $\begin{array}{c}-0.004^{* * *} \\
(0.0002)\end{array}$ & $\begin{array}{c}-0.004^{* * *} \\
(0.0002)\end{array}$ & $\begin{array}{c}-0.003^{* * *} \\
(0.0002)\end{array}$ \\
\hline marriage & & $\begin{array}{c}2.207^{* * *} \\
(0.034)\end{array}$ & $\begin{array}{c}1.845^{* * *} \\
(0.033)\end{array}$ & $\begin{array}{c}1.838^{* * *} \\
(0.033)\end{array}$ & $\begin{array}{c}1.116^{* * *} \\
(0.031)\end{array}$ \\
\hline infant mortality & & & $\begin{array}{c}4.239^{* * *} \\
(0.083)\end{array}$ & $\begin{array}{c}4.203^{* * *} \\
(0.083)\end{array}$ & $\begin{array}{c}2.672^{* * *} \\
(0.077)\end{array}$ \\
\hline GDP per capita & & & & $\begin{array}{c}-3.925^{* * *} \\
(0.392)\end{array}$ & $\begin{array}{c}-1.660^{* * *} \\
(0.348)\end{array}$ \\
\hline women's education & & & & & $\begin{array}{c}-0.094^{* * *} \\
(0.004)\end{array}$ \\
\hline women's education ${ }^{2}$ & & & & & $\begin{array}{c}-0.004^{* * *} \\
(0.0003) \\
\end{array}$ \\
\hline Country fixed effects & yes & yes & yes & yes & yes \\
\hline Observations & 24,769 & 24,769 & 24,769 & 24,769 & 24,769 \\
\hline $\mathrm{R}^{2}$ & 0.569 & 0.632 & 0.667 & 0.668 & 0.740 \\
\hline Adjusted $\mathrm{R}^{2}$ & 0.568 & 0.631 & 0.666 & 0.668 & 0.739 \\
\hline
\end{tabular}

Note: ${ }^{* * *} \mathrm{p}<0.01$, robust standard errors in parentheses.

Table 3: Results at the cluster level

have a large number of children.

In Column (4), we also control for differences in GDP per capita across clusters as wealthier places could have higher returns to human capital and therefore a lower fertility, for example, which would be in line with Beckerian theory. The impact of density on fertility is not altered significantly when controlling for the GDP per capita of the cluster, as shown in Column (4). Finally, in Column (5) we add mothers' level of education as a control. The squared term is significant showing a stronger negative effect of education on fertility for higher education levels. A similar argument to the one used to discuss mortality can be applied here. The provision of education services is higher in more densely populated areas, enabling mothers to become more educated. More education leads to lower fertility rates either because the opportunity cost of having children is higher, or because women are more aware of contraception. The estimate 
in Column (5) provides a lower bound on the effect of density on fertility, as all the main controls have been introduced. Under this specification, fertility decreases by 0.26 children when population density increases from $10 \mathrm{ind} / \mathrm{km}^{2}$ to $1000 \mathrm{ind} / \mathrm{km}^{2}$.

In Appendix $\mathrm{H}$ we investigate whether or not adding additional controls renders the effect of population density insignificant. In doing so, however, we loose some observations for which these control variables are not available. Column (1) of Table H.1 provides the estimates when controlling for the religious composition of the cluster. Only Hindus appear to have a fertility rate that is statistically significantly lower than the others at the $1 \%$ level. ${ }^{21}$ Columns (2) and (3) add controls for the electricity availability rate in the cluster and refrigerator ownership rate in the cluster respectively. Higher electricity or refrigerator rates are negatively associated with fertility, ${ }^{22}$ perhaps as a result of the effect of modernization and access to other norms, as shown by La Ferrara, Chong, and Duryea (2012) in the case of television transmitted soap opera in Brazil, for example. Including these two additional controls lowers the coefficient of density slightly as compared to Column (5) of Table 3. One possible explanation of this is that density has a positive impact on the provision of public goods like as electricity.

Appendix I provides the results pertaining to the relationship between population density and fertility for each specific continent. The magnitudes of the relationships between fertility and population density across different contexts remain remarkably similar to the estimates at the global level, shown in Table 3. The coefficients of $\ln (1+$ density) in Model (5) are -0.047 in SubSaharan Africa, -0.049 in Middle-East and North Africa, -0.037 in Asia, and -0.065 in Latin America (all significant at the 1\% level). Finally, instead of sorting countries by continent, we also group them according to two income levels: the countries belonging to the least developed economies according to the United Nations Economic and Social Council $(\mathrm{N}=25)$, and the remaining, wealthier, countries $(\mathrm{N}=19)$. The results of this are presented in Appendix J. The effect of density is significant in both samples, with a size of -0.032 for the poorest countries, and -0.066 for the richest. Hence, this effect is not entirely driven by Malthusian elements affecting only the very poor, it is also present and stronger in more developed economies.

\section{Two-Stage Least Squares}

One might suspect that the coefficient of density estimated by OLS is plagued by an endogeneity bias due to a local omitted variable affecting both population density and women's fertility. This

\footnotetext{
${ }^{21}$ In line with de la Croix and Delavallade (2015) who study the role of religion in both the quantity and quality of children in South East Asia.

${ }^{22}$ Contrary to what we would be expected by Greenwood, Seshadri, and Vandenbroucke (2005) who explain the baby boom in terms of better home production technology.
} 
could lead to a spurious relationship between these two variables without causal effect. Reverse causality is unlikely for two reasons: (i) we take the earliest available data for population density and the latest available for fertility rates. Therefore, fertility cannot affect past density. (ii) Fertility is measured at the individual level while population density is measured at the cluster level.

Three candidates for omitted variables could affect both fertility rates and population density. First, favorable economic conditions can affect both population density, as people are more likely to want to live in these places, and fertility (either in a positive - Malthusian - or negative Sadlerian - way). We control for income in several ways. In the benchmark regression (column 5 of Table 3) we control for GDP per capita using satellite night-light data, individual's education and country fixed effects as proxies. In the robustness checks (Table H.1) we also add electricity availability and refrigerator ownership. Therefore, income is unlikely to affect fertility rates via a channel other than population density.

A second omitted variable could be the existence of norms related to fertility. These could be linked to certain ethnicities rather than countries, as we already control for country fixed effects. A region inhabited by groups of individuals that observe a a pro-natalist norm or experience higher fecundity will have a higher population density as a result. If our instrument cannot account for this persistence, then the bias that it introduces reduces the estimated impact of population density on fertility. This leads to a conservative estimate and therefore does not invalidate the claim that population density has a causal impact on fertility. A similar argument can be made in the presence of unobserved fecundity factors specific to ethnicities.

Lastly, unobserved amenities at the local level can lead to the migration of people with certain characteristics and the persistence of these could affect fertility rates.

If the omitted variables we just described affect both population density and fertility positively, they will attenuate the measured effect of density on fertility in the regressions without instrumentation. Instrumenting population density should therefore increase the effect of population density on fertility rates.

The generally accepted means of dealing with omitted variables is to instrument the suspected endogenous variable. Density is a variable that is commonly used in studies on firms' productivity, as a way of capturing agglomeration effects. As surveyed by Combes and Gobillon (2015), the literature has adopted different strategies to address this issue. Two of these dominate: using the historical value of population density, and using geographical and geological variables that were important with regard to human settlements centuries ago, but only have negligible effects on outcomes today. The exogeneity of both types of instruments may depend on whether 
or not one is able to control for local permanent characteristics that may have affected past location choices and still affect fertility locally.

We chose two instruments that affected the choice of settling in a place around or before the year 1500. Both reflect technological progress in the past, but not in the present. The reasons to be in these places today are therefore not the same as they were in the past. Therefore, the main reason why these populations are there is the persistence of population density.

Our first instrument consists of the distance to buildings and cities belonging to UNESCO World Heritage Sites, constructed between the neolithic revolution and 1900. Appendix F.1 shows the maps of the retained sites and the computed distance from each cluster in our sample. Being close to one of the UNESCO World Heritage Sites is likely to increase population density on average as such cites were trade, religious, or political centers. While these were all a good reasons to reside close to these locales at the time, they no longer apply. However, if population density is persistent over time, then this is a strong instrument. There are reasons to believe that some of these sites may still affect income today. For example, Valencia Caicedo (2014) shows that Jesuit Missions in Guarani lands have a persistent effect on education and income of those who live close to their location today. As we control for both clusters' mean education and income, this should not lead us to violate the exclusion restriction.

A second instrument, ${ }^{23}$ more of the geological type, is the difference between the Caloric Suitability Index post-1500 and the Caloric Suitability Index prior to 1500 from Galor and Özak (2014). Appendix F.2 provides the corresponding map. This difference comes in large part from the expansion of crops due to the Columbian Exchange. The introduction of previously unknown species improved nutrition and resulted in a significant increase in population (see Mokyr (1981), Nunn and Qian (2011), and Iyigun, Nunn, and Qian (2015)) for both the New and the Old Worlds. The Old World brought, potatoes, sweet potatoes, maize, tomatoes, and manioc from the New World, while the New World climate was beneficial to some Old World crops such as sugar cane, soybeans, bananas, oranges, and barley (see Nunn and Qian (2010)). The places in which there is a substantial difference between the Caloric Suitability Index post-1500 and the Caloric Suitability Index prior to 1500 are those that gained the most from the Columbian Exchange, i.e. those that were rated as useless prior to 1500 because of altitude (such as Nepal and north of Pakistan) or aridity (such as Burkina Faso and Nigeria) but were suitable for the production of the new crops. This is likely to lead to a larger increase in population relative to those areas in which the difference is smaller. As we control for Caloric Suitability Index post 1500 in the regression, the instrument refers to circumstances that prevailed before 1500, and are thus irrelevant to productivity today. Hence, they affect fertility

\footnotetext{
${ }^{23}$ Using two instruments allows us to run a Sargan test to assess over-identification restrictions. This test assumes that at least one of the instruments is exogenous and attributes validity to the other.
} 
only through the persistence of population density.

A potential issue that could invalidate one of these instruments may be that the proximity to UNESCO World heritage sites affects fertility by way of an institutional channel, namely the antiquity of the state. These monuments could indeed symbolize great societies of the past whose effects persist today via norms. Indeed, Chanda and Putterman (2007) show that antique states such as Egypt, China and India, still have an advantage today perhaps as a result of culture and institutional capabilities. Most of this effect is controlled for by the inclusion of country fixed effects. Finally, one may still wonder whether some endogeneity bias may persist despite instrumentation through enduring norms. This type of bias would, however, play out in our favor. Indeed, since this persistence leads to a positive relationship between population density and fertility rates, our estimate from the second stage instrumental variable regression is a lower bound for the effect of population density on fertility. In all cases, the presence of country dummies helps satisfy the exclusion restriction, as many historical and geographical determinants of institutions possibly affecting fertility are controlled for.

Table 4 presents the results. Column (5) of Table 4 is the same as that of Table 3 . The second column shows the estimates for the first stage, and the third the estimates of the second stage. The F-test for the first stage is greater than the various threshold values proposed in the literature. We therefore reject the hypothesis that the instruments is weak. The Sargan test for overidentification restrictions checks that all exogenous instruments are in fact exogenous, and uncorrelated with the model residuals, under the assumption that at least one of the instruments is exogenous. The result of the test is insignificant, and thus we are not required to reject the instruments as invalid. From Table 4, we see that the effect of population density on fertility is, as expected, stronger than in the benchmark of column (5). The effect of increasing density from 10 to $1000 \mathrm{ind} / \mathrm{km}^{2}$ now leads to a drop of 0.61 children, instead of 0.26 in the model without instrumentation. The endogeneity bias is therefore an attenuation bias, arising from the positive correlation between an unobserved variable and both density and fertility.

To conclude, population density has a negative causal effect on fertility rates. This leads us to reject a pure Beckerian model (Proposition 3). But a Beckerian model allowing for an effect of density through education captures parts of the relationships revealed in the data. Indeed, controlling for education reduces the direct effect of density, suggesting that some of its impact is brought to bear through education. Moreover, even when controlling for education, mortality, income, and marriage, there remains a direct effect of density on fertility, which might be related to Malthusian (Proposition 1) mechanisms still at work today.

Before investigating whether or not these conclusions still hold at the individual level, we test for a Lokta-Volterra type of interaction. In their model, the effect of population density on 


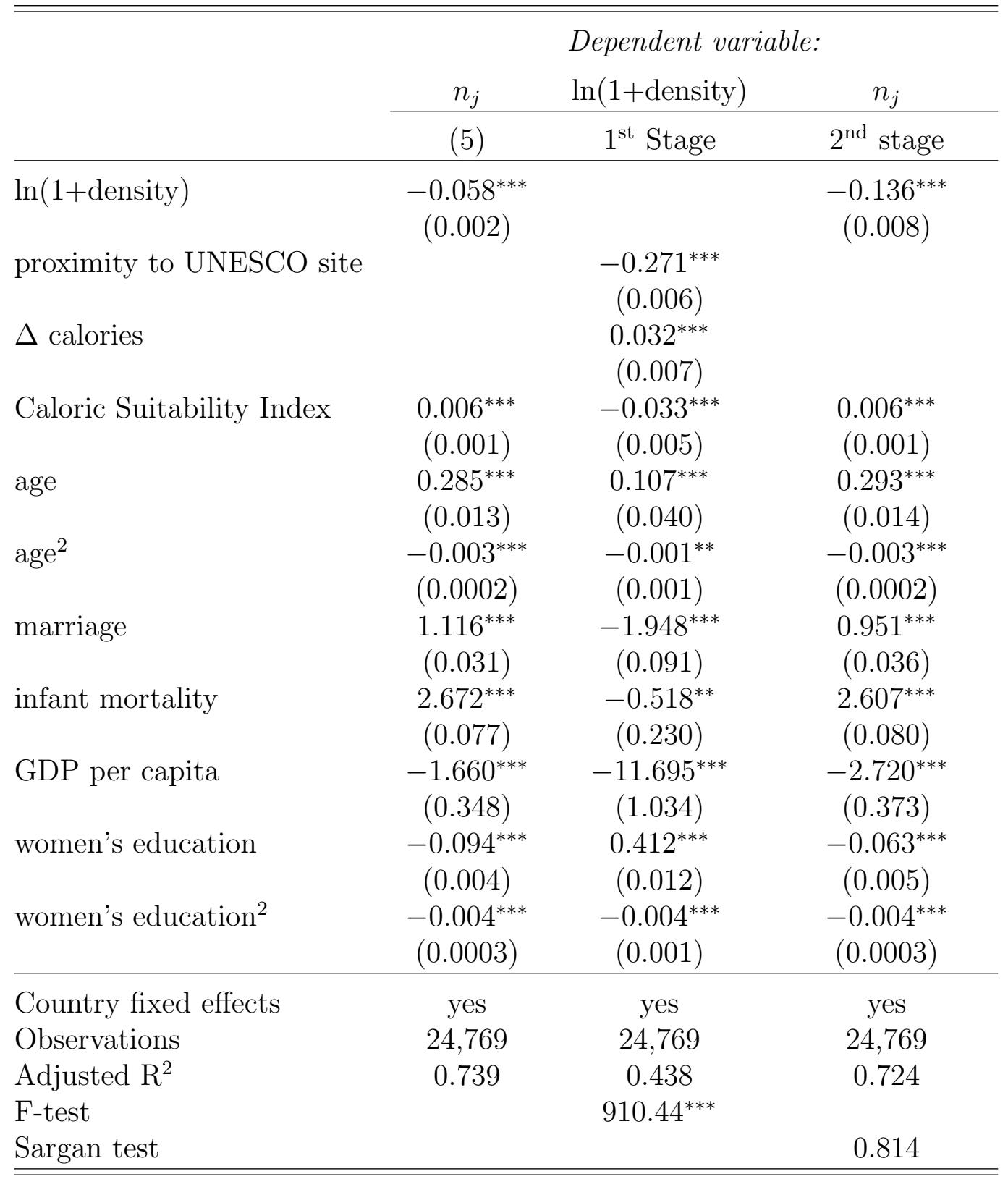

Note: ${ }^{*} \mathrm{p}<0.1 ;{ }^{* *} \mathrm{p}<0.05 ;{ }^{* *} \mathrm{p}<0.01$, robust standard errors in parentheses.

Table 4: Results at the cluster level when instrumenting population density 
fertility should be negative for high levels of density, but positive for low levels. We test this prediction by allowing the effect of $\ln (1+$ density $)$ to be different above and below a certain threshold. Taking as threshold the first quartile of density (44ind $/ \mathrm{km}^{2}$ ), the effect of density is negative both below and above the threshold. Lowering the value of this threshold does not reveal any positive relationship.

\subsection{Analysis at the Individual Level}

The analysis above reveals the main determinants of fertility rates at the cluster level. Moving to the individual level allows us to disentangle the effects of personal variables, like own education, from the effect of the environment, like the mean education in the cluster. Kravdal (2013) argues that there are strong educational spillovers from cluster-level data to individual behavior. To exclude the fact that population density at the cluster level may proxy such spillovers, thereby influencing individual fertility, in this section we study fertility at the individual level. Since the dependent variable, children ever born $n_{j}$, is a count variable, we estimate a Poisson regression model to predict the impact of density on births. The model is:

$$
E\left[n_{j}\right]=\exp \left\{\pi_{0}+\pi_{1} \ln \left(1+\text { density }_{j}\right)+\sum_{i=2}^{N} \pi_{i} X_{i j}\right\}
$$

where $n_{j} \in \mathbb{N}$ is distributed according to a Poisson distribution. The estimated coefficients $\pi$ cannot be directly compared to the $\beta$ 's of the OLS. They are related through $\beta_{i}=\pi_{i} E\left[n_{j}\right]$. Building on Equation (1), in Equation (2), we add controls for average education, marriage, and mortality rates in the cluster in which the woman is living. Results are shown in Table 5. To facilitate comparison with the regression at the cluster level, Column (x) of Table 5 has the same set of variates as Column (x) of Table 3. Column (IV) shows the estimates of the Poisson regression where we instrument population density using the two instrumental variables used in Section 4.1.

The effect of density from Column (1) is close to that at the cluster level. Indeed, $\pi_{1} \times E\left[n_{j}\right]=$ $-0.071 \times 2.711=-0.192$ can be compared to $\beta_{1}=-0.195$. The estimate from Column (5) is not statistically different from that at the cluster level either. As in the cluster analysis, instrumentation leads to a greater effect of density on number of children born; when population density goes from 10 to $1000 \mathrm{ind} / \mathrm{km}^{2}$, we estimate that fertility decreases by 0.7 children at the individual level. This again reflects the attenuation bias brought about by the omitted variables.

Among the other control variables, one should take notice of the effect of education. At the 


\begin{tabular}{|c|c|c|c|c|c|c|}
\hline & \multicolumn{6}{|c|}{ Dependent variable: Children ever born } \\
\hline & $(1)$ & $(2)$ & $(3)$ & $(4)$ & $(5)$ & $(\mathrm{IV})$ \\
\hline $\ln (1+$ density $)$ & $\begin{array}{c}-0.071^{* * *} \\
(0.0005)\end{array}$ & $\begin{array}{c}-0.051^{* * *} \\
(0.0005)\end{array}$ & $\begin{array}{c}-0.047^{* * *} \\
(0.001)\end{array}$ & $\begin{array}{c}-0.047^{* * *} \\
(0.001)\end{array}$ & $\begin{array}{c}-0.021^{* * *} \\
(0.001)\end{array}$ & $\begin{array}{c}-0.057^{* * *} \\
(0.002)\end{array}$ \\
\hline Caloric Suitability & $\begin{array}{l}0.007^{* * *} \\
(0.0004)\end{array}$ & $\begin{array}{l}0.004^{* * *} \\
(0.0004)\end{array}$ & $\begin{array}{l}0.005^{* * *} \\
(0.0004)\end{array}$ & $\begin{array}{l}0.005^{* * *} \\
(0.0004)\end{array}$ & $\begin{array}{l}0.004^{* * *} \\
(0.0004)\end{array}$ & $\begin{array}{l}0.004^{* * *} \\
(0.0004)\end{array}$ \\
\hline married & & $\begin{array}{c}1.498^{* * *} \\
(0.007)\end{array}$ & $\begin{array}{c}1.487^{* * *} \\
(0.007)\end{array}$ & $\begin{array}{c}1.487^{* * *} \\
(0.007)\end{array}$ & $\begin{array}{c}1.422^{* * *} \\
(0.007)\end{array}$ & $\begin{array}{c}1.422^{* * *} \\
(0.009)\end{array}$ \\
\hline mean marriage & & $\begin{array}{c}0.312^{* * *} \\
(0.008)\end{array}$ & $\begin{array}{c}0.156^{* * *} \\
(0.008)\end{array}$ & $\begin{array}{c}0.153^{* * *} \\
(0.008)\end{array}$ & $\begin{array}{c}-0.060^{* * *} \\
(0.009)\end{array}$ & $\begin{array}{c}-0.146^{* * *} \\
(0.010)\end{array}$ \\
\hline mortality & & & $\begin{array}{c}0.470^{* * *} \\
(0.005)\end{array}$ & $\begin{array}{c}0.470^{* * *} \\
(0.005)\end{array}$ & $\begin{array}{c}0.427^{* * *} \\
(0.005)\end{array}$ & $\begin{array}{c}0.427^{* * *} \\
(0.006)\end{array}$ \\
\hline mean mortality & & & $\begin{array}{c}0.582^{* * *} \\
(0.018)\end{array}$ & $\begin{array}{c}0.577^{* * *} \\
(0.018)\end{array}$ & $\begin{array}{c}0.177^{* * *} \\
(0.019)\end{array}$ & $\begin{array}{c}0.170^{* * *} \\
(0.020)\end{array}$ \\
\hline GDP per capita & & & & $\begin{array}{c}-1.481^{* * *} \\
(0.094)\end{array}$ & $\begin{array}{c}-0.706^{* * *} \\
(0.091)\end{array}$ & $\begin{array}{c}-1.160^{* * *} \\
(0.097)\end{array}$ \\
\hline woman's educ & & & & & $\begin{array}{c}0.003^{* * *} \\
(0.001)\end{array}$ & $\begin{array}{c}-0.002^{* * *} \\
(0.001)\end{array}$ \\
\hline woman's educ ${ }^{2}$ & & & & & $\begin{array}{c}-0.003^{* * *} \\
(0.0001)\end{array}$ & $\begin{array}{c}-0.003^{* * *} \\
(0.0001)\end{array}$ \\
\hline educ in cluster & & & & & $\begin{array}{c}-0.010^{* * *} \\
(0.001)\end{array}$ & $\begin{array}{l}0.004^{* *} \\
(0.001)\end{array}$ \\
\hline educ $^{2}$ in cluster & & & & & $\begin{array}{c}-0.001^{* * *} \\
(0.0001)\end{array}$ & $\begin{array}{c}-0.001^{* * *} \\
(0.0001)\end{array}$ \\
\hline Age dummies & yes & yes & yes & yes & yes & yes \\
\hline Cntry fixed effects & yes & yes & yes & yes & yes & yes \\
\hline Observations & 490,669 & 490,669 & 490,669 & 490,669 & 490,669 & 490,669 \\
\hline
\end{tabular}

Notes: ${ }^{*} \mathrm{p}<0.1 ;{ }^{* *} \mathrm{p}<0.05 ;{ }^{* * *} \mathrm{p}<0.01$.

Table 5: Results at the individual level (Poisson regression)

cluster level, the effect of education on fertility was negative, with an increasing impetus given by the quadratic term as the level of education increases. As stressed in Kravdal (2002), this measured effect combines both individual and aggregate effects. When one distinguishes between both, we see that the individual effect first increases and then decreases, while the aggregate effect is similar to that observed at the cluster level. Baudin, de la Croix, and Gobbi (2015a) and Vogl (2015) find evidence of income mechanisms affecting fertility of the uneducated in a large number of developing countries. This may explain the hump-shaped relationship between education and fertility found at the individual level. The other controls have the same effect as they do at the cluster level, with the exception of the cluster level 
marriage rate. ${ }^{24}$

In Appendix K.1, we include additional controls (only available for subsamples). As we did at the cluster level, we control for religion, electricity, and refrigerator ownership. We also control for the level of education of the husband. In doing so, we restrict ourselves to the ever-married and living with a partner sample of women. The spouse's education has a negative effect on fertility. In all cases, the effect of density persists, and is of the same magnitude as in the last column of Table 5 .

To be sure that our estimation is not only capturing a tempo effect, but that completed fertility also decreases with density, we restrict the sample to women aged 40+. The estimations are presented in Appendix K.2. The sample size is very much reduced as a result: 95k women instead of 490k. However, most coefficients, including the effect of density, are remarkably stable.

Finally, we also look at the impact of population density on two other dependent variables that can be used to analyze fertility behavior. These are the number of births in the last five years and the ideal number of children that a woman declares. Tables K.3 and K.4 replicate Table 5 for these two dependent variables respectively. The impact of population density is always negative and significant at the $1 \%$ level for both of these variables across all specifications. In particular, in terms of desired number of children, we observe that the estimates are close to those revealed in Table 5, using the number of children ever born. This means that the impact of population density on fertility comes from rational adjustment behavior rather than from availability of information on contraceptive in more densely populated areas.

We now address three issues that might affect the results: cluster-specific random effects, selection bias, and the quality of DHS data.

\section{Cluster specific random effects}

The results presented above were generated without consideration of the fact that individuals were groups into into clusters. However, in such a setting, errors for individuals in the same cluster may be correlated because of some unobserved cluster effect. The standard errors listed in Table 5 may therefore greatly overstate estimator precision (see Cameron and Miller (2013) for a survey on this issue). To evaluate the extent of the overestimation of precision in the

\footnotetext{
${ }^{24}$ In the last two columns of Table 5, the coefficient of the average marriage rate in the cluster is negatively related to fertility of individuals. This might be the result of the following: in clusters where marriage rates are higher, the chance of finding a partner in the event of divorce is lower and women may therefore choose to have fewer children in order to limit the cost of divorcing.
} 
standard Poisson regression, we control for clustered errors in two different ways. First, we use the estimation of the regression model with no explicit control for within-cluster error correlation but compute standard errors differently using the cluster-robust standard errors proposed by Zeger and Liang (1986) for nonlinear models. These cluster-robust standard errors only require the additional assumption that the number of clusters, rather than just the number of observations, increases to infinity. The column "clustering s.e." in Table 6 shows this correction for the variable of interest. The standard error of the coefficient of $\ln (1+$ density) is larger with the correction, but not sufficiently so as to modify its significance at the $1 \%$ level. Second, we specify a model with a cluster-specific random effect drawn from a Gaussian distribution and consistently estimate the parameters of this model (Broström and Holmberg 2011). If the within-cluster error correlation is correctly specified, this provides valid statistical inference, as well as estimates of the parameters of the original regression model that are more efficient (Cameron and Miller 2013). The last two columns of Table 6 show the results. The effect of $\ln (1+$ density $)$ is reinforced with this specification, while its significance level is slightly diminished. This model is estimated by maximum likelihood, and, therefore, one can implement a test of the null hypothesis that there is no cluster-specific random effect using a likelihood ratio test. Unsurprisingly, we reject this null hypothesis at the $1 \%$ level, in all specifications. On the whole, although cluster-specific unobserved effects are present, they do not meaningfully affect the significance of the effect of population density on fertility rates.

\begin{tabular}{c|cc|c|cc}
\hline \hline & \multicolumn{2}{|c|}{ no correction } & clustering & \multicolumn{2}{c}{ random effect } \\
Model & coef & s.e. & s.e. & coef & s.e. \\
\hline$(1)$ & $-0.07107^{* * *}$ & 0.00046 & 0.00093 & $-0.07795^{* * *}$ & 0.00086 \\
$(2)$ & $-0.05130^{* * *}$ & 0.00050 & 0.00088 & $-0.05712^{* * *}$ & 0.00082 \\
$(3)$ & $-0.04656^{* * *}$ & 0.00050 & 0.00084 & $-0.05160^{* * *}$ & 0.00079 \\
$(4)$ & $-0.04701^{* * *}$ & 0.00050 & 0.00084 & $-0.05205^{* * *}$ & 0.00079 \\
$(5)$ & $-0.02053^{* * *}$ & 0.00056 & 0.00079 & $-0.02252^{* * *}$ & 0.00075 \\
\hline \hline
\end{tabular}

Table 6: Cluster-Robust Inference - Coefficient of $\ln (1+$ density)

\section{Selection}

As specified in Proposition 4, density may be correlated with fertility because of a selection problem: women with a lower desire for children or lower fecundity may migrate from rural to urban areas. One example of how this selection might operate is that barren women tend to move to more densely populated areas in order to hide their childlessness (Lesthaeghe 1989). In addition the instrumentation methods discussed above, we control for selection in three different ways. 


\begin{tabular}{|c|c|c|c|c|c|}
\hline & \multicolumn{5}{|c|}{ Dependent variable: Children ever born } \\
\hline & $(5)$ & $(5 \mathrm{a})$ & $(5 b)$ & $(5 c)$ & $(5 \mathrm{~d})$ \\
\hline $\ln (1+$ density $)$ & $\begin{array}{c}-0.021^{* * *} \\
(0.001)\end{array}$ & $\begin{array}{c}-0.020^{* * *} \\
(0.001)\end{array}$ & $\begin{array}{c}-0.021^{* * *} \\
(0.001)\end{array}$ & $\begin{array}{c}-0.021^{* * *} \\
(0.001)\end{array}$ & $\begin{array}{c}-0.018^{* * *} \\
(0.001)\end{array}$ \\
\hline Caloric Suitability Index & $\begin{array}{l}0.004^{* * *} \\
(0.0004)\end{array}$ & $\begin{array}{l}0.003^{* * *} \\
(0.0005)\end{array}$ & $\begin{array}{c}0.006^{* * *} \\
(0.001)\end{array}$ & $\begin{array}{l}0.004^{* * *} \\
(0.0004)\end{array}$ & $\begin{array}{l}0.004^{* * *} \\
(0.0004)\end{array}$ \\
\hline married & $\begin{array}{c}1.422^{* * *} \\
(0.007)\end{array}$ & $\begin{array}{c}1.476^{* * *} \\
(0.008)\end{array}$ & $\begin{array}{c}1.575^{* * *} \\
(0.009)\end{array}$ & $\begin{array}{c}1.425^{* * *} \\
(0.007)\end{array}$ & $\begin{array}{c}1.423^{* * *} \\
(0.007)\end{array}$ \\
\hline mean marriage & $\begin{array}{c}-0.060^{* * *} \\
(0.009)\end{array}$ & $\begin{array}{c}-0.047^{* * *} \\
(0.012)\end{array}$ & $\begin{array}{c}-0.051^{* * *} \\
(0.014)\end{array}$ & $\begin{array}{c}-0.057^{* * *} \\
(0.009)\end{array}$ & $\begin{array}{c}-0.059^{* * *} \\
(0.009)\end{array}$ \\
\hline mortality & $\begin{array}{c}0.427^{* * *} \\
(0.005)\end{array}$ & $\begin{array}{c}0.449^{* * *} \\
(0.006)\end{array}$ & $\begin{array}{c}0.457^{* * *} \\
(0.007)\end{array}$ & $\begin{array}{c}0.427^{* * *} \\
(0.005)\end{array}$ & $\begin{array}{c}0.427^{* * *} \\
(0.005)\end{array}$ \\
\hline mean mortality & $\begin{array}{c}0.179^{* * *} \\
(0.019)\end{array}$ & $\begin{array}{c}0.237^{* * *} \\
(0.024)\end{array}$ & $\begin{array}{c}0.174^{* * *} \\
(0.029)\end{array}$ & $\begin{array}{c}0.178^{* * *} \\
(0.019)\end{array}$ & $\begin{array}{c}0.172^{* * *} \\
(0.019)\end{array}$ \\
\hline GDP per capita & $\begin{array}{c}-0.706^{* * *} \\
(0.091)\end{array}$ & $\begin{array}{c}-0.645^{* * *} \\
(0.122)\end{array}$ & $\begin{array}{c}-0.579^{* * *} \\
(0.128)\end{array}$ & $\begin{array}{c}-0.689^{* * *} \\
(0.091)\end{array}$ & $\begin{array}{c}-0.624^{* * *} \\
(0.092)\end{array}$ \\
\hline educ & $\begin{array}{c}0.003^{* * *} \\
(0.001)\end{array}$ & $\begin{array}{c}0.003^{* * *} \\
(0.001)\end{array}$ & $\begin{array}{c}0.006^{* * *} \\
(0.001)\end{array}$ & $\begin{array}{c}0.003^{* * *} \\
(0.001)\end{array}$ & $\begin{array}{c}0.003^{* * *} \\
(0.001)\end{array}$ \\
\hline educsq & $\begin{array}{c}-0.003^{* * *} \\
(0.0001)\end{array}$ & $\begin{array}{c}-0.003^{* * *} \\
(0.0001)\end{array}$ & $\begin{array}{c}-0.003^{* * *} \\
(0.0001)\end{array}$ & $\begin{array}{c}-0.003^{* * *} \\
(0.0001)\end{array}$ & $\begin{array}{c}-0.003^{* * *} \\
(0.0001)\end{array}$ \\
\hline meaneduc & $\begin{array}{c}-0.010^{* * *} \\
(0.001)\end{array}$ & $\begin{array}{c}-0.008^{* * *} \\
(0.002)\end{array}$ & $\begin{array}{c}-0.012^{* * *} \\
(0.002)\end{array}$ & $\begin{array}{c}-0.009^{* * *} \\
(0.001)\end{array}$ & $\begin{array}{c}-0.008^{* * *} \\
(0.001)\end{array}$ \\
\hline meaneducsq & $\begin{array}{c}-0.001^{* * *} \\
(0.0001)\end{array}$ & $\begin{array}{c}-0.001^{* * *} \\
(0.0001)\end{array}$ & $\begin{array}{c}-0.001^{* * *} \\
(0.0001)\end{array}$ & $\begin{array}{c}-0.001^{* * *} \\
(0.0001)\end{array}$ & $\begin{array}{c}-0.001^{* * *} \\
(0.0001)\end{array}$ \\
\hline migrant & & & & $\begin{array}{c}-0.014^{* * *} \\
(0.002)\end{array}$ & \\
\hline migrant (NA) & & & & $\begin{array}{l}-0.023 \\
(0.028)\end{array}$ & \\
\hline urban & & & & & $\begin{array}{c}-0.019^{* * *} \\
(0.006)\end{array}$ \\
\hline urban $\times \ln (1+$ density $)$ & & & & & $\begin{array}{l}-0.001 \\
(0.001)\end{array}$ \\
\hline Age dummies & yes & yes & yes & yes & yes \\
\hline Country fixed effects & yes & yes & yes & yes & yes \\
\hline Observations & 490,669 & 328,871 & 221,935 & 490,669 & 490,669 \\
\hline
\end{tabular}

Notes: ${ }^{*} \mathrm{p}<0.1 ;{ }^{* *} \mathrm{p}<0.05 ;{ }^{* * *} \mathrm{p}<0.01$

DHS data on the years lived in the place of residence is not available for Burundi, Comoros, Cote d'Ivoire, Gabon, Guinea, Honduras, Indonesia, Mozambique and Pakistan.

Table 7: Results at the individual level (Poisson regression), without migrants (5a), without migrants when restricting the sample to individuals with information on migration status (5b), controlling for migration status (5c) and adding an interaction term urban $\times \ln (1+$ density). 
First, we run the same Poisson regression as specified in column (5) removing from the sample: (a) those we know who have moved (keeping those for which information on the years lived in the place of residence is not available (na) in the sample), and (b) everyone but those we know did not migrate (we also exclude those for whom we do not have information on migration). We consider a migrant to be a person who arrived at their place of residence when she was between age 15 and her age at the time of the interview. The results are shown in columns (5a) and (5b) in Table 7. Alternatively, instead of removing observations, we introduce a dummy variable into the regression that takes the value one if the woman is a migrant and zero otherwise and another dummy that is equal to one when there is no information on migration for the woman and zero otherwise. This prevents us from losing observations unnecessarily. Results are shown in column (5c). Comparing these results to the benchmark column (5), we see that in spite of the fact that the sample size is very much reduced after removing migrants, the effect of population density on children ever born is still significant and negative, and its size is not significantly affected by the removal of migrants. This is also the case with the coefficient in column (5c) when controlling for migration status. The coefficient of the dummy identifying those women who moved ("migrant" in the table) is significant and negative; fertility rates among these women are therefore lower on average.

A limitation of the above approach based on the observed migration status is the following. If the desire for children is transmitted over generations and it is the parents of the woman who moved and not the woman herself that affect this decision, then we are missing part of the selection channel. We cannot know this based on the data we use.

In the last column of Table 7, we allow for differential effects of density within and across urban and rural regions. A model like the one solved in Proposition 4 implies that the dummy "urban" should be significant, but that the effect of density within zones should not. Column (5d) shows that the coefficient of the urban dummy is indeed significant, suggesting that the cost of rearing children and/or the return to human capital are different in urban clusters than in rural clusters. However, the effect of density persists, even within areas. Looking at the interaction term between the dummy "urban" and population density, we see that population density does not have a stronger negative effect on fertility rates in rural ares than in urban areas, or vice versa. This shows that its global effect is not entirely driven by urban/rural selection. One could, however, still argue that some selection is taking place within zones that we cannot control for. 


\section{Quality of the data}

Another possible issue is that our data might include misreported births, as detailed in Appendix K.4. In particular, older women with low or no education, are more likely to omit first births, thereby reporting fewer children than they actually have. Table K.5 reproduces the first and last columns of Table 5 and those of Table K.1 taking into consideration only those countries with the "best quality" data, as suggested by Schoumaker (2014). In doing so, we drop more than half of the observations. Comparing the results, we see that when we restrict the analysis to these countries, the overall impact of population density on fertility rates is amplified for all specifications. The effect of some covariates differs, however. In particular, the impact of individual education on fertility is now systematically negative and significant.

To conclude, distinguishing individual variates from cluster-level variates highlights the importance of agglomeration externalities that higher population density entails. These play an important role in reducing fertility as population density increases by providing education, health and electricity, for example. This result lends support to Sadler's interpretation of Proposition 1.

\subsection{Duration Analysis}

The negative effect of population density on the number of children per woman is achieved in practice because women in more densely populated areas marry later and/or start to have children later in life. Alternatively, it may also be due to increasing the time between each birth (spacing), or by stopping having children earlier in life. Standard DHS surveys provide the complete history of birth for each woman. The weaknesses of these surveys, as reported in Appendix K.4, are particularly relevant to analyzing the spacing between births. We can however still check for the first proximate determinant of fertility - birth and marriage postponement by studying the determinants of age at first birth and age at first marriage.

Before carrying out the regression analysis, let us look at how the probability (hazard rate) of becoming a mother and to marrying change with density. We divide the population into two groups depending on the density of the area they live in. The first group represents $75 \%$ of the sample, living in areas with fewer than $914 \mathrm{ind} / \mathrm{km}^{2}$, while the second group is the top $25 \%$, living in more density populated areas. Figure 3 plots the hazard rates $^{25}$ as a function of age for the bottom $75 \%$ on the left, and the top $25 \%$ on the right. This is an unconditional probability, i.e. we do not control for anything but age. As shown in the top two panels, in low

\footnotetext{
${ }^{25}$ Computed in $\mathrm{R}$ with the package muhaz which estimates a hazard function from right-censored data using kernel-based methods.
} 

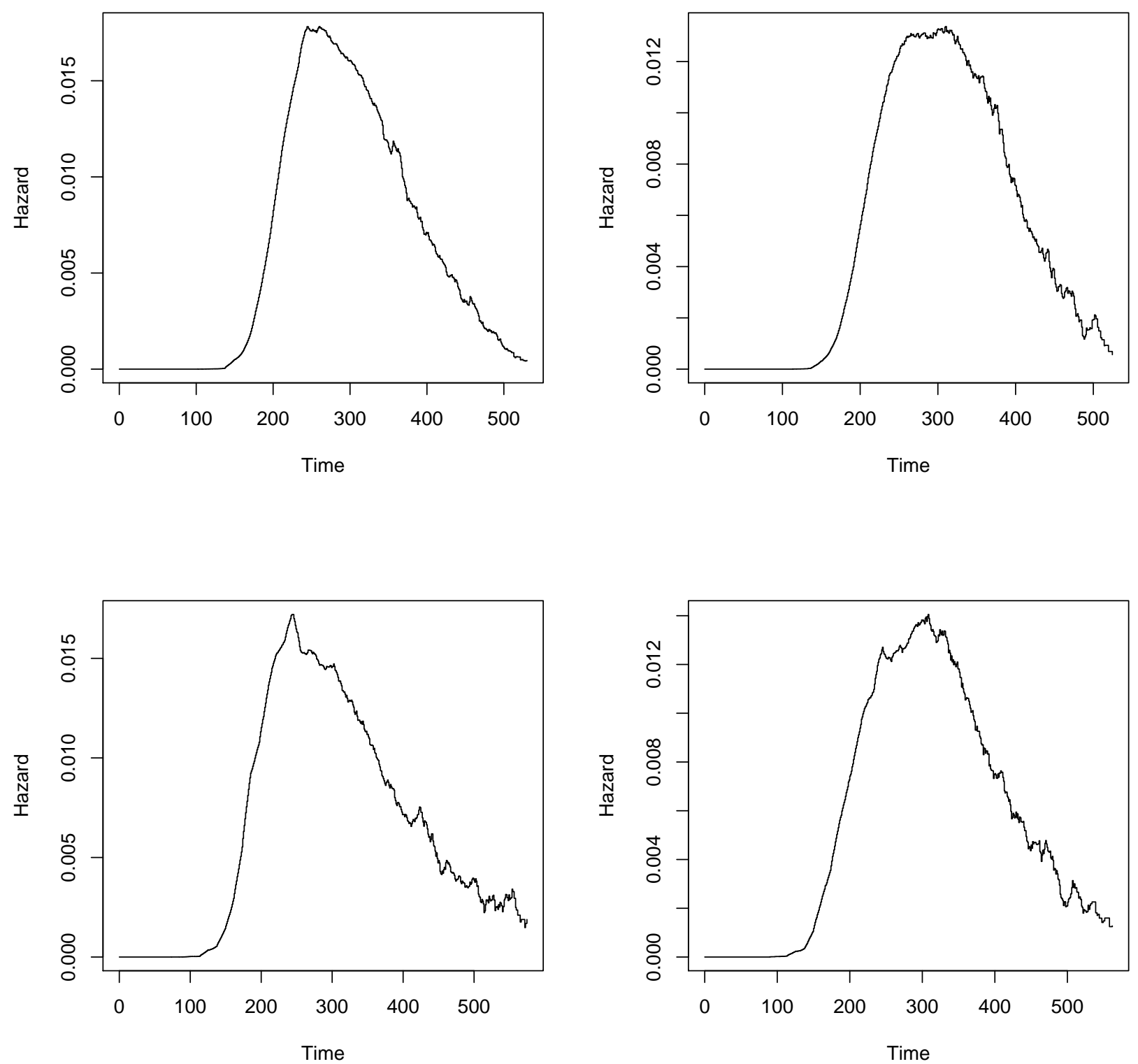

Figure 3: Unconditional probability of becoming a mother (top) and marrying (bottom) as a function of age (in months) in low-density areas (left) and high-density areas (right).

density areas, the probability of becoming a mother peaks at 20 years (240 months), and drops quickly after this peak. In densely populated areas, the hazard rate peaks over the range of 20-25 years, and thus stays high longer than in low density areas. The same description applies to the probability of marrying (bottom panels).

In order to simplify the exposition, we denote either birth or marriage as an "event". In order to estimate the effect of density on the age at first event, we use a proportional hazard model. 
The probability that individual $j$ will exit childlessness or singlehood at time $a$, denoted $\lambda_{j}(a)$, is

$$
\lambda_{j}(a)=\lambda_{0}(a) \exp \left\{\tau_{1} \ln \left(1+\operatorname{density}_{j}\right)+\sum_{i=2}^{N} \tau_{i} X_{i j}\right\} .
$$

According to Equation (3), the baseline hazard rate, $\lambda_{0}(a)$, is shifted proportionally by the characteristics $\ln \left(1+\right.$ density $\left._{j}\right)$ and $X_{i j}$.

For the age at first marriage and the age at first birth, the hazard rate $\lambda$ is computed from women's data, where one observes for subject $j$ the couple $\left(y_{j} ; I_{j}\right)$, where $y_{j}=\min \left(t_{j} ; c_{j}\right)$ is the minimum between the age at first event $t_{j}$ (i.e. the survival time) and the age at the interview $c_{j}$ (i.e. the censoring time). For the interval between marriage and first birth, $t_{j}$ is the difference between the age at first birth and the age at marriage if the event has occurred and the difference between the age at the interview and the age at first marriage otherwise. The event indicator $I_{j}$ equals 1 if the event has been observed (i.e. $t_{j} \leq c_{j}$ ), and zero otherwise. Table 8 presents the results of the estimation of the effect of population density on age at first birth (Columns (1x)-(5x)), age at first marriage (Columns (1y)-(5y)) and the duration from marriage to first birth (Columns (1z)-(5z)). As before, columns (1x), (1y), and (1z) show the effect of density without other controls, while columns (5x), (5y), and (5z) include the other usual covariates.

For a given age, the chance of becoming a mother is $54.4 \%$ higher $^{26}$ in an area with a density of $10 \mathrm{ind} / \mathrm{km}^{2}$ than in an area with a density of $1000 \mathrm{ind} / \mathrm{km}^{2}$. The chance of being married is $67.5 \%$ higher. These two effects are reduced to $9.5 \%$ and $4.1 \%$ respectively after controlling for the other covariates, but remain significant.

The effect of density on the interval between marriage and first birth is positive when we only control for the Caloric Suitability Index, but negative when we add the usual controls. This ambiguous effect is probably driven by the positive correlation between population density and a woman's education together with the hump-shaped relationship between the interval between marriage and first birth and a woman's education. Galor and Klemp (2014) use the interval between marriage and first birth as a proxy for fecundity. Our results in column (1z) suggest that in less-dense areas, individuals might be more affected by subfecundity factors than in more-dense areas in which health care facilities are more available and individuals are better educated. See Baudin, de la Croix, and Gobbi (2015b) on social causes of sterility.

$$
{ }^{26}=(1-\exp (-0.085 \ln (1001)) / \exp (-0.085 \ln (11)) .
$$




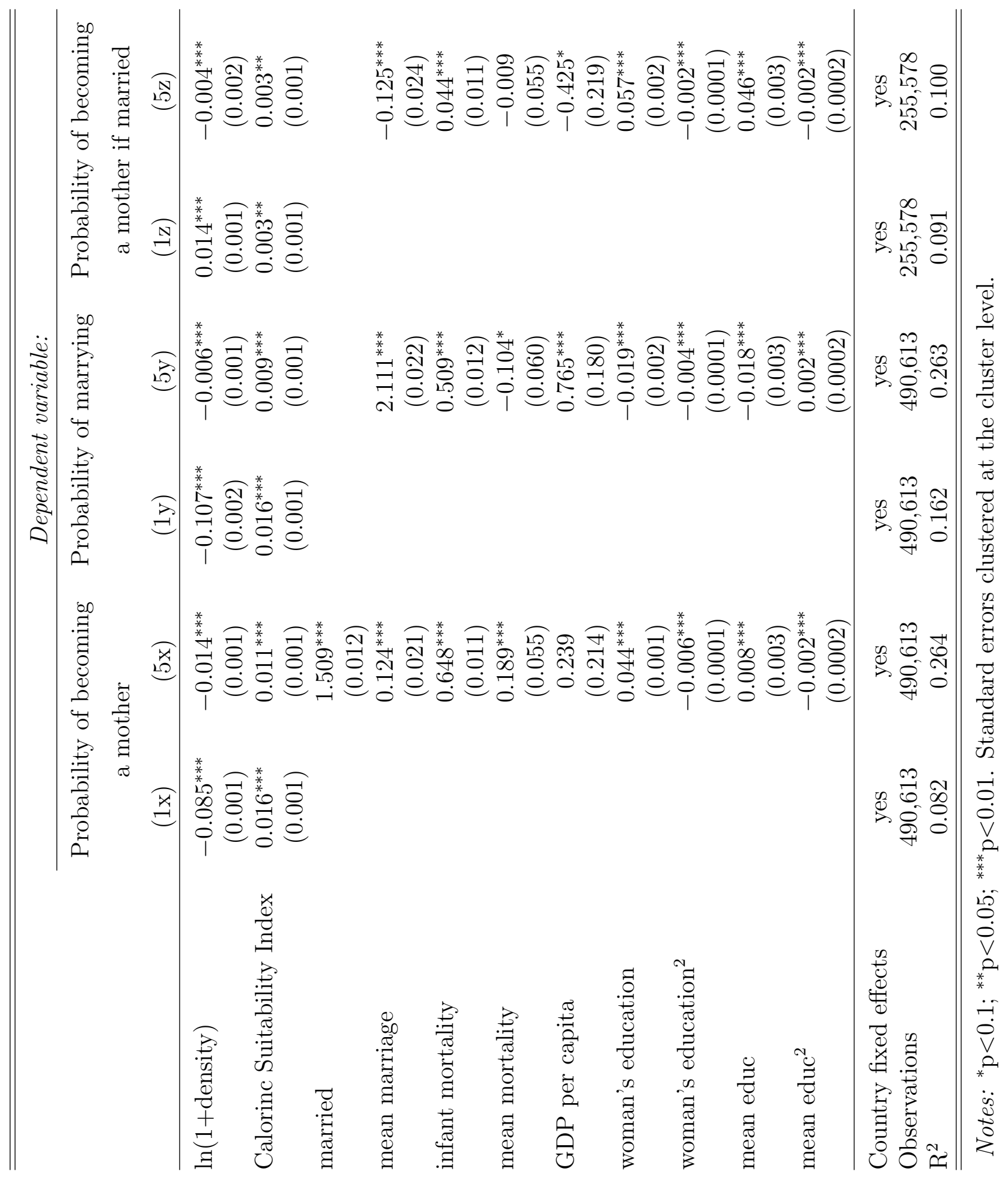

Table 8: Duration model 


\section{Demographic Convergence}

Sections 4.1 and 4.2 show that, on average, greater population density reduces fertility rates. Assuming that population dynamics are governed by the same function $\Phi$ (see Proposition 1), the size of this negative impact of population density on fertility determines the speed at which the global population level converges to its steady state.

Let us now first remind the reader of the basic definitions used in convergence analysis. Consider a sequence $\left\{x_{t}\right\}$ converging to a long-run value $\bar{x}$. Its rate of convergence is:

$$
\lim _{t \rightarrow \infty} \frac{\left|x_{t+1}-\bar{x}\right|}{\left|x_{t}-\bar{x}\right|}<1
$$

A low rate of convergence implies that $x_{t}$ is converging quickly. Assume that the dynamic behavior of $x_{t}$ is governed by the difference equation:

$$
x_{t+1}=f\left(x_{t}\right) .
$$

If $f(\cdot)$ is differentiable, we can take a first order Taylor expansion around $\bar{x}$,

$$
\frac{x_{t+1}-\bar{x}}{x_{t}-\bar{x}}=f^{\prime}(\bar{x})
$$

When dynamics are monotonic, $x_{t+1}-\bar{x}$ and $x_{t}-\bar{x}$ have the same sign, and we can relate the speed of convergence to the first order derivative of $f(\cdot)$ evaluated at steady state. We can also define the half-life of $x_{t}, T$, as the time it takes to fill half the gap with the steady state. It is given by:

$$
x_{t+T}-\bar{x}=\frac{1}{2}\left(x_{t}-\bar{x}\right),
$$

and can be computed from:

$$
f^{\prime}(\bar{x})^{T}=1 / 2
$$

Let us now compute the speed of convergence of a population, which we call demographic convergence, using our model of fertility. The law of motion of the global population at time $t+1$ (time represents a generation) is:

$$
P_{t+1}=n_{t} P_{t}+(1-d) P_{t}
$$

where $d$ is the death rate, which is assumed to be constant. Based on the previous section, the 
following equation describes the fertility rate:

$$
n_{t}=b_{0}-b_{1} \ln \left(1+\frac{P_{t}}{L}\right)
$$

where $P_{t} / L$ is population density. Replacing $n_{t}$ in (4) we have:

$$
P_{t+1}=f\left(P_{t}\right)=\left(b_{0}-b_{1} \ln \left(1+\frac{P_{t}}{L}\right)\right) P_{t}+(1-d) P_{t}
$$

At steady state $\bar{P}$, births necessarily balance deaths: $n_{t}-d=0$. The rate of convergence of the population is the derivative of $f\left(P_{t}\right)$ at the steady state:

$$
\begin{aligned}
f^{\prime}(\bar{P}) & =\left(b_{0}-b_{1} \ln \left(1+\frac{\bar{P}}{L}\right)\right)-\left(\frac{b_{1}}{1+\bar{P} / L}\right) \frac{\bar{P}}{L}+1-d \\
& =1-\frac{\bar{P} / L}{1+\bar{P} / L} b_{1} \approx 1-b_{1} .
\end{aligned}
$$

Hence it is simply one minus the coefficient $\beta_{1}$ of $\ln (1+$ density $)$ from the OLS regression, or $1-E[n] \pi_{1}$ in the case of the Poisson regression.

\begin{tabular}{lcrc}
\hline \hline & $-b_{1}$ & half-life & (s.e.) \\
\hline cluster unconditional & -0.195 & 3.20 & $(0.041)$ \\
woman unconditional & -0.193 & 3.24 & $(0.023)$ \\
\hline cluster conditional & -0.058 & 11.55 & $(0.424)$ \\
woman conditional & -0.056 & 12.11 & $(0.336)$ \\
woman conditional with cluster random effect & -0.061 & 11.02 & $(0.385)$ \\
\hline cluster instrumented & -0.136 & 4.77 & $(0.308)$ \\
woman instrumented & -0.155 & 4.11 & $(0.188)$ \\
\hline Sato $(2007)$ & -0.110 & 6.23 & $(1.580)$ \\
\hline \hline
\end{tabular}

Note: s.e. computed using Monte Carlo simulations

Table 9: Summary of results

Table 9 summarizes our results. The first column reports the coefficients $b_{1}$ produced by some of the various specifications at the cluster and individual levels. We include specifications (1) and (5) in Tables 3 and 5, specification (5) with a cluster-specific random effect (column 6 of Table 6), and the instrumental variable specifications (last column of Table 4 and column 6 of Table 5). The last two columns of Table 9 show the time it takes to close half the gap with the steady state, and standard errors.

From the specifications that only include density as an explanatory variable (Model (1)), the 
half-life estimates at the cluster and individual levels lie in the confidence interval of the coefficient obtained using Sato (2007)'s data for Japanese regions in 2000. ${ }^{27}$ Half of the gap with the steady state is filled in 3.2 generations. This "unconditional" effect of density, includes deep economic changes such as an increase in education, better access to services such as health care, electricity, or the internet, and changes in cultural norms that urbanization brings with it. Adding additional controls to the regressions makes the estimated demographic convergence slower. For instance, fixing education level, urbanization rate, marriage rate and mortality rate, as we do in regression (5), implies that the half-life will be reached in between 11.0 and 12.1 generations. Correcting for the attenuation bias with instrumental methods leads to shorter half-lives, between 4 and 5 generations.

To provide an idea of what it implies for population projections, let us forecast population as follows. Suppose one generation is 25 years. In a first step, we compute $\bar{P}$ to solve:

$$
P_{2015}-\bar{P}=\left(1-\beta_{1}\right)\left(P_{1990}-\bar{P}\right) .
$$

In a second step, we take as initial conditions $P_{i}$ with $i=1990 . .2015$, and we use the following equation

$$
P_{i}-\bar{P}=\left(1-\beta_{1}\right)\left(P_{i-15}-\bar{P}\right)
$$

to compute $P_{i}$, with $i=2016 . .2100$. Figure 4 compares the UN population projections (2015 revisions) with our hypothetical dynamics solely based on the reaction of fertility to population density. We take as the lower bound on population dynamics those obtained with the conditional estimation of $\beta_{1}$, and, as upper bound, those obtained with the unconditional estimation.

The middle of the line scenario put forward by the UN falls within our bounds until 2071. Beyond that point, it estimates a world population below the one implied by our lower bound. This may reflect that their fertility rates adjust more than what is predicted by the spontaneous convergence forces present in our model. Notice also that our dynamics decrease less than theirs, implying a higher peak population at 15.8 billion with the unconditional estimation and 39.9 with the conditional estimation. This last number seems highly exaggerated, but recall that it was obtained by keeping education and health constant. The gap between the two limits, 39.9 and 15.8, shows the importance of those factors in controlling population.

\footnotetext{
${ }^{27}$ We thank Professor Yasuhiro Sato for kindly sharing the data with us.
} 


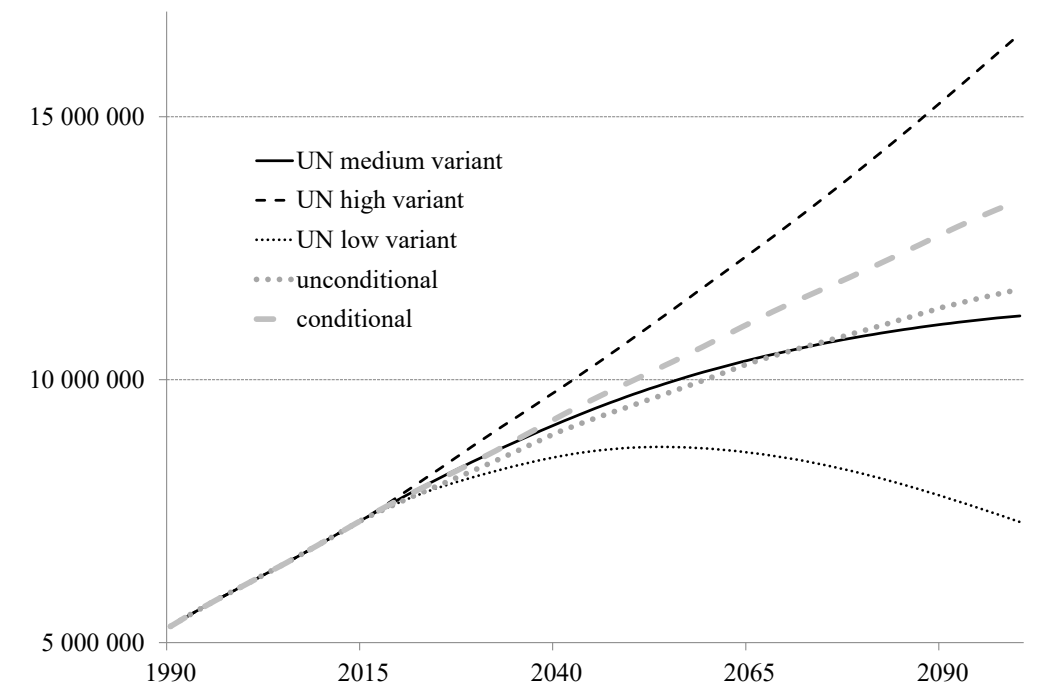

Figure 4: World Population - UN projections \& population dynamics (5)

\section{Conclusion}

Using data from DHS surveys and raster files from CIESIN et al. (2011), this paper provides empirical evidence of the negative impact of population density on fertility in developing countries.

After having reviewed the different strands of the literature that have modeled this relationship, we find stronger support for the Sadlerian / Marshallian view. For Sadler (1830) affluence increases with population density, as it does in the modern theories of agglomeration, and prolificness decreases with affluence, as in the Beckerian view. Comparing the impact of density on fertility at the cluster level and at the individual level sheds light on the importance of the consequences of agglomeration on fertility. Among the components of agglomeration, higher education, better health services, and access to public infrastructure play a role in decreasing fertility.

A contribution of this paper is also to relate the microeconomic estimate of the effect of density on fertility to the macroeconomic notion of convergence applied to the demographic context. The total effect of density, including increase in education, better access to services such as health care, and changes in cultural norms that come with it, imply a relatively rapid rate of convergence: population levels take 3 to 4 generations to fill half the gap with their long-run levels. 


\section{References}

Adelman, Irma. 1963. "An econometric analysis of population growth." American Economic Review 53 (3): 314-339 (June).

André, Catherine, and Jean-Philippe Platteau. 1998. "Land Relations Under Unbearable Stress: Rwanda Caught in the Malthusian Trap." Journal of Economic Behavior and Organization 34, no. 1.

Ashraf, Quamrul, and Oded Galor. 2011. "Dynamics and Stagnation in the Malthusian Epoch." American Economic Review 101 (5): 2003-41 (August).

Ashraf, Quamrul, Oded Galor, and Marc Klemp. 2015. "Heterogeneity and Productivity." Working papers 2015-4, Brown University, Department of Economics.

Barro, Robert J., and Xavier Sala-i Martin. 1986. "Convergence." Journal of Political Economy 100 (2): 223-51 (April).

Barro, Robert J, and Gary S Becker. 1989. "Fertility Choice in a Model of Economic Growth." Econometrica 57 (2): 481-501 (March).

Baudin, Thomas, David de la Croix, and Paula E. Gobbi. 2015a. "Development Policies when Accounting for the Extensive Margin of Fertility." IRES Discussion paper 2015-03.

—. 2015b. "Fertility and Childlessness in the US." American Economic Review 105 (6): $1852-1882$.

Becker, Gary. 1993. "Nobel Lecture: The Economic Way of Looking at Behavior." Journal of Political Economy 101 (3): 385-409.

Becker, Gary S, and Robert J Barro. 1988. "A Reformulation of the Economic Theory of Fertility." The Quarterly Journal of Economics 103 (1): 1-25 (February).

Becker, Sascha O., Francesco Cinnirella, and Ludger Woessmann. 2010. "The trade-off between fertility and education: evidence from before the demographic transition." Journal of Economic Growth 15 (3): 177-204.

Boucekkine, Raouf, David de la Croix, and Dominique Peeters. 2007. "Early literacy achievements, population density and the transition to modern growth." Journal of the European Economic Association 5 (1): 183-226 (March).

Brander, James A, and M Scott Taylor. 1998. "The Simple Economics of Easter Island: A Ricardo-Malthus Model of Renewable Resource Use." American Economic Review 88 (1): $119-38$.

Broström, G., and H. Holmberg. 2011. "Generalized linear models with clustered data: Fixed and random effects models." Computational Statistics and Data Analysis 55:3123-3134. 
Bruckner, John. 1768. A philosophical Survey of the Animal Creation, an Essay. London: Johnson and Payne. translated from the French.

Cameron, A. Colin, and Douglas L. Miller. 2013. "A Practitioner's Guide to Cluster-Robust Inference." Department of Economics, University of California - Davis. In preparation for The Journal of Human Resources.

Chanda, Areendam, and Louis Putterman. 2007. "Early Starts, Reversals and Catch-up in the Process of Economic Development." Scandinavian Journal of Economics 109 (2): 387-413 (06).

CIESIN, Center for International Earth Science Information Network, International Food Policy Research Institute IFPRI, The World Bank, and Centro Internacional de Agricultura Tropical CIAT. 2011. "Global Rural-Urban Mapping Project, Version 1 (GRUMPv1): Population Density Grid." NASA Socioeconomic Data and Applications Center (SEDAC). Palisades, NY.

Combes, Pierre-Philippe, and Laurent Gobillon. 2015. "The empirics of agglomeration economies." paper prepared for the Handbook of Urban and Regional Economics, vol. 5, Gilles Duranton, Vernon Henderson, Will Strange (eds.), to be published by Elsevier.

Courgeau, Daniel. 1989. "Family formation and urbanization." Population: An English Selection 44 (1): 123-146 (September).

de la Croix, David, and Davide Dottori. 2008. "Easter Island's collapse: a tale of a population race." Journal of Economic Growth 13:27-55.

de la Croix, David, and Clara Delavallade. 2015. "Religions, Fertility, and Growth in SouthEast Asia." IRES Discussion paper 2015-02.

de la Croix, David, and Axel Gosseries. 2012. "The natalist bias of pollution control." Journal of Environmental Economics and Management 63 (2): 271-287.

Dendrinos, S. Dimitrios, and Henry Mullally. 1981. "Evolutionary Patterns of Urban Population." Geographical Analysis 13, no. 4.

Doepke, Matthias. 2005. "Child mortality and fertility decline: Does the Barro-Becker model fit the facts?" Journal of Population Economics 18 (2): 337-366 (06).

Firebaugh, Glenn. 1982. "Density and fertility in 22 Indian villages." Demography 19 (4): 481.

Fujita, Masahisa, and Jacques François Thisse. 2002. Economics of Agglomeration. Cambridge University Press.

Galor, Oded. 1996. "Convergence?: Inference from theoretical models." Economic Journal 106:1056-1069. 
Galor, Oded, and Marc Klemp. 2014. "The Biocultural Origins of Human Capital Formation." NBER Working Paper No. 20474.

Galor, Oded, and Ömer Özak. 2014. "The agricultural origins of time preference." NBER Working Paper (20438).

— 2015. "Land productivity and economic development: caloric suitability vs. agricultural suitability." June version.

Galor, Oded, and David N. Weil. 2000. "Population, Technology, and Growth: From Malthusian Stagnation to the Demographic Transition and Beyond." American Economic Review 90 (4): 806-828 (September).

Gerland, Patrick, A Raftery, Hana Sevcikova, Nan Li, Danan Gu, Thomas Spoorenberg, Leontine Alkema, Bailey Fosdick, Jennifer Chunn, Nevena Lalic, Guiomar Bay, Thomas Buettner, Gerhard Heilig, and John Wilmoth. 2014. "World population stabilization unlikely this century." Science 346 (6206): 234-237.

Ghosh, T., R. Powell, C. D. Elvidge, K. E. Baugh, P. C. Sutton, and S. Anderson. 2010. "Shedding light on the global distribution of economic activity." The Open Geography Journal 3:148-161.

Greenwood, Jeremy, Ananth Seshadri, and Guillaume Vandenbroucke. 2005. "The Baby Boom and Baby Bust." American Economic Review 95 (1): 183-207 (March).

Heer, David M. 1966. "Economic development and fertility." Demography 3 (2): 423-444 (June).

Henderson, J. Vernon, Adam Storeygard, and David. N. Weil. 2012. "Measuring economic growth from outer space." American Economic Review 102 (2): 994-1028.

Iyigun, Murat, Nathan Nunn, and Nancy Qian. 2015. "Agricultural Productivity, Conflict and State Size: Evidence from Potatoes, 1400-1900.” unpublished.

Kravdal, Øystein. 2002. "Education and fertility in Sub-Saharan Africa: Individual and community effects." Demography 39, no. 2 (May).

- 2013. "Further evidence of community education effects on fertility in sub-Saharan Africa." Demographic Research 27 (November): 645-680.

Kulu, H., and P. Boyle. 2009. "High Fertility in City Suburbs: Compositional or Contextual Effects?" Population, Space and Place 25 (2): 157-174.

La Ferrara, Eliana, Alberto Chong, and Suzanne Duryea. 2012. "Soap Operas and Fertility: Evidence from Brazil." American Economic Journal: Applied Economics 4 (4): 1-31.

Lee, Ronald. 1987. "Population Dynamics of Humans and Other Animals." Demography 24 (4): 443-465. 
Lesthaeghe, Ron J. 1989. Chapter 4, A comparative study of the levels and the differentials of sterility in Cameroon, Kenya, and Sudan of Reproduction and Social Organization in Sub-Saharan Africa, 168-212. Berkeley: University of California Press.

Livi-Bacci, Massimo. 1997. A Concise History of World Population. Second. Oxford: Balckwell.

Lotka, Alfred James. 1925. Elements of Physical Biology. Baltimore: Williams and Wilkins.

Lutz, Wolfgang, and William P. Butz. 2014. World Population and Human Capital in the Twenty-First Century. Oxford: Oxford University Press.

Lutz, Wolfgang, and Ren Qiang. 2002. "Determinants of population growth." Philosophical Transactions of the Royal Society B: Biological Sciences 357:1197-1210.

Lutz, Wolfgang, Maria Rita Testa, and Dustin J. Penn. 2006. "Population density is a key factor in declining human fertility." Population Environment 289 (2): 69-81 (November).

Malthus, Thomas. 1807. An Essay on the Principle of Population. Fourth Edition. London: T. Bensley.

Marshall, Alfred. 1890. Principles of Economics (8th ed.). London: MacMilland and Co.

Mokyr, Joel. 1981. "Irish History with the Potato." Irish Economic and Social History 8:8-29.

Montesquieu. 1749. De l'Esprit des Loix. Amsterdam: Chatelain.

Murphy, Kevin M., Curtis Simon, and Robert Tamura. 2008. "Fertility Decline, Baby Boom, and Economic Growth." Journal of Human Capital 2 (3): 262-302.

Nunn, N., and N. Qian. 2010. "The Columbian Exchange: A History of Disease, Food and Ideas." Journal of Economic Perspectives 24 (2): 163-188.

Nunn, Nathan, and Nancy Qian. 2011. "The Potato's Contribution to Population and Urbanization: Evidence From A Historical Experiment." The Quarterly Journal of Economics 126 (2): 593-650.

Potter, J. E. 1977. "Problems in using birth-history analysis to estimate trends in fertility." Population Studies: A Journal of Demography 31 (2): 335-364.

Pullum, Thomas W. 2006. "An Assessment of Age and Date Reporting in the DHS Surveys, 1985-2003." Technical Report, Methodological Reports No. 5. Calverton, Maryland: Macro International Inc.

Ramankutty, N., J. A. Foley, J. Norman, and K. McSweeney. 2002. "The global distribituion of cultivable land: current patterns and sensitivity to possible climate change." Global Ecology and Biogeography 11 (5): 377-392. 
Rutstein, Shea Oscar, and Guillermo Rojas. 2006. Guide to DHS statistics, Demographic and Health Surveys methodology.

Sadler, Michael Thomas. 1830. The Law of Population - in disproof of the superfecundity of human beings, and developing the real principle of their increase. London: John Murray.

Samuelson, Paul A. 1971. "Generalized Predator-Prey Oscillations in Ecological and Economic Equilibrium." Proceedings of the National Academy of Sciences of the United States of America 68 (5): 980-983 (May).

Sato, Kazuo. 1966. "On the adjustment time in neo-classical growth models." Review of Economic Studies 33:263-8.

Sato, Yasuhiro. 2007. "Economic geography, fertility and migration." Journal of Urban Economics 61:372-387.

Schoumaker, Bruno. 2013a. "Reconstructing Long Term Fertility Trends with Pooled Birth Histories." Paper presented at the XXVII International Population Conference, Busan (South Korea).

— 2013b. "A Stata Module to Compute Fertility Rates and TFRs from Birth Histories: tfr2." Demographic Research 28 (38): 1093-144.

—. 2014. "Quality and Consistency of DHS Fertility Estimates, 1990 to 2012." Technical Report, DHS Methodological Reports No. 12. Rockville, Maryland, USA: ICF International.

Simon, Curtis J., and Robert Tamura. 2009. "Do higher rents discourage fertility? Evidence from U.S. cities, 1940-2000." Regional Science and Urban Economics 39:33-42.

United Nations. 2004. "World Population to 2300." Technical Report, Economic \& Social Affairs.

—. 2014. "World Urbanization Prospects [highlights]." Technical Report, Economic \& Social Affairs.

Valencia Caicedo, Felipe. 2014. "The Mission: Economic Persistence, Human Capital Transmission and Culture in South America." November, 2014 version.

Vogl, Tom. 2015. "Differential Fertility, Human Capital, and Development." Review of Economic Studies.

Volterra, Vito. 1926. "Fluctuations in the abundance of a species considered mathematically." Nature 118:558-560.

Zeger, Scott L., and Kung-Yee Liang. 1986. "Longitudinal Data Analysis for Discrete and Continuous Outcomes." Biometrics 42 (1): 121-130. 


\section{A Theory}

\section{Example of a Malthusian model.}

Production is given by: $Y_{t}=P_{t}^{1-\alpha}$, where land has been normalized to 1 , and $\alpha \in(0,1)$. Fertility depends positively on income per person: $n_{t}=\left(Y_{t} / P_{t}\right)^{\beta}$, with $\beta \in(0,1)$. Population dynamics obey $P_{t+1}=n_{t} P_{t}$. Solving this model yields a negative relationship between population density and fertility, $n_{t}=P_{t}^{-\alpha \beta}$ and globally stable population dynamics, $P_{t+1}=P_{t}^{1-\alpha \beta}$.

\section{Example of a Sadlerian model.}

Production includes a technological factor that is population augmenting: $Y_{t}=P_{t}^{\gamma} P_{t}^{1-\alpha}$, where $\alpha \in(0,1)$. Fertility depends negatively on income per person: $n_{t}=\left(Y_{t} / P_{t}\right)^{-\delta}$, with $\delta \in(0,1)$. Population dynamics obey $P_{t+1}=n_{t} P_{t}$. Solving this model under a strong externality $(\gamma>\alpha)$ yields a negative relationship between population density and fertility, $n_{t}=P_{t}^{-\delta(\gamma-\alpha)}$ and globally stable dynamics of population, $P_{t+1}=P_{t}^{1-\delta(\gamma-\alpha)}$.

\section{Proof of Proposition 1.}

Using the mean value theorem for derivatives, one has:

$$
\exists \delta \in(0,1) \text { such that } \frac{\Phi\left(P_{t}\right)-\Phi(0)}{P_{t}}=\Phi^{\prime}\left(\delta P_{t}\right)
$$

It follows that:

$$
\frac{P_{t+1}}{P_{t}}=\frac{\Phi(0)}{P_{t}}+\Phi^{\prime}\left(\delta P_{t}\right) .
$$

As $\Phi^{\prime \prime}\left(\dot{)}<0\right.$, population growth $P_{t+1} / P_{t}$ is negatively correlated with density $P_{t}$.

\section{Proof of Proposition 2.}

In a neighborhood of a hyperbolic steady state, the linearized system is topologically equivalent to the original non-linear system (Hartman-Grobman Theorem). When the eigenvalues of the matrix are complex, the general solution of the linear system displays oscillations.

\section{Proof of Proposition 3.}

Dividing $\Phi\left(P_{t-i}, \ldots, P_{t-1}, P_{t}, P_{t+1}, \ldots, P_{t+j}\right)=0$ by $P_{t}$, the dynamics can be expressed in terms of $n_{t-i}, \ldots, n_{t}, \ldots, n_{t+j-1}$ only, independent of the level of $P_{t}$. 


\section{B Maps}

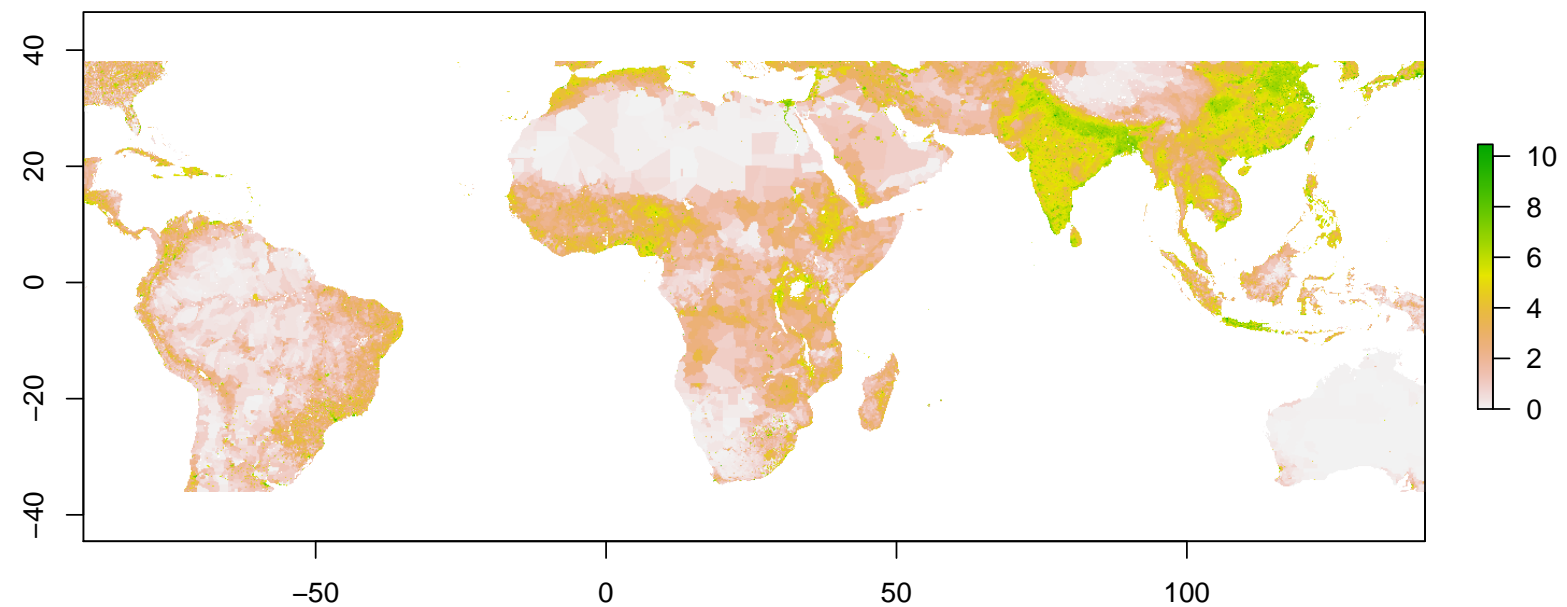

Figure B.1: Map of $\ln (1+$ population density $)$ in 1990

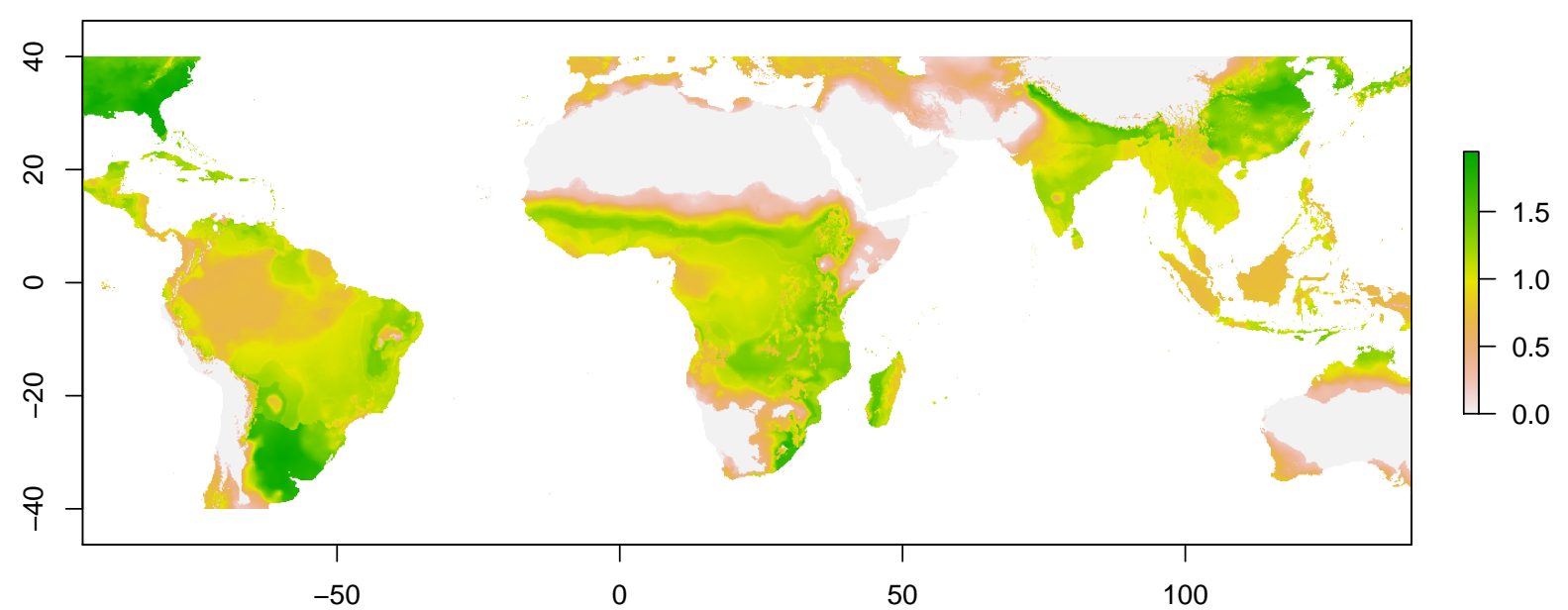

Figure B.2: Map of land productivity (maximum potential caloric yield) 


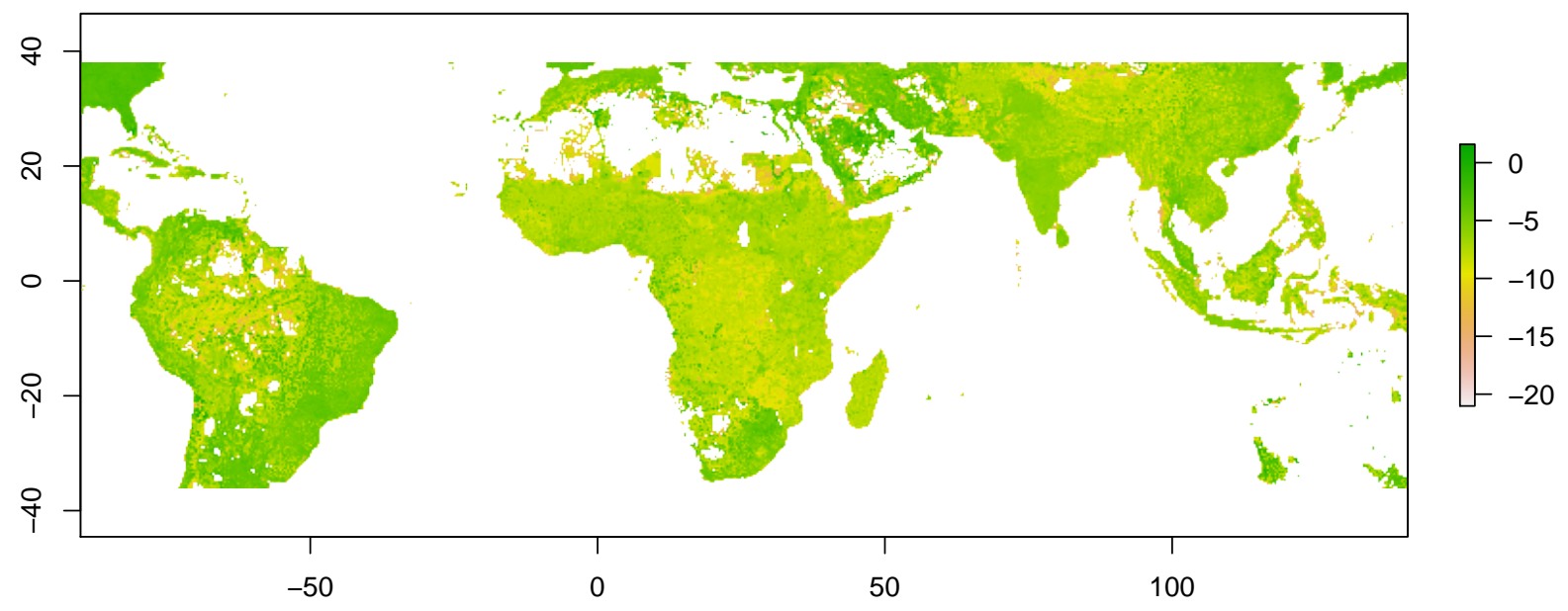

Figure B.3: Map of GDP per capita 


\section{Sample}

\begin{tabular}{|c|c|c|c|c|c|}
\hline \multirow[t]{2}{*}{ Country } & & \multirow[t]{2}{*}{ Year } & \multirow[t]{2}{*}{ Phase } & \multicolumn{2}{|c|}{ Shares } \\
\hline & & & & cluster & individual \\
\hline \multicolumn{6}{|l|}{ Sub-Saharan Africa } \\
\hline Benin & BJ & 2001 & IV & 0.010 & 0.013 \\
\hline Burkina Faso & $\mathrm{BF}$ & 1998-99 & III & 0.008 & 0.013 \\
\hline Burundi & $\mathrm{BU}$ & 2010 & VI & 0.015 & 0.019 \\
\hline Cameroon & $\mathrm{CM}$ & 2004 & IV & 0.019 & 0.022 \\
\hline Central African Republic & $\mathrm{CF}$ & 1994-1995 & III & 0.009 & 0.012 \\
\hline Comoros & KM & 2012 & VI & 0.010 & 0.01 \\
\hline Congo Democratic Republic & $\mathrm{CD}$ & 2007 & $\mathrm{~V}$ & 0.012 & 0.02 \\
\hline Cote d'Ivoire & $\mathrm{CI}$ & 1998-99 & III & 0.006 & 0.006 \\
\hline Ethiopia & $\mathrm{ET}$ & 2000 & IV & 0.022 & 0.031 \\
\hline Gabon & GA & 2012 & VI & 0.013 & 0.017 \\
\hline Ghana & $\mathrm{GH}$ & 1998 & IV & 0.016 & 0.01 \\
\hline Guinea & GN & 1999 & IV & 0.012 & 0.014 \\
\hline Kenya & $\mathrm{KE}$ & 2003 & IV & 0.016 & 0.017 \\
\hline Lesotho & $\mathrm{LS}$ & 2004 & IV & 0.015 & 0.014 \\
\hline Liberia & LB & 2007 & $\mathrm{~V}$ & 0.012 & 0.014 \\
\hline Madagascar & $\mathrm{MD}$ & 1997 & III & 0.011 & 0.014 \\
\hline Malawi & MW & 2000 & IV & 0.023 & 0.027 \\
\hline Mali & ML & 2001 & IV & 0.016 & 0.026 \\
\hline Mozambique & $\mathrm{MZ}$ & 2011 & VI & 0.025 & 0.028 \\
\hline Namibia & $\mathrm{NM}$ & 2000 & IV & 0.010 & 0.014 \\
\hline Niger & NI & 1998 & III & 0.011 & 0.015 \\
\hline Nigeria & NG & 2003 & IV & 0.015 & 0.015 \\
\hline Rwanda & RW & 2005 & $\mathrm{~V}$ & 0.018 & 0.023 \\
\hline Senegal & $\mathrm{SN}$ & 2005 & IV & 0.015 & 0.029 \\
\hline Sierra Leone & SL & 2008 & $\mathrm{~V}$ & 0.014 & 0.015 \\
\hline Swaziland & $\mathrm{SZ}$ & 2006-2007 & $\mathrm{V}$ & 0.011 & 0.01 \\
\hline Tanzania & $\mathrm{TZ}$ & 1999 & IV & 0.007 & 0.008 \\
\hline Togo & $\mathrm{TG}$ & 1998 & III & 0.012 & 0.017 \\
\hline Uganda & $\mathrm{UG}$ & 2000-2001 & IV & 0.011 & 0.013 \\
\hline Zambia & $\mathrm{ZM}$ & 2007 & $\mathrm{~V}$ & 0.013 & 0.015 \\
\hline Zimbabwe & ZW & 1999 & IV & 0.009 & 0.012 \\
\hline
\end{tabular}




\begin{tabular}{lccc}
\hline Country & Year & Phase & \multicolumn{2}{c}{ Shares } \\
cluster individual
\end{tabular}

Middle East and North Africa (MENA)

$\begin{array}{lrrrrr}\text { Egypt } & \text { EG } & 2000 & \text { IV } & 0.040 & 0.032 \\ \text { Jordan } & \text { JO } & 2002 & \text { IV } & 0.020 & 0.012 \\ \text { Morocco } & \text { MA } & 2003-2004 & \text { IV } & 0.019 & 0.034\end{array}$

\section{Latin America}

Bolivia

Colombia

Honduras

Peru

$\begin{array}{lrlll}\text { BO } & 2008 & \text { V } & 0.040 & 0.034 \\ \text { CO } & 2010 & \text { VI } & 0.196 & 0.099 \\ \text { HN } & 2011-2012 & \text { VI } & 0.046 & 0.045 \\ \text { PE } & 2000 & \text { IV } & 0.057 & 0.057\end{array}$

South and South East Asia

$\begin{array}{llrlcc}\text { Bangladesh } & \text { BD } & 1999-2000 & \text { IV } & 0.014 & 0.021 \\ \text { Cambodia } & \text { KH } & 2000 & \text { IV } & 0.019 & 0.031 \\ \text { Indonesia } & \text { ID } & 2002-2003 & \text { IV } & 0.053 & 0.057 \\ \text { Nepal } & \text { NO } & 2001 & \text { IV } & 0.010 & 0.018 \\ \text { Pakistan } & \text { PK } & 2006-2007 & \text { V } & 0.039 & 0.02 \\ \text { Philippines } & \text { PH } & 2003 & \text { IV } & 0.033 & 0.028\end{array}$

Total number of Observations

$24,769 \quad 490,513$

Table C.1: Countries with corresponding year, DHS phase, number of the survey and release version (respectively of the Individual and Household Recode and the Geographical datasets). 


\section{Household Level Data}
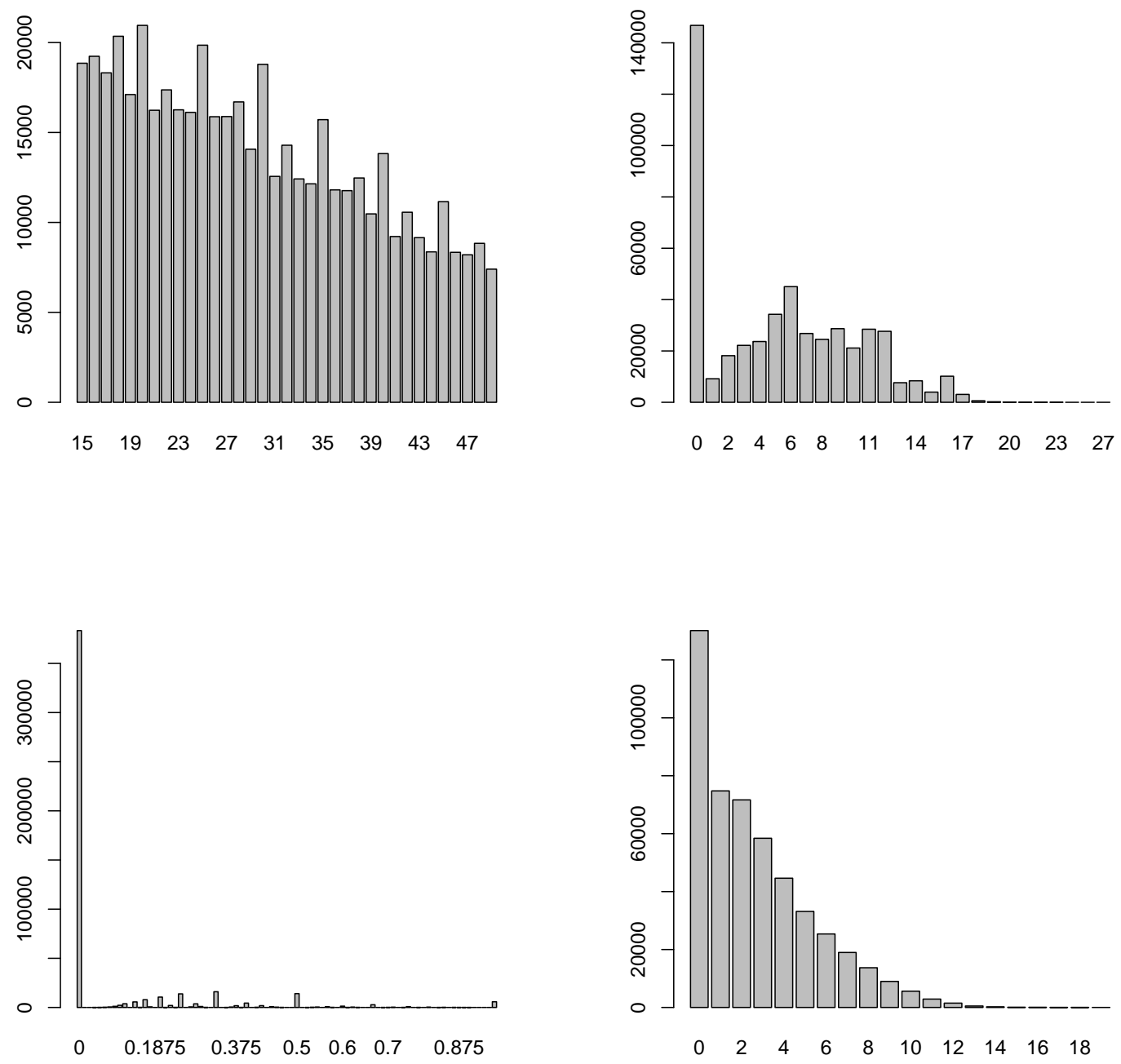

Figure D.1: Distribution of Women's Characteristics: age, education, infant mortality, number of births 


\section{E Cluster Level Data}
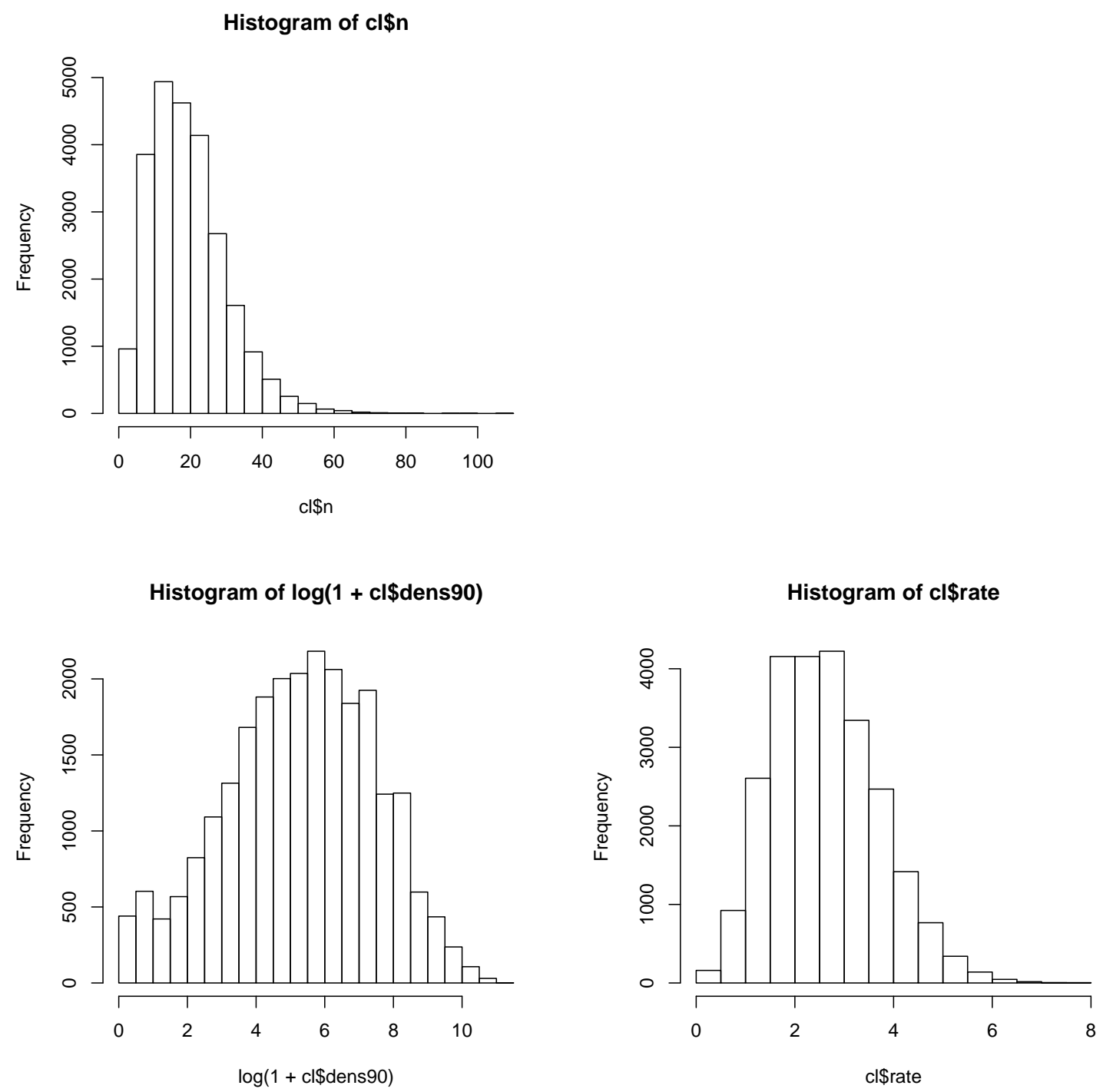

Figure E.1: Distribution of Clusters' Characteristics: number of women, $\log (1+$ density $)$ and birth rate 

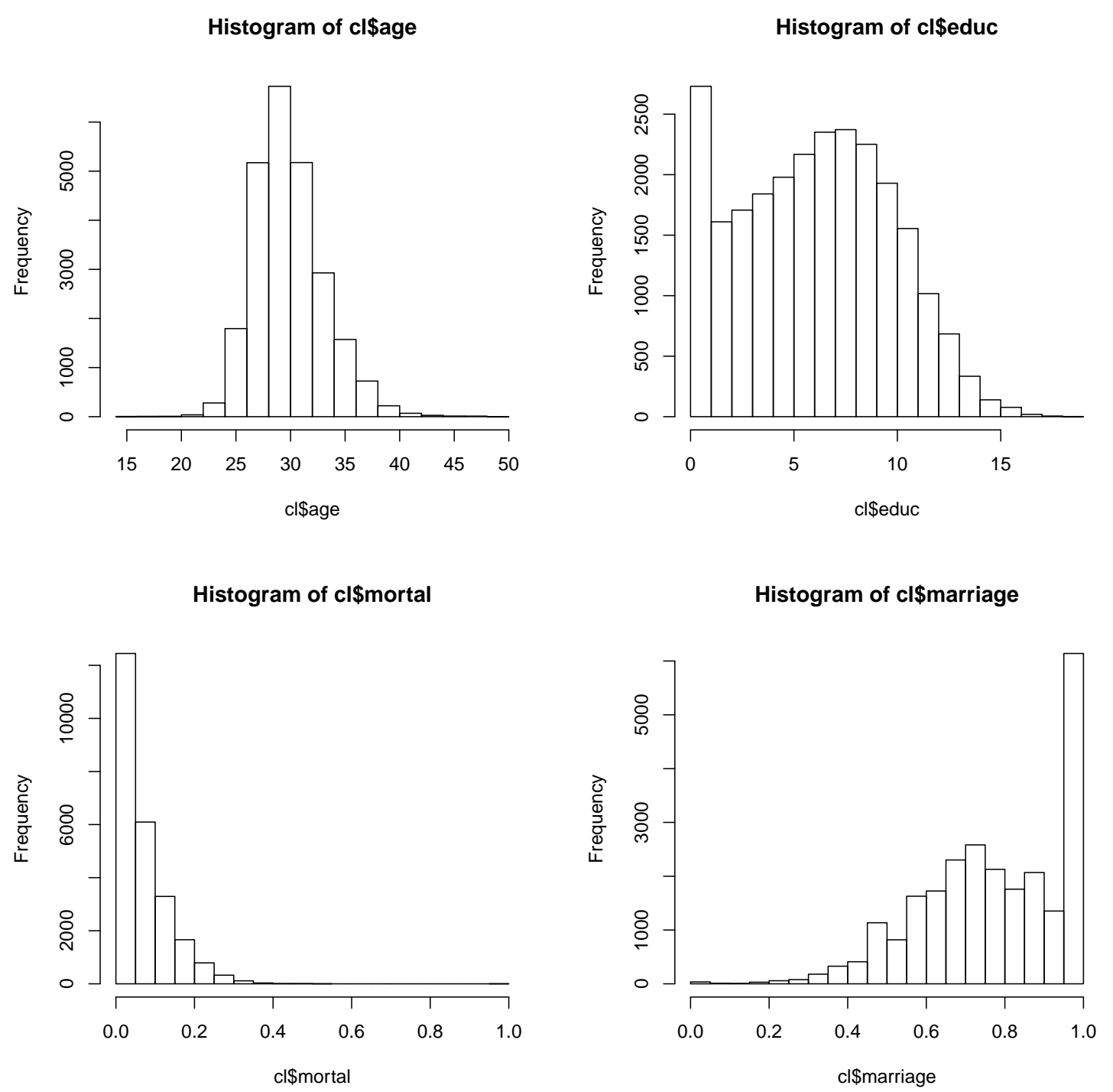

Figure E.2: Distribution of Clusters' Characteristics: age, education, infant mortality, marriage rates 


\section{F Figures for the Instruments}

\section{F.1 UNESCO World Heritage Sites}

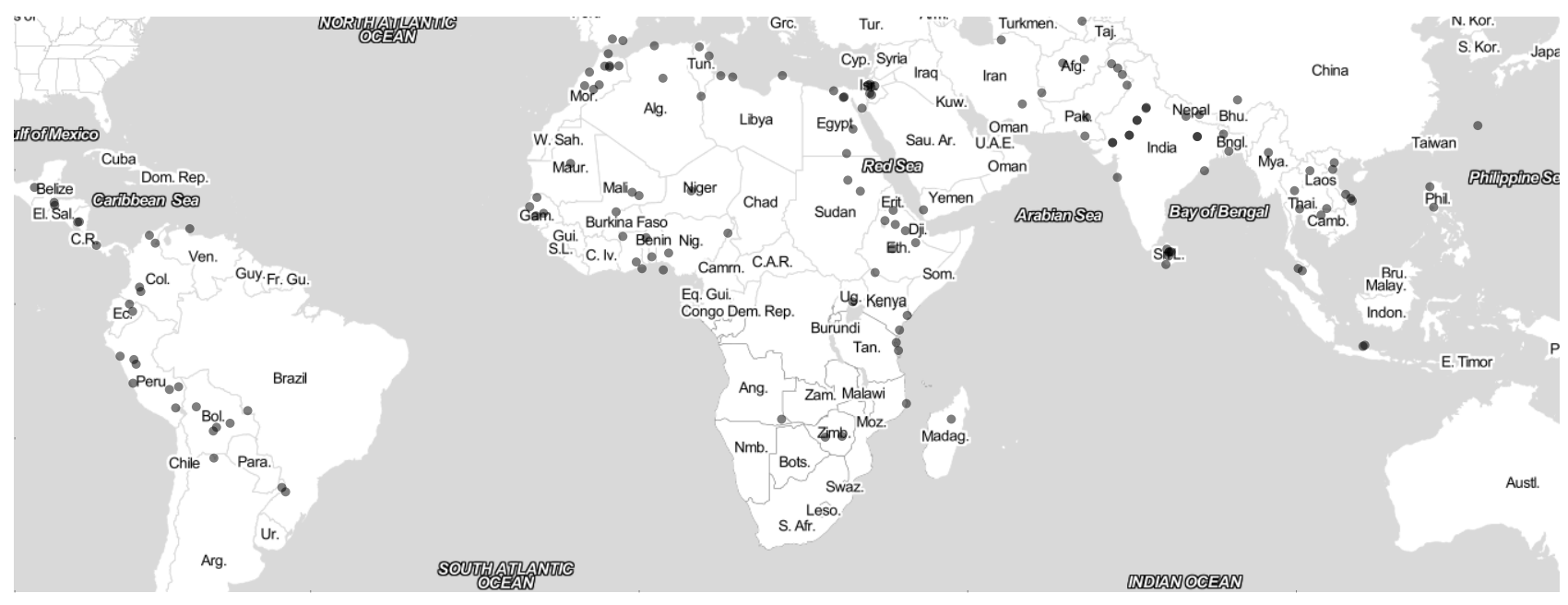

Figure F.1: Retained UNESCO World Heritage Sites

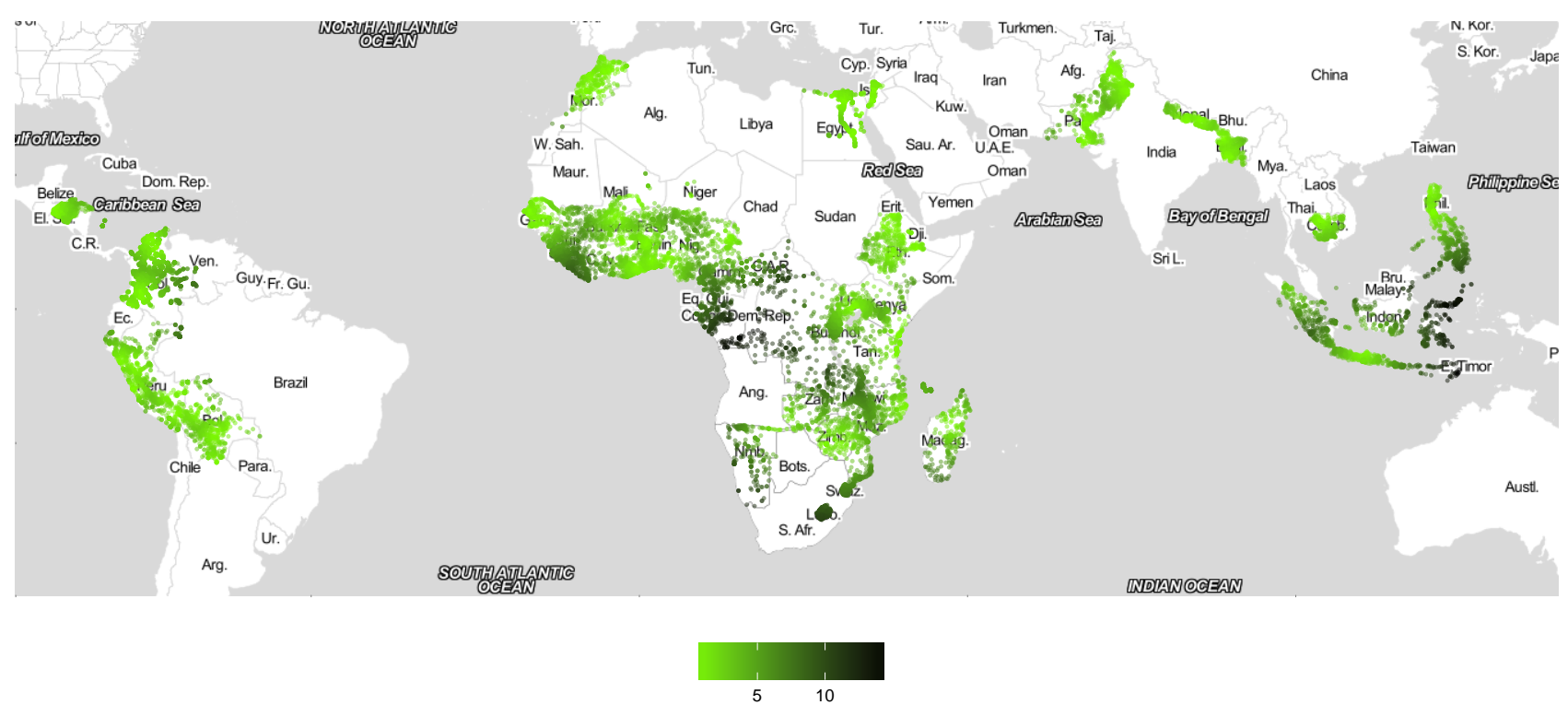

Figure F.2: Clusters' Shortest Distance to UNESCO Site 


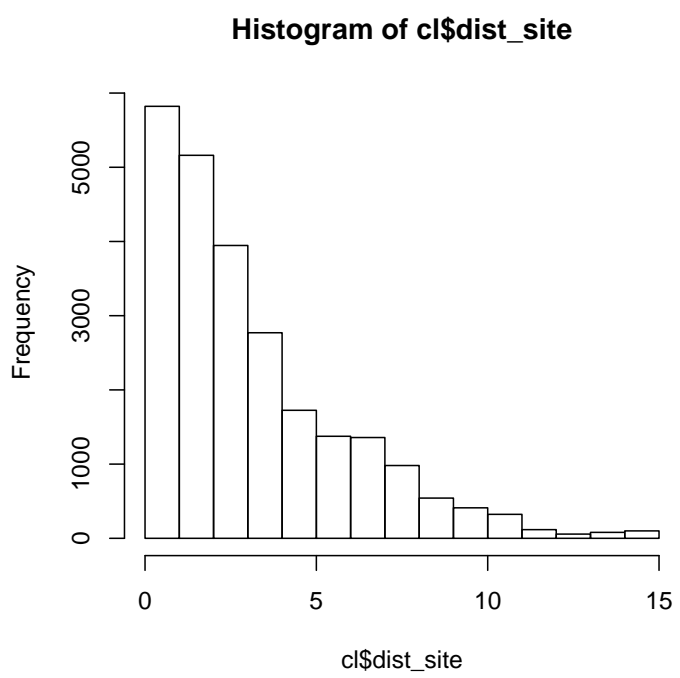

Figure F.3: Distribution of Clusters' Shortest Distance to UNESCO Sites

\section{F.2 Caloric Gain from the Columbian Exchange}

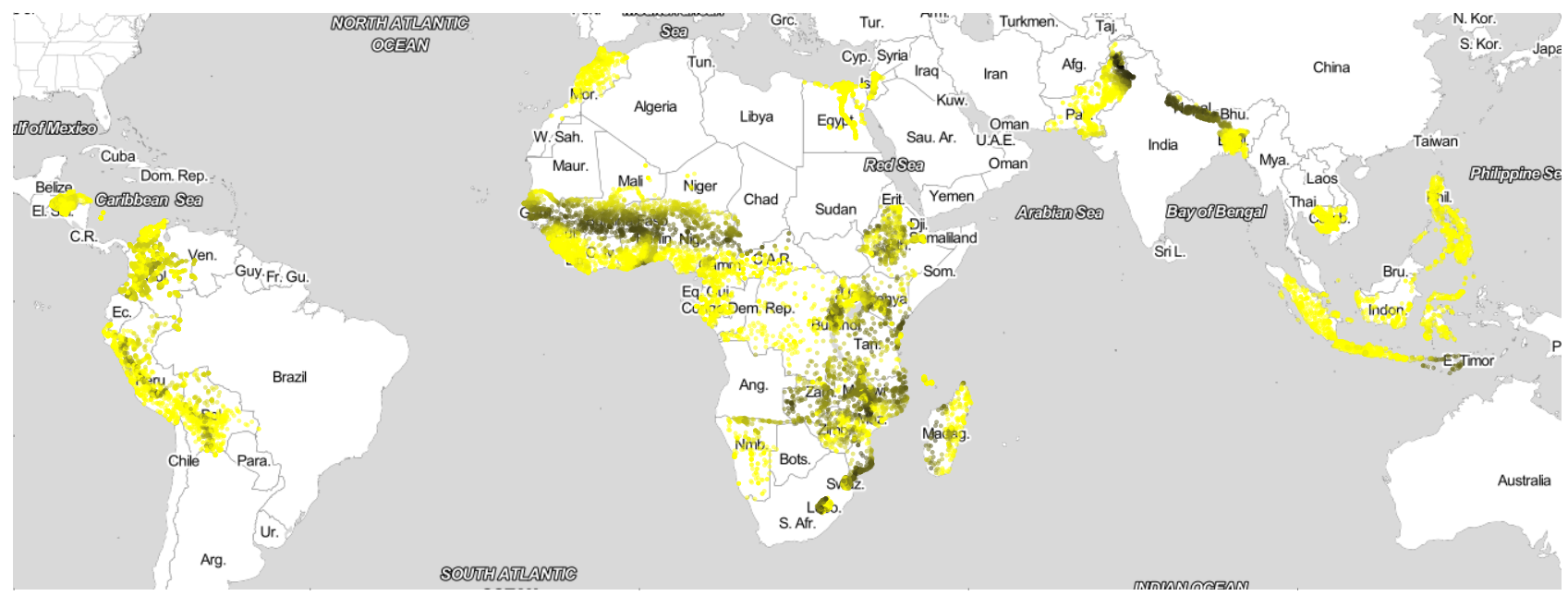

\section{$\begin{array}{llll}0 & 3 & 6 & 9\end{array}$}

Figure F.4: Differences in the Caloric Suitability Index Post and Pre-1500 (/100). 


\section{G Examples of Different Densities}
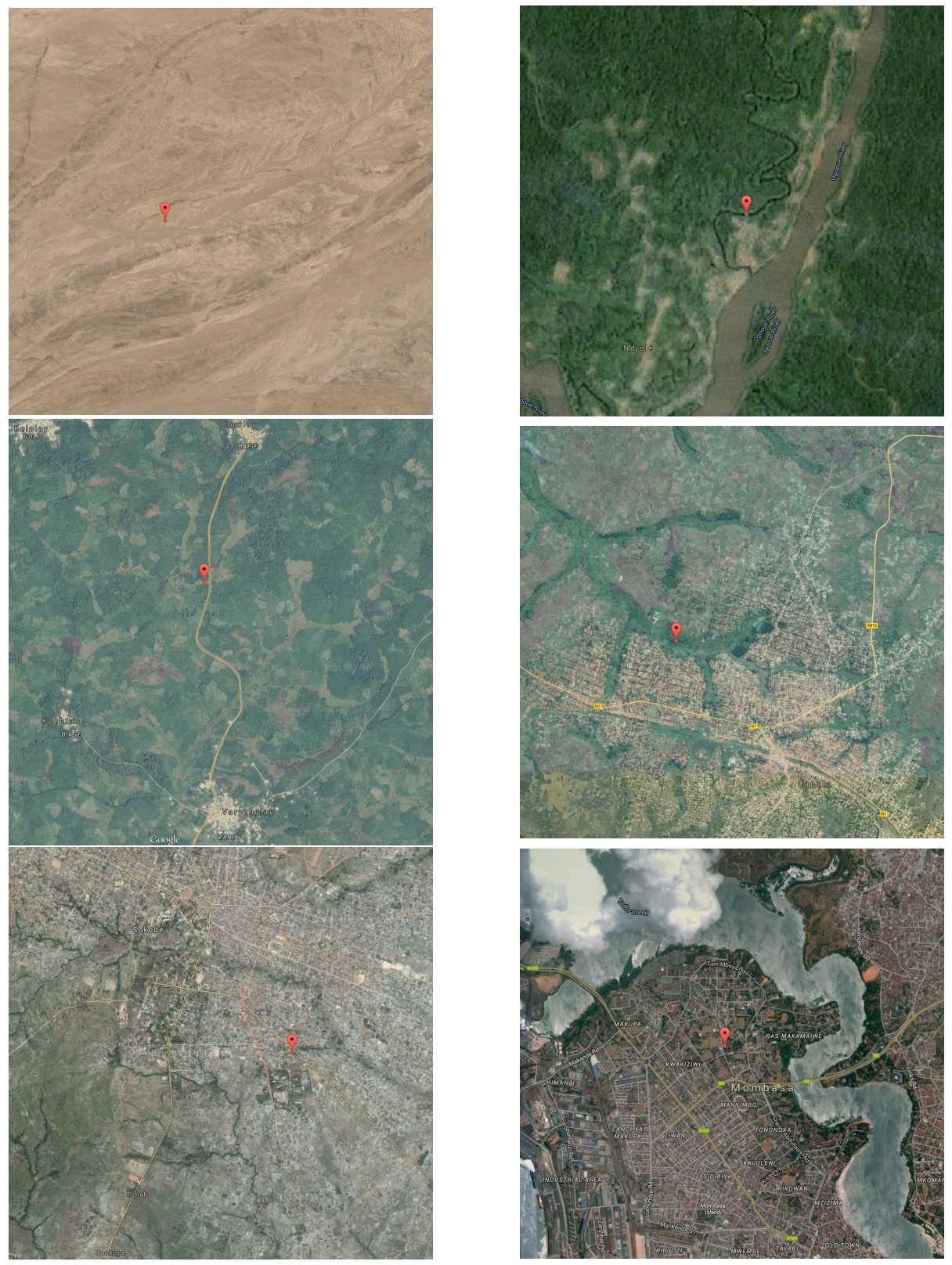

Figure G.1: Densities of $0.1,1,10,100,1000$, and 10000 inhabitants per square km 


\section{H Additional Controls at the Cluster Level}

Note: DHS data on religion is not available in Bolivia, Colombia, Egypt, Pakistan, Peru and Morocco. DHS data on having electricity is not available for Honduras. DHS data on refrigerator ownership is not available for Bangladesh, Ethiopia, Malawi and Nepal.

\begin{tabular}{|c|c|c|c|}
\hline & \multicolumn{3}{|c|}{$\begin{array}{l}\text { Dependent variable: children ever born, } \\
\text { per woman (average in cluster) }\end{array}$} \\
\hline & $(1)$ & $(2)$ & $(3)$ \\
\hline $\ln (1+$ density $)$ & $\begin{array}{c}-0.051^{* * *} \\
(0.003)\end{array}$ & $\begin{array}{c}-0.048^{* * *} \\
(0.002)\end{array}$ & $\begin{array}{c}-0.045^{* * *} \\
(0.002)\end{array}$ \\
\hline Caloric Suitability Index & $\begin{array}{c}0.003 \\
(0.002)\end{array}$ & $\begin{array}{c}0.005^{* * *} \\
(0.001)\end{array}$ & $\begin{array}{c}0.008^{* * *} \\
(0.001)\end{array}$ \\
\hline age & $\begin{array}{c}0.354^{* * *} \\
(0.021)\end{array}$ & $\begin{array}{c}0.292^{* * *} \\
(0.014)\end{array}$ & $\begin{array}{c}0.285^{* * *} \\
(0.014)\end{array}$ \\
\hline $\operatorname{age}^{2}$ & $\begin{array}{c}-0.004^{* * *} \\
(0.0003)\end{array}$ & $\begin{array}{c}-0.003^{* * *} \\
(0.0002)\end{array}$ & $\begin{array}{c}-0.003^{* * *} \\
(0.0002)\end{array}$ \\
\hline marriage & $\begin{array}{c}1.034^{* * *} \\
(0.042)\end{array}$ & $\begin{array}{c}1.089^{* * *} \\
(0.032)\end{array}$ & $\begin{array}{c}1.118^{* * *} \\
(0.031)\end{array}$ \\
\hline infant mortality & $\begin{array}{c}2.374^{* * *} \\
(0.089)\end{array}$ & $\begin{array}{c}2.562^{* * *} \\
(0.079)\end{array}$ & $\begin{array}{c}2.717^{* * *} \\
(0.082)\end{array}$ \\
\hline GDP per capita & $\begin{array}{c}-1.724^{* * *} \\
(0.505)\end{array}$ & $\begin{array}{c}-1.177^{* * *} \\
(0.352)\end{array}$ & $\begin{array}{c}-0.750^{* *} \\
(0.350)\end{array}$ \\
\hline woman's education & $\begin{array}{c}-0.064^{* * *} \\
(0.006)\end{array}$ & $\begin{array}{c}-0.068^{* * *} \\
(0.005)\end{array}$ & $\begin{array}{c}-0.072^{* * *} \\
(0.004)\end{array}$ \\
\hline women's education ${ }^{2}$ & $\begin{array}{c}-0.006^{* * *} \\
(0.0004)\end{array}$ & $\begin{array}{c}-0.005^{* * *} \\
(0.0003)\end{array}$ & $\begin{array}{c}-0.003^{* * *} \\
(0.0003)\end{array}$ \\
\hline Islam & $\begin{array}{l}-0.053 \\
(0.035)\end{array}$ & & \\
\hline Christian & $\begin{array}{l}-0.051 \\
(0.036)\end{array}$ & & \\
\hline Buddhism & $\begin{array}{l}-0.124 \\
(0.088)\end{array}$ & & \\
\hline Hinduism & $\begin{array}{c}-0.605^{* * *} \\
(0.067)\end{array}$ & & \\
\hline electricity & & $\begin{array}{c}-0.269^{* * *} \\
(0.016)\end{array}$ & \\
\hline refrigerator & & & $\begin{array}{c}-0.431^{* * *} \\
(0.019) \\
\end{array}$ \\
\hline Observations & 14,928 & 23,284 & 22,592 \\
\hline $\mathrm{R}^{2}$ & 0.708 & 0.741 & 0.748 \\
\hline Adjusted $\mathrm{R}^{2}$ & 0.707 & 0.740 & 0.747 \\
\hline
\end{tabular}

Note: ${ }^{* * *} \mathrm{p}<0.01$.

Table H.1: Results at the cluster level with more controls 


\section{Analysis at the Cluster Level for Countries grouped by Continent}

\begin{tabular}{|c|c|c|c|c|c|}
\hline & \multicolumn{5}{|c|}{$\begin{array}{l}\text { Dependent variable: } \\
\text { children ever born, per woman (average in cluster) }\end{array}$} \\
\hline & (1) & $(2)$ & $(3)$ & $(4)$ & $(5)$ \\
\hline $\ln (1+$ density $)$ & $\begin{array}{c}-0.181^{* * *} \\
(0.003)\end{array}$ & $\begin{array}{c}-0.122^{* * *} \\
(0.003)\end{array}$ & $\begin{array}{c}-0.108^{* * *} \\
(0.003)\end{array}$ & $\begin{array}{c}-0.106^{* * *} \\
(0.003)\end{array}$ & $\begin{array}{c}-0.047^{* * *} \\
(0.003)\end{array}$ \\
\hline Caloric Suitability Index & $\begin{array}{c}0.018^{* * *} \\
(0.003)\end{array}$ & $\begin{array}{l}0.016^{* * *} \\
(0.003)\end{array}$ & $\begin{array}{c}0.014^{* * *} \\
(0.003)\end{array}$ & $\begin{array}{c}0.013^{* * *} \\
(0.003)\end{array}$ & $\begin{array}{c}0.008^{* * *} \\
(0.003)\end{array}$ \\
\hline age & $\begin{array}{l}0.546^{* * *} \\
(0.036)\end{array}$ & $\begin{array}{c}0.397^{* * *} \\
(0.033)\end{array}$ & $\begin{array}{l}0.390^{* * *} \\
(0.032)\end{array}$ & $\begin{array}{l}0.397^{* * *} \\
(0.032)\end{array}$ & $\begin{array}{c}0.373^{* * *} \\
(0.029)\end{array}$ \\
\hline $\operatorname{age}^{2}$ & $\begin{array}{c}-0.006^{* * *} \\
(0.001)\end{array}$ & $\begin{array}{c}-0.004^{* * *} \\
(0.001)\end{array}$ & $\begin{array}{c}-0.004^{* * *} \\
(0.001)\end{array}$ & $\begin{array}{c}-0.004^{* * *} \\
(0.001)\end{array}$ & $\begin{array}{c}-0.004^{* * *} \\
(0.001)\end{array}$ \\
\hline marriage & & $\begin{array}{c}2.125^{* * *} \\
(0.047)\end{array}$ & $\begin{array}{c}1.689^{* * *} \\
(0.047)\end{array}$ & $\begin{array}{c}1.685^{* * *} \\
(0.047)\end{array}$ & $\begin{array}{c}0.965^{* * *} \\
(0.047)\end{array}$ \\
\hline infant mortality & & & $\begin{array}{c}3.039^{* * *} \\
(0.100)\end{array}$ & $\begin{array}{c}3.010^{* * *} \\
(0.100)\end{array}$ & $\begin{array}{c}2.099^{* * *} \\
(0.096)\end{array}$ \\
\hline GDP per capita & & & & $\begin{array}{c}-9.119^{* * *} \\
(1.505)\end{array}$ & $\begin{array}{c}-4.702^{* * *} \\
(1.393)\end{array}$ \\
\hline woman's education & & & & & $\begin{array}{c}-0.060^{* * *} \\
(0.007)\end{array}$ \\
\hline woman's education ${ }^{2}$ & & & & & $\begin{array}{c}-0.006^{* * *} \\
(0.001) \\
\end{array}$ \\
\hline Country fixed effect & yes & yes & yes & yes & yes \\
\hline Observations & 10,262 & 10,262 & 10,262 & 10,262 & 10,262 \\
\hline Adjusted $\mathrm{R}^{2}$ & 0.568 & 0.640 & 0.669 & 0.671 & 0.720 \\
\hline
\end{tabular}

Note: ${ }^{* * *} \mathrm{p}<0.01$.

Table I.1: Results at the cluster level - Sub-Saharan Africa 


\begin{tabular}{|c|c|c|c|c|c|}
\hline & \multicolumn{5}{|c|}{$\begin{array}{l}\text { Dependent variable: } \\
\text { children ever born, per woman (average in cluster) }\end{array}$} \\
\hline & $(1)$ & $(2)$ & $(3)$ & $(4)$ & $(5)$ \\
\hline $\ln (1+$ density $)$ & $\begin{array}{c}-0.151^{* * *} \\
(0.011)\end{array}$ & $\begin{array}{c}-0.138^{* * *} \\
(0.011)\end{array}$ & $\begin{array}{c}-0.112^{* * *} \\
(0.010)\end{array}$ & $\begin{array}{c}-0.118^{* * *} \\
(0.010)\end{array}$ & $\begin{array}{c}-0.049^{* * *} \\
(0.009)\end{array}$ \\
\hline Caloric Suitability Index & $\begin{array}{c}0.002 \\
(0.014)\end{array}$ & $\begin{array}{c}0.005 \\
(0.013)\end{array}$ & $\begin{array}{l}0.026^{* *} \\
(0.012)\end{array}$ & $\begin{array}{l}0.020^{*} \\
(0.012)\end{array}$ & $\begin{array}{l}0.024^{* *} \\
(0.010)\end{array}$ \\
\hline age & $\begin{array}{c}0.350^{* * *} \\
(0.096)\end{array}$ & $\begin{array}{c}0.301^{* * *} \\
(0.095)\end{array}$ & $\begin{array}{l}0.210^{* *} \\
(0.084)\end{array}$ & $\begin{array}{l}0.207^{* *} \\
(0.084)\end{array}$ & $\begin{array}{c}0.277^{* * *} \\
(0.072)\end{array}$ \\
\hline $\operatorname{age}^{2}$ & $\begin{array}{c}-0.004^{* * *} \\
(0.001)\end{array}$ & $\begin{array}{c}-0.003^{* *} \\
(0.001)\end{array}$ & $\begin{array}{c}-0.002^{*} \\
(0.001)\end{array}$ & $\begin{array}{c}-0.002^{*} \\
(0.001)\end{array}$ & $\begin{array}{c}-0.002^{* *} \\
(0.001)\end{array}$ \\
\hline marriage & & $\begin{array}{c}2.702^{* * *} \\
(0.342)\end{array}$ & $\begin{array}{c}1.974^{* * *} \\
(0.304)\end{array}$ & $\begin{array}{c}1.937^{* * *} \\
(0.304)\end{array}$ & $\begin{array}{c}1.214^{* * *} \\
(0.265)\end{array}$ \\
\hline infant mortality & & & $\begin{array}{c}9.807^{* * *} \\
(0.418)\end{array}$ & $\begin{array}{c}9.732^{* * *} \\
(0.418)\end{array}$ & $\begin{array}{c}5.417^{* * *} \\
(0.391)\end{array}$ \\
\hline GDP per capita & & & & $\begin{array}{c}-1.403^{* *} \\
(0.560)\end{array}$ & $\begin{array}{l}-0.451 \\
(0.481)\end{array}$ \\
\hline woman's education & & & & & $\begin{array}{c}-0.137^{* * *} \\
(0.014)\end{array}$ \\
\hline woman's education ${ }^{2}$ & & & & & $\begin{array}{l}-0.001 \\
(0.001) \\
\end{array}$ \\
\hline Country fixed effect & yes & yes & yes & yes & yes \\
\hline Observations & 1,973 & 1,973 & 1,973 & 1,973 & 1,973 \\
\hline Adjusted $\mathrm{R}^{2}$ & 0.514 & 0.529 & 0.632 & 0.633 & 0.732 \\
\hline
\end{tabular}

Notes: ${ }^{*} \mathrm{p}<0.1 ;{ }^{* *} \mathrm{p}<0.05 ;{ }^{* *} \mathrm{p}<0.01$.

In Egypt and Jordan, all women are ever married in the data.

Table I.2: Results at the cluster level - Middle East and North Africa 


\begin{tabular}{|c|c|c|c|c|c|}
\hline & \multicolumn{5}{|c|}{$\begin{array}{l}\text { Dependent variable: } \\
\text { children ever born, per woman (average in cluster) }\end{array}$} \\
\hline & (1) & $(2)$ & $(3)$ & $(4)$ & $(5)$ \\
\hline $\ln (1+$ density $)$ & $\begin{array}{c}-0.142^{* * *} \\
(0.007)\end{array}$ & $\begin{array}{l}-0.120^{* * *} \\
(0.007)\end{array}$ & $\begin{array}{c}-0.100^{* * *} \\
(0.006)\end{array}$ & $\begin{array}{c}-0.098^{* * *} \\
(0.006)\end{array}$ & $\begin{array}{l}-0.037^{* * *} \\
(0.006)\end{array}$ \\
\hline Caloric Suitability Index & $\begin{array}{c}-0.014^{* * *} \\
(0.004)\end{array}$ & $\begin{array}{c}-0.015^{* * *} \\
(0.004)\end{array}$ & $\begin{array}{c}-0.013^{* * *} \\
(0.003)\end{array}$ & $\begin{array}{c}-0.014^{* * *} \\
(0.003)\end{array}$ & $\begin{array}{c}-0.012^{* * *} \\
(0.003)\end{array}$ \\
\hline age & $\begin{array}{c}0.679^{* * *} \\
(0.058)\end{array}$ & $\begin{array}{c}0.482^{* * *} \\
(0.058)\end{array}$ & $\begin{array}{c}0.470^{* * *} \\
(0.055)\end{array}$ & $\begin{array}{c}0.472^{* * *} \\
(0.055)\end{array}$ & $\begin{array}{c}0.440^{* * *} \\
(0.052)\end{array}$ \\
\hline $\operatorname{age}^{2}$ & $\begin{array}{c}-0.009^{* * *} \\
(0.001)\end{array}$ & $\begin{array}{c}-0.006^{* * *} \\
(0.001)\end{array}$ & $\begin{array}{c}-0.006^{* * *} \\
(0.001)\end{array}$ & $\begin{array}{c}-0.006^{* * *} \\
(0.001)\end{array}$ & $\begin{array}{c}-0.005^{* * *} \\
(0.001)\end{array}$ \\
\hline marriage & & $\begin{array}{c}2.440^{* * *} \\
(0.148)\end{array}$ & $\begin{array}{c}2.092^{* * *} \\
(0.142)\end{array}$ & $\begin{array}{c}2.084^{* * *} \\
(0.142)\end{array}$ & $\begin{array}{c}1.574^{* * *} \\
(0.135)\end{array}$ \\
\hline infant mortality & & & $\begin{array}{c}4.059^{* * *} \\
(0.203)\end{array}$ & $\begin{array}{l}4.030^{* * *} \\
(0.203)\end{array}$ & $\begin{array}{c}2.666^{* * *} \\
(0.200)\end{array}$ \\
\hline GDP per capita & & & & $\begin{array}{c}-9.537^{* * *} \\
(3.426)\end{array}$ & $\begin{array}{c}-5.488^{*} \\
(3.207)\end{array}$ \\
\hline woman's education & & & & & $\begin{array}{c}-0.094^{* * *} \\
(0.012)\end{array}$ \\
\hline woman's education ${ }^{2}$ & & & & & $\begin{array}{c}-0.002^{* *} \\
(0.001)\end{array}$ \\
\hline Country fixed effect & yes & yes & yes & yes & yes \\
\hline Observations & 4,151 & 4,151 & 4,151 & 4,151 & 4,151 \\
\hline Adjusted $\mathrm{R}^{2}$ & 0.480 & 0.512 & 0.555 & 0.556 & 0.612 \\
\hline
\end{tabular}

Note: ${ }^{*} \mathrm{p}<0.1 ;{ }^{* *} \mathrm{p}<0.05 ;{ }^{* * *} \mathrm{p}<0.01$

Table I.3: Results at the cluster level - South and South-East Asia 


\begin{tabular}{|c|c|c|c|c|c|}
\hline & \multicolumn{5}{|c|}{$\begin{array}{l}\text { Dependent variable: } \\
\text { children ever born, per woman (average in cluster) }\end{array}$} \\
\hline & $(1)$ & $(2)$ & $(3)$ & $(4)$ & $(5)$ \\
\hline $\ln (1+$ density $)$ & $\begin{array}{l}-0.208^{* * *} \\
(0.003)\end{array}$ & $\begin{array}{c}-0.157^{* * *} \\
(0.003)\end{array}$ & $\begin{array}{c}-0.137^{* * *} \\
(0.003)\end{array}$ & $\begin{array}{c}-0.137^{* * *} \\
(0.003)\end{array}$ & $\begin{array}{l}-0.065^{* * *} \\
(0.003)\end{array}$ \\
\hline Caloric Suitability Index & $\begin{array}{l}0.019^{* * *} \\
(0.003)\end{array}$ & $\begin{array}{c}0.002 \\
(0.003)\end{array}$ & $\begin{array}{l}0.004^{*} \\
(0.002)\end{array}$ & $\begin{array}{l}0.004^{*} \\
(0.002)\end{array}$ & $\begin{array}{c}0.009^{* * *} \\
(0.002)\end{array}$ \\
\hline age & $\begin{array}{c}0.331^{* * *} \\
(0.025)\end{array}$ & $\begin{array}{c}0.187^{* * *} \\
(0.023)\end{array}$ & $\begin{array}{c}0.163^{* * *} \\
(0.021)\end{array}$ & $\begin{array}{c}0.163^{* * *} \\
(0.021)\end{array}$ & $\begin{array}{c}0.173^{* * *} \\
(0.018)\end{array}$ \\
\hline $\operatorname{age}^{2}$ & $\begin{array}{c}-0.004^{* * *} \\
(0.0004)\end{array}$ & $\begin{array}{c}-0.002^{* * *} \\
(0.0004)\end{array}$ & $\begin{array}{c}-0.002^{* * *} \\
(0.0003)\end{array}$ & $\begin{array}{c}-0.002^{* * *} \\
(0.0003)\end{array}$ & $\begin{array}{c}-0.002^{* * *} \\
(0.0003)\end{array}$ \\
\hline marriage & & $\begin{array}{c}2.224^{* * *} \\
(0.048)\end{array}$ & $\begin{array}{c}2.015^{* * *} \\
(0.045)\end{array}$ & $\begin{array}{c}2.016^{* * *} \\
(0.044)\end{array}$ & $\begin{array}{c}1.294^{* * *} \\
(0.039)\end{array}$ \\
\hline infant mortality & & & $\begin{array}{c}6.790^{* * *} \\
(0.194)\end{array}$ & $\begin{array}{c}6.523^{* * *} \\
(0.193)\end{array}$ & $\begin{array}{c}3.834^{* * *} \\
(0.167)\end{array}$ \\
\hline GDP per capita & & & & $\begin{array}{c}-13.797^{* * *} \\
(1.018)\end{array}$ & $\begin{array}{c}-5.112^{* * *} \\
(0.862)\end{array}$ \\
\hline woman's education & & & & & $\begin{array}{c}-0.234^{* * *} \\
(0.009)\end{array}$ \\
\hline woman's education ${ }^{2}$ & & & & & $\begin{array}{c}0.005^{* * *} \\
(0.001)\end{array}$ \\
\hline Country fixed effects & yes & yes & yes & yes & yes \\
\hline Observations & 8,383 & 8,383 & 8,383 & 8,383 & 8,383 \\
\hline Adjusted $\mathrm{R}^{2}$ & 0.412 & 0.534 & 0.594 & 0.602 & 0.723 \\
\hline
\end{tabular}

Note: ${ }^{*} \mathrm{p}<0.1 ;{ }^{* *} \mathrm{p}<0.05 ;{ }^{* * *} \mathrm{p}<0.01$

Table I.4: Results at the cluster level - Latin America 


\section{J Analysis at the Cluster Level for Countries Grouped by Income}

\begin{tabular}{|c|c|c|c|c|}
\hline & \multicolumn{4}{|c|}{$\begin{array}{l}\text { Dependent variable: } \\
\text { children ever born, per woman (average in cluster) }\end{array}$} \\
\hline & $(1)$ & $(2)$ & $(3)$ & $(4)$ \\
\hline $\log (1+\operatorname{dens} 90)$ & $\begin{array}{l}-0.176^{* * *} \\
(0.004)\end{array}$ & $\begin{array}{c}-0.032^{* * *} \\
(0.004)\end{array}$ & $\begin{array}{l}-0.196^{* * *} \\
(0.003)\end{array}$ & $\begin{array}{c}-0.066^{* * *} \\
(0.002)\end{array}$ \\
\hline Caloric Suitability Index & $\begin{array}{c}0.017^{* * *} \\
(0.004)\end{array}$ & $\begin{array}{c}0.013^{* * *} \\
(0.003)\end{array}$ & $\begin{array}{c}0.012^{* * *} \\
(0.002)\end{array}$ & $\begin{array}{c}0.005^{* * *} \\
(0.002)\end{array}$ \\
\hline age & $\begin{array}{l}0.662^{* * *} \\
(0.045)\end{array}$ & $\begin{array}{l}0.406^{* * *} \\
(0.037)\end{array}$ & $\begin{array}{r}0.422^{* * *} \\
(0.020)\end{array}$ & $\begin{array}{l}0.202^{* * *} \\
(0.016)\end{array}$ \\
\hline $\operatorname{age}^{2}$ & $\begin{array}{c}-0.008^{* * *} \\
(0.001)\end{array}$ & $\begin{array}{c}-0.005^{* * *} \\
(0.001)\end{array}$ & $\begin{array}{c}-0.005^{* * *} \\
(0.0003)\end{array}$ & $\begin{array}{c}-0.002^{* * *} \\
(0.0002)\end{array}$ \\
\hline marriage & & $\begin{array}{c}1.133^{* * *} \\
(0.057)\end{array}$ & & $\begin{array}{c}1.153^{* * *} \\
(0.037)\end{array}$ \\
\hline infant mortality & & $\begin{array}{c}2.265^{* * *} \\
(0.105)\end{array}$ & & $\begin{array}{c}2.954^{* * *} \\
(0.110)\end{array}$ \\
\hline GDP per capita & & $\begin{array}{c}-6.775^{* * *} \\
(2.196)\end{array}$ & & $\begin{array}{c}-1.623^{* * *} \\
(0.363)\end{array}$ \\
\hline woman's education & & $\begin{array}{c}-0.089^{* * *} \\
(0.008)\end{array}$ & & $\begin{array}{c}-0.106^{* * *} \\
(0.006)\end{array}$ \\
\hline woman's education ${ }^{2}$ & & $\begin{array}{c}-0.004^{* * *} \\
(0.001)\end{array}$ & & $\begin{array}{c}-0.003^{* * *} \\
(0.0003)\end{array}$ \\
\hline Country fixed effects & yes & yes & yes & yes \\
\hline Observations & 8,479 & 8,479 & 16,290 & 16,290 \\
\hline Adjusted $\mathrm{R}^{2}$ & 0.562 & 0.704 & 0.551 & 0.739 \\
\hline
\end{tabular}

Table J.5: Results at the cluster level by Income Groups

\section{K Robustness of the Analysis at the Individual Level}

\section{K.1 Additional Controls at the Individual Level}




\begin{tabular}{|c|c|c|c|c|}
\hline & \multicolumn{4}{|c|}{ Dependent variable: Children ever born } \\
\hline & $(1)$ & $(2)$ & $(3)$ & $(4)$ \\
\hline $\ln (1+$ density $)$ & $\begin{array}{c}-0.017^{* * *} \\
(0.001)\end{array}$ & $\begin{array}{c}-0.016^{* * *} \\
(0.001)\end{array}$ & $\begin{array}{c}-0.016^{* * *} \\
(0.001)\end{array}$ & $\begin{array}{c}-0.017^{* * *} \\
(0.001)\end{array}$ \\
\hline Caloric Suitability Index & $\begin{array}{c}0.003^{* * *} \\
(0.001)\end{array}$ & $\begin{array}{l}0.003^{* * *} \\
(0.0004)\end{array}$ & $\begin{array}{l}0.004^{* * *} \\
(0.0004)\end{array}$ & $\begin{array}{l}-0.001 \\
(0.001)\end{array}$ \\
\hline married & $\begin{array}{c}1.296^{* * *} \\
(0.008)\end{array}$ & $\begin{array}{c}1.412^{* * *} \\
(0.007)\end{array}$ & $\begin{array}{c}1.394^{* * *} \\
(0.007)\end{array}$ & \\
\hline mean marriage & $\begin{array}{c}-0.061^{* * *} \\
(0.010)\end{array}$ & $\begin{array}{c}-0.072^{* * *} \\
(0.009)\end{array}$ & $\begin{array}{c}-0.045^{* * *} \\
(0.009)\end{array}$ & $\begin{array}{c}0.163 \\
(0.157)\end{array}$ \\
\hline mortality & $\begin{array}{c}0.386^{* * *} \\
(0.005)\end{array}$ & $\begin{array}{c}0.426^{* * *} \\
(0.005)\end{array}$ & $\begin{array}{c}0.434^{* * *} \\
(0.005)\end{array}$ & $\begin{array}{c}0.540^{* * *} \\
(0.011)\end{array}$ \\
\hline mean mortality & $\begin{array}{c}0.185^{* * *} \\
(0.021)\end{array}$ & $\begin{array}{c}0.150^{* * *} \\
(0.020)\end{array}$ & $\begin{array}{c}0.190^{* * *} \\
(0.021)\end{array}$ & $\begin{array}{c}0.427^{* * *} \\
(0.041)\end{array}$ \\
\hline GDP per capita & $\begin{array}{c}-0.741^{* * *} \\
(0.132)\end{array}$ & $\begin{array}{c}-0.506^{* * *} \\
(0.091)\end{array}$ & $\begin{array}{c}-0.276^{* * *} \\
(0.091)\end{array}$ & $\begin{array}{c}-0.429^{* * *} \\
(0.100)\end{array}$ \\
\hline woman's education & $\begin{array}{c}0.007^{* * *} \\
(0.001)\end{array}$ & $\begin{array}{c}0.005^{* * *} \\
(0.001)\end{array}$ & $\begin{array}{l}0.001^{*} \\
(0.001)\end{array}$ & $\begin{array}{c}0.001 \\
(0.002)\end{array}$ \\
\hline woman's education ${ }^{2}$ & $\begin{array}{c}-0.003^{* * *} \\
(0.0001)\end{array}$ & $\begin{array}{c}-0.003^{* * *} \\
(0.0001)\end{array}$ & $\begin{array}{c}-0.003^{* * *} \\
(0.0001)\end{array}$ & $\begin{array}{c}-0.002^{* * *} \\
(0.0001)\end{array}$ \\
\hline mean educ & $\begin{array}{c}-0.014^{* * *} \\
(0.001)\end{array}$ & $\begin{array}{c}-0.003^{* *} \\
(0.001)\end{array}$ & $\begin{array}{c}0.001 \\
(0.001)\end{array}$ & $\begin{array}{c}-0.028^{* * *} \\
(0.003)\end{array}$ \\
\hline mean educ ${ }^{2}$ & $\begin{array}{c}-0.001^{* * *} \\
(0.0001)\end{array}$ & $\begin{array}{c}-0.001^{* * *} \\
(0.0001)\end{array}$ & $\begin{array}{c}-0.001^{* * *} \\
(0.0001)\end{array}$ & $\begin{array}{l}0.0004^{* *} \\
(0.0002)\end{array}$ \\
\hline Islam & $\begin{array}{c}0.004 \\
(0.005)\end{array}$ & & & \\
\hline Christian & $\begin{array}{c}-0.013^{* * *} \\
(0.004)\end{array}$ & & & \\
\hline Buddhism & $\begin{array}{c}-0.055^{* * *} \\
(0.013)\end{array}$ & & & \\
\hline Hinduism & $\begin{array}{c}-0.162^{* * *} \\
(0.011)\end{array}$ & & & \\
\hline electricity & & $\begin{array}{c}-0.045^{* * *} \\
(0.004)\end{array}$ & & \\
\hline mean electricity & & $\begin{array}{c}-0.064^{* * *} \\
(0.006)\end{array}$ & & \\
\hline refrigerator & & & $\begin{array}{c}-0.072^{* * *} \\
(0.003)\end{array}$ & \\
\hline mean refrigerator & & & $\begin{array}{c}-0.138^{* * *} \\
(0.006)\end{array}$ & \\
\hline spouse's education & & & & $\begin{array}{c}-0.003^{* * *} \\
(0.001)\end{array}$ \\
\hline mean educ spouse & & & & $\begin{array}{c}0.007^{* * *} \\
(0.002)\end{array}$ \\
\hline Age dummies & yes & yes & yes & yes \\
\hline Country fixed effects & yes & yes & yes & yes \\
\hline Observations & 355,306 & 458,535 & 430,318 & 78,995 \\
\hline
\end{tabular}

Note: ${ }^{*} \mathrm{p}<0.1 ;{ }^{* *} \mathrm{p}<0.05 ;{ }^{* * *} \mathrm{p}<0.01$

Table K.1: Results at the individual level with more controls 


\section{K.2 Subsample of Women Aged 40+}

\begin{tabular}{|c|c|c|}
\hline & \multicolumn{2}{|c|}{$\begin{array}{l}\text { Dependent variable: } \\
\text { children ever born }\end{array}$} \\
\hline & all women & women aged $40+$ \\
\hline $\log (1+$ density 90$)$ & $\begin{array}{c}-0.021^{* * *} \\
(0.001)\end{array}$ & $\begin{array}{c}-0.021^{* * *} \\
(0.001)\end{array}$ \\
\hline Caloric Suitability Index & $\begin{array}{l}0.004^{* * *} \\
(0.0004)\end{array}$ & $\begin{array}{c}0.004^{* * *} \\
(0.001)\end{array}$ \\
\hline married & $\begin{array}{l}1.422^{* * *} \\
(0.007)\end{array}$ & $\begin{array}{l}1.187^{* * *} \\
(0.016)\end{array}$ \\
\hline mean marriage & $\begin{array}{c}-0.059^{* * *} \\
(0.009)\end{array}$ & $\begin{array}{c}-0.203^{* * *} \\
(0.014)\end{array}$ \\
\hline infant mortality & $\begin{array}{c}0.427^{* * *} \\
(0.005)\end{array}$ & $\begin{array}{c}0.379^{* * *} \\
(0.008)\end{array}$ \\
\hline mean mortality & $\begin{array}{c}0.177^{* * *} \\
(0.019)\end{array}$ & $\begin{array}{c}0.133^{* * *} \\
(0.032)\end{array}$ \\
\hline GDP per capita & $\begin{array}{c}-0.706^{* * *} \\
(0.091)\end{array}$ & $\begin{array}{c}-0.546^{* * *} \\
(0.139)\end{array}$ \\
\hline woman's education & $\begin{array}{l}0.003^{* * *} \\
(0.001)\end{array}$ & $\begin{array}{l}0.003^{* * *} \\
(0.001)\end{array}$ \\
\hline woman's education ${ }^{2}$ & $\begin{array}{c}-0.003^{* * *} \\
(0.0001)\end{array}$ & $\begin{array}{c}-0.002^{* * *} \\
(0.0001)\end{array}$ \\
\hline mean educ & $\begin{array}{c}-0.010^{* * *} \\
(0.001)\end{array}$ & $\begin{array}{c}-0.006^{* * *} \\
(0.002)\end{array}$ \\
\hline mean educ ${ }^{2}$ & $\begin{array}{c}-0.001^{* * *} \\
(0.0001) \\
\end{array}$ & $\begin{array}{c}-0.002^{* * *} \\
(0.0001) \\
\end{array}$ \\
\hline Age dummies & yes & yes \\
\hline Country fixed effects & yes & yes \\
\hline Observations & 490,669 & 95,053 \\
\hline
\end{tabular}

Table K.2: Restricting the Sample to Women Aged 40+ 


\section{K.3 Other Dependent Variables}

\begin{tabular}{|c|c|c|c|c|c|}
\hline & \multicolumn{5}{|c|}{ Dependent variable: children born in last 5yrs } \\
\hline & $(1)$ & $(2)$ & $(3)$ & $(4)$ & $(5)$ \\
\hline $\ln (1+$ density $)$ & $\begin{array}{c}-0.089^{* * *} \\
(0.001)\end{array}$ & $\begin{array}{c}-0.053^{* * *} \\
(0.001)\end{array}$ & $\begin{array}{c}-0.049^{* * *} \\
(0.001)\end{array}$ & $\begin{array}{c}-0.050^{* * *} \\
(0.001)\end{array}$ & $\begin{array}{c}-0.028^{* * *} \\
(0.001)\end{array}$ \\
\hline Caloric Suitability Index & $\begin{array}{c}0.006^{* * *} \\
(0.001)\end{array}$ & $\begin{array}{c}0.001 \\
(0.001)\end{array}$ & $\begin{array}{l}0.002^{* *} \\
(0.001)\end{array}$ & $\begin{array}{c}0.001 \\
(0.001)\end{array}$ & $\begin{array}{l}0.001^{*} \\
(0.001)\end{array}$ \\
\hline married & & $\begin{array}{c}1.651^{* * *} \\
(0.010)\end{array}$ & $\begin{array}{c}1.641^{* * *} \\
(0.010)\end{array}$ & $\begin{array}{c}1.641^{* * *} \\
(0.010)\end{array}$ & $\begin{array}{c}1.614^{* * *} \\
(0.010)\end{array}$ \\
\hline mean marriage & & $\begin{array}{c}0.369^{* * *} \\
(0.016)\end{array}$ & $\begin{array}{c}0.219^{* * *} \\
(0.017)\end{array}$ & $\begin{array}{c}0.216^{* * *} \\
(0.017)\end{array}$ & $\begin{array}{l}-0.008 \\
(0.018)\end{array}$ \\
\hline infant mortality & & & $\begin{array}{c}0.342^{* * *} \\
(0.009)\end{array}$ & $\begin{array}{c}0.342^{* * *} \\
(0.009)\end{array}$ & $\begin{array}{c}0.329^{* * *} \\
(0.009)\end{array}$ \\
\hline mean mortality & & & $\begin{array}{c}0.663^{* * *} \\
(0.036)\end{array}$ & $\begin{array}{c}0.650^{* * *} \\
(0.036)\end{array}$ & $\begin{array}{c}0.243^{* * *} \\
(0.037)\end{array}$ \\
\hline GDP per capita & & & & $\begin{array}{c}-1.769^{* * *} \\
(0.202)\end{array}$ & $\begin{array}{c}-1.080^{* * *} \\
(0.198)\end{array}$ \\
\hline woman's education & & & & & $\begin{array}{c}-0.007^{* * *} \\
(0.001)\end{array}$ \\
\hline woman's education ${ }^{2}$ & & & & & $\begin{array}{c}-0.0004^{* * *} \\
(0.0001)\end{array}$ \\
\hline mean educ & & & & & $\begin{array}{c}-0.031^{* * *} \\
(0.002)\end{array}$ \\
\hline mean educ ${ }^{2}$ & & & & & $\begin{array}{c}-0.0004^{* *} \\
(0.0002)\end{array}$ \\
\hline Age dummies & yes & yes & yes & yes & yes \\
\hline Country fixed effects & yes & yes & yes & yes & yes \\
\hline Observations & 490,669 & 490,669 & 490,669 & 490,669 & 490,669 \\
\hline
\end{tabular}

Notes: ${ }^{*} \mathrm{p}<0.1 ;{ }^{* *} \mathrm{p}<0.05 ;{ }^{* * *} \mathrm{p}<0.01$

Table K.3: Results at the individual level - Dependent variable: children born over the last five years. 


\begin{tabular}{|c|c|c|c|c|c|}
\hline & \multicolumn{5}{|c|}{ Dependent variable: ideal number of children } \\
\hline & $(1)$ & $(2)$ & $(3)$ & $(4)$ & $(5)$ \\
\hline $\ln (1+$ density $)$ & $\begin{array}{c}-0.048^{* * *} \\
(0.0004)\end{array}$ & $\begin{array}{c}-0.036^{* * *} \\
(0.0004)\end{array}$ & $\begin{array}{c}-0.033^{* * *} \\
(0.0004)\end{array}$ & $\begin{array}{c}-0.033^{* * *} \\
(0.0004)\end{array}$ & $\begin{array}{c}-0.015^{* * *} \\
(0.0005)\end{array}$ \\
\hline Caloric Suitability Index & $\begin{array}{c}-0.003^{* * *} \\
(0.0003)\end{array}$ & $\begin{array}{c}-0.004^{* * *} \\
(0.0003)\end{array}$ & $\begin{array}{c}-0.004^{* * *} \\
(0.0003)\end{array}$ & $\begin{array}{c}-0.004^{* * *} \\
(0.0003)\end{array}$ & $\begin{array}{c}-0.003^{* * *} \\
(0.0003)\end{array}$ \\
\hline married & & $\begin{array}{c}0.117^{* * *} \\
(0.003)\end{array}$ & $\begin{array}{c}0.115^{* * *} \\
(0.003)\end{array}$ & $\begin{array}{c}0.115^{* * *} \\
(0.003)\end{array}$ & $\begin{array}{c}0.093^{* * *} \\
(0.003)\end{array}$ \\
\hline mean marriage & & $\begin{array}{c}0.327^{* * *} \\
(0.007)\end{array}$ & $\begin{array}{c}0.218^{* * *} \\
(0.007)\end{array}$ & $\begin{array}{c}0.217^{* * *} \\
(0.007)\end{array}$ & $\begin{array}{c}0.010 \\
(0.007)\end{array}$ \\
\hline infant mortality & & & $\begin{array}{c}0.069^{* * *} \\
(0.004)\end{array}$ & $\begin{array}{c}0.069^{* * *} \\
(0.004)\end{array}$ & $\begin{array}{c}0.052^{* * *} \\
(0.004)\end{array}$ \\
\hline mean mortality & & & $\begin{array}{c}0.628^{* * *} \\
(0.016)\end{array}$ & $\begin{array}{c}0.621^{* * *} \\
(0.016)\end{array}$ & $\begin{array}{c}0.171^{* * *} \\
(0.016)\end{array}$ \\
\hline GDP per capita & & & & $\begin{array}{c}-0.980^{* * *} \\
(0.095)\end{array}$ & $\begin{array}{c}-0.428^{* * *} \\
(0.094)\end{array}$ \\
\hline woman's education & & & & & $\begin{array}{c}-0.019^{* * *} \\
(0.001)\end{array}$ \\
\hline woman's education ${ }^{2}$ & & & & & $\begin{array}{l}0.0004^{* * *} \\
(0.00004)\end{array}$ \\
\hline mean educ & & & & & $\begin{array}{c}-0.060^{* * *} \\
(0.001)\end{array}$ \\
\hline mean educ ${ }^{2}$ & & & & & $\begin{array}{l}0.003^{* * *} \\
(0.0001)\end{array}$ \\
\hline Age dummies & yes & yes & yes & yes & yes \\
\hline Country fixed effects & yes & yes & yes & yes & yes \\
\hline Observations & 455,194 & 455,194 & 455,194 & 455,194 & 455,194 \\
\hline
\end{tabular}

Notes: ${ }^{*} \mathrm{p}<0.1 ;{ }^{* *} \mathrm{p}<0.05 ;{ }^{* * *} \mathrm{p}<0.01$

Table K.4: Results at the individual level - Dependent variable: ideal number of children. 


\section{K.4 Data Quality}

Misreporting date of birth or underreporting number of births are common sources of error in surveys that look at birth history (Schoumaker (2014)). These errors are very much linked to low education levels of respondents (Pullum (2006)), and can affect age at first birth in three ways. The first is the so-called the "Potter effect" when the woman reports that an earlier birth occurred later than it actually did (Potter (1977)). This will likely increase the age at first birth for older women. The second source of error is adjustment of birth date by interviewers or respondents in order to avoid completing the health section of the DHS questionnaire (for children younger than 5 or 3 ). This will cause a reduction in the average age at first birth for younger women. The last problem is omission of earlier births, which most likely occurs with older respondents and is likely to increase the average age at first birth in a population.

Schoumaker (2014) explores the quality of the data using three approaches. The first consists of reconstructing trends in the total fertility rate (TFR) using a Poisson regression, and relying on one survey per country (see Schoumaker (2013b) for details on this method). The second approach consists of pooling all the surveys conducted in the same country and then reconstructing fertility trends from the pooled dataset (Schoumaker (2013a)). The third approach aims to correct birth histories by adjusting or adding births.

Table 5 in Schoumaker (2014) distinguishes between good, moderate, and poor quality data. As a robustness check of our results in Section 4.2, we run the Poisson regression only for those countries with good quality data. Those countries are Colombia, Egypt, Gabon, Honduras, Indonesia, Morocco, Lesotho, Namibia, Nepal, Peru, Philippines, and Zimbabwe. Results are shown in Table K.5. 


\begin{tabular}{|c|c|c|c|c|c|c|}
\hline & \multicolumn{6}{|c|}{ Dependent variable: Children ever born } \\
\hline & $(1)$ & $(2)$ & $(3)$ & $(4)$ & $(5)$ & $(6)$ \\
\hline $\ln (1+$ density $)$ & $\begin{array}{c}-0.080^{* * *} \\
(0.001)\end{array}$ & $\begin{array}{c}-0.029^{* * *} \\
(0.001)\end{array}$ & $\begin{array}{c}-0.023^{* * *} \\
(0.001)\end{array}$ & $\begin{array}{c}-0.025^{* * *} \\
(0.001)\end{array}$ & $\begin{array}{c}-0.021^{* * *} \\
(0.001)\end{array}$ & $\begin{array}{c}-0.022^{* * *} \\
(0.002)\end{array}$ \\
\hline Caloric Suitability Index & $\begin{array}{c}0.010^{* * *} \\
(0.001)\end{array}$ & $\begin{array}{c}0.003^{* * *} \\
(0.001)\end{array}$ & $\begin{array}{c}-0.006^{* * *} \\
(0.001)\end{array}$ & $\begin{array}{c}0.003^{* * *} \\
(0.001)\end{array}$ & $\begin{array}{c}0.003^{* * *} \\
(0.001)\end{array}$ & $\begin{array}{c}-0.011^{* * *} \\
(0.002)\end{array}$ \\
\hline married & & $\begin{array}{c}1.370^{* * *} \\
(0.009)\end{array}$ & $\begin{array}{c}0.975^{* * *} \\
(0.012)\end{array}$ & $\begin{array}{c}1.347^{* * *} \\
(0.010)\end{array}$ & $\begin{array}{c}1.382^{* * *} \\
(0.010)\end{array}$ & \\
\hline mean marriage & & $\begin{array}{c}-0.071^{* * *} \\
(0.014)\end{array}$ & $\begin{array}{c}-0.144^{* * *} \\
(0.021)\end{array}$ & $\begin{array}{c}-0.077^{* * *} \\
(0.015)\end{array}$ & $\begin{array}{c}-0.068^{* * *} \\
(0.014)\end{array}$ & \\
\hline infant mortality & & $\begin{array}{c}0.572^{* * *} \\
(0.009)\end{array}$ & $\begin{array}{c}0.474^{* * *} \\
(0.012)\end{array}$ & $\begin{array}{c}0.577^{* * *} \\
(0.010)\end{array}$ & $\begin{array}{c}0.569^{* * *} \\
(0.010)\end{array}$ & $\begin{array}{c}0.624^{* * *} \\
(0.015)\end{array}$ \\
\hline mean mortality & & $\begin{array}{c}0.536^{* * *} \\
(0.042)\end{array}$ & $\begin{array}{c}0.573^{* * *} \\
(0.057)\end{array}$ & $\begin{array}{c}0.530^{* * *} \\
(0.043)\end{array}$ & $\begin{array}{c}0.506^{* * *} \\
(0.045)\end{array}$ & $\begin{array}{c}0.784^{* * *} \\
(0.061)\end{array}$ \\
\hline GDP per capita & & $\begin{array}{c}-0.777^{* * *} \\
(0.122)\end{array}$ & $\begin{array}{c}-1.517^{* * *} \\
(0.382)\end{array}$ & $\begin{array}{c}-0.611^{* * *} \\
(0.122)\end{array}$ & $\begin{array}{c}-0.216^{*} \\
(0.123)\end{array}$ & $\begin{array}{c}-0.559^{* * *} \\
(0.138)\end{array}$ \\
\hline woman's education & & $\begin{array}{c}-0.009^{* * *} \\
(0.001)\end{array}$ & $\begin{array}{c}-0.004^{* *} \\
(0.002)\end{array}$ & $\begin{array}{c}-0.005^{* * *} \\
(0.001)\end{array}$ & $\begin{array}{c}-0.010^{* * *} \\
(0.001)\end{array}$ & $\begin{array}{l}-0.003 \\
(0.002)\end{array}$ \\
\hline woman's education ${ }^{2}$ & & $\begin{array}{c}-0.002^{* * *} \\
(0.0001)\end{array}$ & $\begin{array}{c}-0.002^{* * *} \\
(0.0001)\end{array}$ & $\begin{array}{c}-0.002^{* * *} \\
(0.0001)\end{array}$ & $\begin{array}{c}-0.002^{* * *} \\
(0.0001)\end{array}$ & $\begin{array}{c}-0.002^{* * * *} \\
(0.0001)\end{array}$ \\
\hline mean educ & & $\begin{array}{c}-0.018^{* * *} \\
(0.002)\end{array}$ & $\begin{array}{c}-0.011^{* * *} \\
(0.004)\end{array}$ & $\begin{array}{c}-0.011^{* * *} \\
(0.002)\end{array}$ & $\begin{array}{l}0.005^{* *} \\
(0.002)\end{array}$ & $\begin{array}{c}-0.038^{* * *} \\
(0.004)\end{array}$ \\
\hline mean educ ${ }^{2}$ & & $\begin{array}{c}-0.0004^{* * *} \\
(0.0002)\end{array}$ & $\begin{array}{c}-0.001^{* *} \\
(0.0003)\end{array}$ & $\begin{array}{c}-0.001^{* * *} \\
(0.0002)\end{array}$ & $\begin{array}{c}-0.001^{* * *} \\
(0.0002)\end{array}$ & $\begin{array}{l}0.001^{* * *} \\
(0.0002)\end{array}$ \\
\hline Islam & & & $\begin{array}{c}0.018 \\
(0.013)\end{array}$ & & & \\
\hline Christian & & & $\begin{array}{c}0.013 \\
(0.009)\end{array}$ & & & \\
\hline Buddhism & & & $\begin{array}{c}-0.100^{* * *} \\
(0.024)\end{array}$ & & & \\
\hline Hinduism & & & $\begin{array}{c}-0.149^{* * *} \\
(0.017)\end{array}$ & & & \\
\hline electricity & & & & $\begin{array}{c}-0.058^{* * *} \\
(0.007)\end{array}$ & & \\
\hline mean electricity & & & & $\begin{array}{c}-0.024^{* * *} \\
(0.009)\end{array}$ & & \\
\hline refrigerator & & & & & $\begin{array}{c}-0.075^{* * *} \\
(0.005)\end{array}$ & \\
\hline mean refrigerator & & & & & $\begin{array}{c}-0.169^{* * *} \\
(0.009)\end{array}$ & \\
\hline spouse's education & & & & & & $\begin{array}{c}-0.003^{* * *} \\
(0.001)\end{array}$ \\
\hline mean educ spouse & & & & & & $\begin{array}{c}0.014^{* * *} \\
(0.002)\end{array}$ \\
\hline Age dummies & yes & yes & yes & yes & yes & yes \\
\hline Country fixed effects & yes & yes & yes & yes & yes & yes \\
\hline Observations & 208,510 & 208,510 & 100,079 & 184,071 & 195,184 & 49,475 \\
\hline
\end{tabular}

Notes: ${ }^{*} \mathrm{p}<0.1 ;{ }^{* *} \mathrm{p}<0.05 ;{ }^{* * *} \mathrm{p}<0.01$

Table K.5: Results at the individual level restricted to countries with highest quality data 
Institut de Recherches Économiques et Sociales

Université catholique de Louvain

Place Montesquieu, 3

1348 Louvain-la-Neuve, Belgique 